\title{
Accrual Accounting Implementation in the Canadian
}

\section{Federal Government}

\author{
By \\ Kristin Lapointe Seguin, B.Comm.
}

A thesis submitted to the Faculty of Graduate Studies and Research in partial fulfillment of the requirements for the degree of

Master of Business Administration

Sprott School of Business

Carleton University

Ottawa, Ontario

April, 2008

Copyright $(C)$ 


$\begin{array}{ll}\begin{array}{l}\text { Library and } \\ \text { Archives Canada }\end{array} & \begin{array}{l}\text { Bibliothèque et } \\ \text { Archives Canada }\end{array} \\ \begin{array}{l}\text { Published Heritage } \\ \text { Branch }\end{array} & \begin{array}{l}\text { Direction du } \\ \text { Patrimoine de l'édition }\end{array} \\ \begin{array}{l}\text { 395 Wellington Street } \\ \text { Ottawa ON K1A 0N4 } \\ \text { Canada }\end{array} & \begin{array}{l}\text { 395, rue Wellington } \\ \text { Ottawa ON K1A 0N4 } \\ \text { Canada }\end{array}\end{array}$

Your file Votre référence ISBN: 978-0-494-44106-0 Our file Notre référence ISBN: 978-0-494-44106-0

NOTICE:

The author has granted a nonexclusive license allowing Library and Archives Canada to reproduce, publish, archive, preserve, conserve, communicate to the public by telecommunication or on the Internet, loan, distribute and sell theses worldwide, for commercial or noncommercial purposes, in microform, paper, electronic and/or any other formats.

The author retains copyright ownership and moral rights in this thesis. Neither the thesis nor substantial extracts from it may be printed or otherwise reproduced without the author's permission.
AVIS:

L'auteur a accordé une licence non exclusive permettant à la Bibliothèque et Archives Canada de reproduire, publier, archiver, sauvegarder, conserver, transmettre au public par télécommunication ou par l'Internet, prêter, distribuer et vendre des thèses partout dans le monde, à des fins commerciales ou autres, sur support microforme, papier, électronique et/ou autres formats.

L'auteur conserve la propriété du droit d'auteur et des droits moraux qui protège cette thèse. $\mathrm{Ni}$ la thèse ni des extraits substantiels de celle-ci ne doivent être imprimés ou autrement reproduits sans son autorisation.
In compliance with the Canadian Privacy Act some supporting forms may have been removed from this thesis.

While these forms may be included in the document page count, their removal does not represent any loss of content from the thesis.
Conformément à la loi canadienne sur la protection de la vie privée, quelques formulaires secondaires ont été enlevés de cette thèse.

Bien que ces formulaires aient inclus dans la pagination, il n'y aura aucun contenu manquant.

\section{Canada}




\begin{abstract}
The Canadian Federal Government began implementing an accrual accounting system in 1995 and completed it in fiscal year 2003. The objective of this study is to explore accrual accounting implementation in the public sector. In an exploratory, qualitative study, interviews performed with senior government personnel provide information regarding the implementation of the accrual accounting system. The interviews were guided by an a priori model that was based upon relevant literature. These interviews reveal activities undertaken by various departments in order to implement the system. Technical and cultural/people challenges were experienced along with varying degrees of benefits. Enterprise systems helped facilitate implementation. Each department's process was somewhat unique along with the benefits and challenges experienced. This study contributes to the literature by developing a model for public sector implementation of accrual accounting. A clearer understanding of the process and obstacles will help government accountants attain the expected benefits from the system.
\end{abstract}




\section{Acknowledgements}

I would like to thank my supervisor, Raili Pollanen, for her patience and guidance throughout this whole process. Thanks are also due to Hugh J. Lapointe who has always been my tireless champion and to my husband, Aaron Loiselle, who was there in the good times and the bad. 


\section{Table of Contents}

List of Figures viii

List of Tables $\quad$ ix

List of Definitions $\quad x$

1.0 Introduction 1

2.0 Literature Review 5

2.1 Accounting Concepts and How They Apply to the

Public Sector $\quad 5$

2.1.1 Accounting Concepts 5

2.1.2 Accrual Accounting Benefits in the Public Sector 9

2.1.3 Public Sector Accrual Accounting Debate:

Asset Valuations

2.1.4 Public Sector Accrual Accounting Debate:

$\begin{array}{ll}\text { Appropriateness of Accruals } & 18\end{array}$

2.2 Development of Accrual Accounting in the Canadian

Federal Government $\quad 22$

2.2.1 History of Accrual Accounting in the Canadian

Federal Government $\quad 22$

2.2.2 Key Organizations in Development and Functioning

of Accrual Accounting $\quad 25$

2.3 Wider Reform Initiatives in the Canadian Federal

$\begin{array}{ll}\text { Government } & 28\end{array}$ 
2.3.1 Relation to Accrual Accounting in the Canadian

Federal Government

2.3.2 Past Reforms in the Canadian Federal Government

2.3.3 Accrual Budgeting and Appropriations

2.3.4 A Potential Accrual Budgeting Reform in the Canadian Federal Government

2.4 Accrual Accounting Implementation in the Canadian

Federal Government

2.4.1 Enterprise Systems

2.4.2 Organizational Culture 45

2.4.3 Implementation Challenges

2.5 Conclusion

3.0 Research Model and Questions 56

3.1 A Priori Model $\quad 56$

3.2 Research Questions $\quad 65$

3.3 Conclusion 66

$\begin{array}{ll}\text { 4.0 Research Methodology } & 67\end{array}$

4.1 Research Design $\quad 67$

$\begin{array}{ll}\text { 4.2 Data Collection } & 73\end{array}$

4.3 Profile of Participants 76

$\begin{array}{ll}\text { 4.4 Data Analysis } & 80\end{array}$

4.5 Research Validity 82

4.6 Conclusion $\quad 85$ 
5.0 Results $\quad 86$

5.1 Implementation Process $\quad 86$

5.1.1General Context $\quad 86$

5.1.2 Phase 1 Activity $\quad 89$

5.1.3 Phase 2 Human Resource Activity 92

5.1.4 Phase 2 Financial System Activity 96

5.1.5 Phase 2 Departmental Activity 99

5.1.6 Phase 3 Activity 103

$\begin{array}{ll}\text { 5.2 Technical Challenges } & 105\end{array}$

$\begin{array}{ll}\text { 5.2.1 Enterprise Systems } & 105\end{array}$

$\begin{array}{ll}\text { 5.2.2 Non-Enterprise Systems } & 110\end{array}$

$\begin{array}{ll}\text { 5.3 Cultural/People Challenges } & 114\end{array}$

$\begin{array}{ll}\text { 5.3.1 Resistance and Support } & 114\end{array}$

$\begin{array}{ll}\text { 5.3.2 Comprehension } & 119\end{array}$

$\begin{array}{ll}5.4 \text { Accrual Accounting Benefits } & 123\end{array}$

5.4.1 Integrated Accrual Accounting System Benefits 123

5.4.2 Compliance and Reporting Benefits 129

$\begin{array}{ll}\text { 5.4.3 Managerial Benefits } & 131\end{array}$

$\begin{array}{ll}5.5 \text { Conclusion } & 135\end{array}$

$\begin{array}{ll}\text { 6.0 Discussion and Model Development } & 137\end{array}$

$\begin{array}{lr}6.1 \text { A Priori Model } & 137\end{array}$

6.1.1 Implementation Processes and Benefits $\quad 137$

6.1.2 ES Characteristics and Cultural Aspects $\quad 144$ 
6.2.1 Implementation Processes and Benefits 146

6.2.2 Technical and Cultural/People Challenges 151

6.2.3 Larger Change Initiatives 155

6.3 Conclusion 156

$\begin{array}{ll}7.0 \text { Conclusions } & 158\end{array}$

$\begin{array}{ll}\text { References } & 163\end{array}$

Appendices

$\begin{array}{ll}\text { Appendix A: Sample Interview Guide } & 173\end{array}$

$\begin{array}{ll}\text { Appendix B: Questionnaire Mapping } & 179\end{array}$

$\begin{array}{ll}\text { Appendix C: Sample E-mail } & 180\end{array}$

Appendix D: Sample Letter of Introduction/Letter of Consent 181

Appendix E: Codes and Their Descriptions 183

Appendix F: Implementing Processes Coding Hierarchy 188

Appendix G: Technical Challenges Coding Hierarchy 189

Appendix H: Cultural/People Challenges Coding Hierarchy 190

Appendix I: Accrual Accounting Benefits Coding Hierarchy 191 


\section{List of Figures}

Figure 1: Accounting System Spectrum 6

Figure 2: The Public Financial Management Reform Environment 29

Figure 3: Hierarchy of Government Reforms in the Canadian Federal

Government

Figure 4: Enterprise System Experience Cycle

Figure 5: SATIRE Process Model of ERP Systems Effectiveness

in Implementing Internal Controls

Figure 6: A Priori Model of Accrual Accounting Implementation

Figure 7: Empirically Developed Model of Accrual Accounting

Implementation in the Canadian Federal

Government

147 


\section{List of Tables}

Table 1: Countries Adopting Public Sector Accrual Accounting 8

Table 2: Current Status of Accrual Accounting in the Government 24

Table 3: Use of Accrual Budgeting in OECD Member Countries 39

Table 4: Opportunities Afforded by ERP Implementation 42

$\begin{array}{ll}\text { Table 5: Organizational Profiles } & 77\end{array}$

$\begin{array}{lr}\text { Table 6: Participant Profiles } & 79\end{array}$

Table 7: Frequency of Larger Change Initiatives $\quad 88$

Table 8: Frequency of Personnel $\quad 89$

Table 9: Frequency of Phase 1 Activity 90

Table 10: Frequency of Phase 2 Human Resource Activity 93

Table 11: Frequency of Phase 2 Financial System Activity 97

Table 12: Frequency of Phase 2 Departmental Activity 100

$\begin{array}{ll}\text { Table 13: Frequency of Phase } 3 \text { Activity } & 104\end{array}$

Table 14: Frequency of ES Challenges 106

$\begin{array}{ll}\text { Table 15: Frequency of Non-ES Challenges } & 110\end{array}$

Table 16: Frequency of Resistance and Support Challenges 115

Table 17: Frequency of Comprehension Challenges $\quad 120$

Table 18: Frequency of Integrated Accrual Accounting Systems Benefits 124

Table 19: Frequency of Compliance and Reporting Benefits 130

Table 20: Frequency of Managerial Benefits 132 


\section{List of Definitions}

Accrual Accounting - "The accrual basis of accounting recognizes the effect of transactions and events in the period in which the transactions and events occur, regardless of whether there has been a receipt or payment of cash or its equivalent. Accrual accounting encompasses deferrals that occur when a cash receipt or payment occurs prior to the criteria for recognition of revenue or expense being satisfied" (Canadian Institute of Chartered Accountants [CICA], 2007, Section 1000, Paragraph $0.46)$.

Accounting System - A set of manual and computerized accounting procedures, along with personnel and policy, which serve to produce financial information for management decisions and external stakeholders.

Appropriations - Spending authority granted through legislation by Parliament (Treasury Board of Canada Secretariat [TBS], 1995).

Assets - "Assets are economic resources controlled by an entity as a result of past transactions or events and from which future economic benefits may be obtained" (CICA, 2007, Section 1000, Paragraph 0.29).

Capital Assets - "Comprising tangible properties such as land, buildings and equipment, and intangible properties are identifiable assets that are held for use in the provision of services, for administrative purposes, for production of goods or for the maintenance, repair, development or construction of other capital assets; have been acquired, constructed or developed with the intention of being used on a continuing basis; are not intended for sale in the ordinary course of operations; and are not held as part of a collection" (CICA, 2007, Section 4430, Paragraph 0.05).

Cash Accounting - Under the cash basis of accounting, revenue is recorded when the cash is received and expenses are recorded when the cash is paid (Kieso, Weygandt, Warfield, Irvine, Silvester, Young, \& Wiecek, 2002). Financial statement items, such as amounts owed or owing would not recorded in the financial statements.

Comptrollership - Comptrollership is the sound management of public resources and effective decision making (Independent Review Panel on the Modernization of Comptrollership in the Government of Canada [Independent Review Panel], 1997).

Cost Accounting - Cost accounting, also known as management accounting, focuses on producing information for internal users in planning, controlling, and decision making (Hansen, Mowen, Senkow, \& Pollanen, 2004).

Depreciation - Depreciation, also known as amortization, "is a charge to income that recognizes that life is finite and that the cost less salvage value or residual value of an 
item of property, plant and equipment is allocated to the periods of service provided by the asset" (CICA, 2007, Section 3061, Paragraph 0.29).

Enterprise Systems - Enterprise systems, also know as Enterprise Resource Planning Systems, are integrated software packages in which multiple functional applications share a common database (Markus \& Tanis, 2000).

Expenses - "Expenses are decreases in economic resources, either by way of outflows or reductions of assets or incurrences of liabilities, resulting from an entity's ordinary revenue generating or service delivery activities" (CICA, 2007, Section 1000, Paragraph $0.38)$.

Liability - "Liabilities are obligations of an entity arising from past transactions or events, the settlement of which may result in the transfer or use of assets, provision of services or other yielding of economic benefits in the future" (CICA, 2007, Section 1000, Paragraph 0.32).

Materiality - "Materiality is the term used to describe the significance of financial statement information to decision makers. An item of information, or an aggregate of items, is material if it is probable that its omission or misstatement would influence or change a decision." (CICA, 2007, Section 1000, Paragraph 0.17)

Modified Accrual Accounting - Modified accrual accounting recognizes an economic transaction or event as revenues in the operating statements when the revenues are both measurable and available to liquidate liabilities of the current period. Similarly, expenditures are usually recognized when an event or transaction is expected to draw on current resources (Kansas Department of Administration, 1998). Modified accrual accounting is a blend of accrual and cash accounting that combines elements of both systems in various proportions.

Receivables - Receivables are claims held against another party for money, goods, or services (Kieso et al., 2002).

Revenue - "Revenues are increases in economic resources, either by way of inflows or enhancements of assets or reductions of liabilities, resulting from the ordinary activities of an entity" (CICA, 2007, Section 1000, Paragraph 0.37). 


\subsection{Introduction}

Accrual accounting is a system of accounting that recognizes a transaction when it actually occurs, as opposed to cash accounting, which recognizes a transaction when it is paid. Traditionally, in the public sector, cash accounting has been predominantly used, but in recent years, there has been an international trend towards the adoption of accrual accounting. Many benefits have been associated with the adoption of accrual accounting, based on the experiences of other jurisdictions such as New Zealand, England, and Australia. However, caution must be taken before applying these benefits directly to the Canadian Federal Government experience, because there are significant differences between governments that could potentially make the implementation experience differ.

The Canadian Federal Government announced its decision to adopt accrual accounting in the 1995 budget. The 2002-2003 Federal Government Financial statements were done on a full accrual basis. This decision has had a long history in Canada, including two Royal Commissions. The key players in the functioning of the Federal Government's accounting system include the Treasury Board of Canada Secretariat (TBS), the Receiver General, the Department of Finance, and the Office of the Auditor General (OAG). Important standard setters in the Canadian landscape are the Public Sector Accounting Board (PSAB), the OAG, and the TBS.

In Canada, along with many other jurisdictions, accrual accounting was implemented as part of larger reform initiatives. Reforms that occurred concurrently with the adoption of accrual accounting include the Financial Information Strategy (FIS), Modern Comptrollership Initiative, and Results for Canadians. These reforms impacted the development and functioning of the accrual accounting system. The benefit of adopting 
accrual accounting in the public sector is much debated. A potential reform that has recently been gaining a lot of attention is accrual-based budgeting. The merits of accrualbased budgeting are even more controversial than accrual accounting; with advocates claiming that an accrual accounting system will not function properly without accrual budgeting, and those opposed claiming that accrual budgeting has detrimental affects. As will be seen in this study, accrual budgeting does affect the functioning of the accrual accounting system in the Canadian Federal Government.

An accounting system does not function in isolation. It impacts and is impacted by other aspects of the organization. This study will focus on enterprise systems (ES) and organizational culture. ES is a software-based system that handles the majority of an enterprise's information requirements in all functional areas. ES benefits are congruent with the objectives of accrual accounting implementation and these systems pose their own set of benefits and challenges relating to the implementation of accrual accounting. It is important to study them in parallel since they are highly integrated. Organizational culture is a pattern of values and beliefs held by members of an organization. Any organizational change will impact, and be impacted, by organizational culture. Change management is a key process in the implementation of any system that affects organizational culture and involves change. Other jurisdictions that have implemented accrual accounting have experienced numerous implementation challenges both technical and cultural. This study will explore how and if these challenges apply to the Canadian Federal Government. 
This study explores the implementation of accrual accounting in the Canadian Federal Government. Five research questions were formulated in order to focus the study. These research questions are:

1. What processes has the Canadian Federal Government used in implementing accrual accounting and what challenges have arisen?

2. What benefits have resulted from accrual accounting implementation in the Canadian Federal Government?

3. What role has ES played in the implementation of accrual accounting in the Canadian Federal Government?

4. What role has culture played in the implementation of accrual accounting in the Canadian Federal Government?

5. For what purposes is accrual accounting information used, and considered useful, in the Canadian Federal Government?

An a priori model of accrual accounting implementation was developed prior to fieldwork in order to guide the direction of the data collection. It was based upon the available literature and on key relevant models, which included the Markus and Tanis' (2000) Enterprise System Experience Cycle. This emergent process model was chosen because it outlines the activities and challenges faced in the implementation of a system, in particular ES. The other key model used to develop the a priori model was the Kumar, Pollanen, and Maheshwari's (2007) SATIRE Process Model of ERP Systems Effectiveness in Implementing Internal Controls. This model was chosen because it looks at how processes and activity leads to benefits of the system. In order to test the $a$ 
priori model, an exploratory qualitative study was designed and carried out using semistructured interviewing.

This study contributes to academic understanding of the implementation of accrual accounting systems in the public sector, by exploring the implementation in a Canadian context. As well, the model developed in this study can be used as a springboard for further research, in both the Canadian Federal Government and other jurisdiction implementing accrual accounting. Managers will benefit by gaining a clearer understanding of the implementation processes. New insights into how the implementation progressed in various departments and the various benefits received will allow them to obtain more benefits from the system. As well, lessons learned in this study can be applied to the implementation of other new systems.

This paper is organized into seven chapters. The first chapter is the introduction, which is followed by the chapter containing the literature review. This literature review has been divided into four main areas. They are accounting concepts and how they apply to the public sector, the development of accrual accounting in the Canadian Federal Government, wider reform initiatives in the Canadian Federal Government, and accrual accounting implementation in the Canadian Federal Government. The third chapter develops an a priori model of accrual accounting implementation and outlines the research questions. Chapter 4 explains the research methodology, the research design, data collection procedures, the profile of participants, data analysis, and then discusses the research validity of this study. Chapter 5 contains the results from the field research and Chapter 6 discusses these results in detail, developing an empirically-based model of accrual accounting implementation. The final chapter presents conclusions of the study. 


\subsection{Literature Review}

In this chapter, relevant literature of accrual accounting implementation in the public sector is reviewed. The literature review is divided into four major sections. The first section discusses accounting concepts, accrual accounting benefits, and summarizes the debate surrounding the adoption of accrual accounting in the public sector. The second section discusses the development of accrual accounting in the Canadian Federal

Government. A brief history of its development will be given, followed by a discussion of the organizations, both within and external to the Canadian Federal Government, that influenced accrual accounting development and standards. The third section gives an overview of the wider reforms in the Canadian Federal Government and how these reforms relate to accrual accounting. This discussion will be followed by a brief overview of past reforms and a look at an important potential reform: accrual budgeting. The final section discusses accrual accounting implementation in relation to enterprise systems (ES) and organizational culture. Implementation challenges will also be explored within this section.

\subsection{Accounting Concepts and How They Apply to the Public Sector}

\subsubsection{Accounting Concepts}

Accounting systems range from cash to accrual accounting and can be visualized as occupying a place in the spectrum in Figure 1. This spectrum consists of four points including cash, modified cash, modified accrual, and full accrual accounting (Baker \& Rennie, 2006). Governments generally move along the spectrum going from cash accounting to full accrual. Traditionally, most sovereign governments have adopted cash 
accounting (Ellwood, 2003). Governments have been operating on a cash basis since the days of King Charles I in England (Buckstein, 1999). The traditional cash accounting system has begun to be supplemented or replaced by accrual accounting methods (Hodges \& Mellett, 2003).

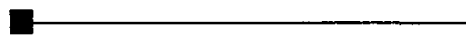

Cash Accounting
Modified Cash

Accounting
Modified Accrual

Accounting

\section{Figure 1: Accounting System Spectrum.}

Source: Adapted from Baker and Rennie (2006), Christensen (2005), and Hodges and Mellett (2003).

This shift towards comprehensive public accrual accounting started in the late 1980's, with New Zealand being the first sovereign nation to adopt public sector accrual accounting (Pallot \& Ball, 1997). Some examples date back to 1913, where the Australian Postmaster-General's department used accrual accounting to prepare commercial accounts (Carlin, 2005). As of 2004, a third of the member counties of OECD had adopted accrual accounting for reporting (Blondal, 2004). It is not necessary that every government embrace every accounting system along the spectrum, though often a government will move from cash accounting to a modified accounting system, before adopting full accrual accounting. In this thesis, full accrual accounting and accrual accounting will be used interchangeably. While there may be similarities in the two ends of the spectrum, cash and accrual accounting, these two systems differ in many regards and are regarded as opposites (Christensen, 2005). In the middle of the spectrum, there are practically an infinite number of combinations of cash accounting and accrual accounting features. When moving from cash accounting towards accrual accounting, 
accounting systems exhibit a progressively greater number of characteristics of accrual accounting and fewer characteristics of cash accounting.

Member countries of the Organization for Economic Co-operation and Development (OECD) that have at least partially adopted a public sector accrual accounting system can be seen in Table 1. This table comprises a four-way classification system, including full accrual basis, accruals with certain exceptions, cash except for certain transactions, and cash basis. It can be seen from this table that only a few European countries, in addition to English-speaking countries, have adopted accrual accounting. Each classification can also be visualized as occupying a place along the spectrum in Figure 1, with accrual, with certain exceptions, corresponding to modified accruals and cash, except for certain transactions corresponding to modified cash. It should be noted that care must be taken when comparing accounting systems in different countries. Differences between countries include wider reform programs, size, and complexity. The differences play a role in the functioning of accounting systems (Likierman, Heald, Georgiou, \& Wright, 1995). Cash, modified accrual, and accrual accounting, which are the accounting systems most relevant to the Canadian Federal Government experience, are described in the remainder of this section in further detail.

Cash accounting records cash payments and receipts when they are made or received (Buckstein, 1999; Guthrie, 1998; Likierman et al., 1995). Financial statement items, such as amounts owed to or by the government or other non-cash items, would not be recorded in the financial statements. Modified accrual accounting is a blend of accrual and cash accounting that combines elements of both systems. The Canadian Federal Government followed a modified accrual accounting system prior to the implementation 
of accrual accounting. Modified accrual accounting can vary from organization to organization. Within the Canadian Federal Government, the modified accrual basis of accounting meant that most expenditures, except capital assets, were recognized when the liability occurred and not when the cash was paid. Capital assets were recorded on a cash

\begin{tabular}{|c|c|c|c|c|}
\hline & Cash basis & $\begin{array}{c}\text { Cash, } \\
\text { except certain transactions } \\
\text { on accruals basis }\end{array}$ & $\begin{array}{l}\text { Accruals, } \\
\text { except for capitalisation } \\
\text { and depreciation of assets }\end{array}$ & Accruals basis \\
\hline Australia & & & & $x$ \\
\hline Austría & $x$ & & & \\
\hline Belgium & $x$ & & & \\
\hline Canada & & & & $x$ \\
\hline Czech Republic & $x$ & & & \\
\hline Denmark & & $x$ & & \\
\hline Finland & & & & $x$ \\
\hline France & & $x$ & & \\
\hline Germany & $x$ & & & \\
\hline Greece & $x$ & & & \\
\hline Hungary & $x$ & & & \\
\hline Iceland & & & $x$ & \\
\hline Ireland & $x$ & & & \\
\hline Italy & $x^{1}$ & & & $x^{1}$ \\
\hline Japan & $x$ & & & \\
\hline Korea & & $x$ & & \\
\hline Luxembourg & $x$ & & & \\
\hline Mexico & & $x$ & & \\
\hline Netherlands & $x$ & & & \\
\hline New Zealand & & & & $x$ \\
\hline Norway & $x$ & & & \\
\hline Poland & & $x$ & & \\
\hline Portugal & & $x$ & & \\
\hline Slovak Republic & $x$ & & & \\
\hline Spain & & $x$ & & \\
\hline Sweden & & & & $x$ \\
\hline Switzerland & $x$ & & & \\
\hline Turkey & $x$ & & & \\
\hline United Kingdom & & & & $x$ \\
\hline United States & & & & $x$ \\
\hline
\end{tabular}

1. To be verified.

Table 1: Countries Adopting Public Sector Accrual Accounting. Source: Blondal (2004) p. 117.

basis meaning they were expensed when purchased. Most revenue, except taxes, was recorded on an accrual basis, meaning it was recorded in the period it was earned. Tax 
revenues were recorded when received. Not all liabilities were fully recorded (Department of Finance [DOF], 2007).

Finally, at the far end of the spectrum is the accrual basis of accounting. According to the Canadian Institute of Chartered Accountants (CICA) (2007, Section 1000, Paragraph 0.46),

The accrual basis of accounting recognizes the effect of transactions and events in the period in which the transactions and events occur, regardless of whether there has been a receipt or payment of cash or its equivalent.

Accrual accounting encompasses deferrals that occur when a cash receipt or payment occurs prior to the criteria for recognition of revenue or expense being satisfied.

Accrual accounting shifts the timing and recording of transactions from when cash was received or paid to when the service was rendered or received (Guthrie, 1998). Capital assets would no longer be expensed, but capitalized and depreciated over their useful lives. Revenue would be recorded when it was earned and expenses recorded when they were consumed, regardless of payment. Liabilities and receivables would be recorded. Accrual-based accounting is complementary to cash control and not a substitute for it, as analysis of cash flow would still be performed (Wright, 1995).

\subsubsection{Accrual Accounting Benefits in the Public Sector}

Benefits of accrual accounting include increased comparability, better decision making, and better management of capital assets. Accrual accounting is a device that will not automatically result in benefits, but potential benefits will be yielded when managers act on the information it provides (Evans, 1995). It makes it possible to focus on assets, on the management of liabilities and on the full cost of programs and services, instead of 
just short-term cash flow balance as in a modified accrual system (Standing Committee on Government Operations and Estimates [SCGOE], 2006).

A benefit attributable to the implementation of accrual accounting found in other governments is an increase in comparability both from year to year and with the private sector (Boxall, 1998; Ellwood, 2003; Likierman et al., 1995; Pallot \& Ball, 1996, 1997; Saleh \& Pendlebury, 2006). Comparability is a characteristic of the relationship between two pieces of information. It enables the users of that information to identify similarities and differences between the information provided by the two sets of financial statements (CICA, 2007). Accrual accounting smoothes fluctuations in financial information. This smoothing increases its comparability. As well, accrual accounting is the generally accepted practice in the private sector. By using accrual accounting for financial reporting purposes, the government can compare itself against the private industry for performance measurement and outsourcing purposes (Pallot \& Ball, 1996). This comparison leads to greater efficiency, because it gives the government a credible alternative service delivery mechanism (Carlin, 2005, 2006) through outsourcing. A government-performed service can be outsourced to the private sector if it is found that the private sector can perform the task more efficiently. Prior to the implementation of accrual accounting, there was no mechanism to fully evaluate the decision to outsource. Increasing the comparability of the government's financial information, both from year to year and with private industry, increases the decision making usefulness of the information. This potential benefit is not undisputed. Carlin (2000) found that discrepancies exist between public and private sector reports produced in Australia, 
reducing the comparability of the information, even though both public and private sectors are using accrual accounting.

Accrual accounting also makes more information available to managers, the Parliament and the public, increasing the quality of overall decision making (Awty, 2002; Blondal, 2003; Boxall, 1998; Buckstein, 1999; Her Majesty’s Treasury [HMT], 2001; Likierman, 2000; Likierman et al., 1995; Lye, Perera, \& Rahman, 2005; Mellor, 1996; Pallot \& Ball, 1997; SCGOE, 2006). It provides a framework for financial information to be used by decision makers within the government (Evans, 1995). This framework gives managers a more comprehensive picture of financial performance, leading to better decision making through better resource management (SCGOE, 2006). Information provided for decision making needs to be a true, and a fair view of the results achieved (Aiken \& Capitanio, 1995). However, it is not universally accepted that accrual accounting provides the truest and fairest view of the results, especially considering that accrual accounting involves the use of estimates and judgment (Aiken \& Capitanio, 1995). The implementation of accrual accounting is often done in the context of wider reforms that aim to make the government responsible for all costs attached to decisions, not just the immediate cash outflow.

The adoption of accrual accounting techniques is a means to enact significant changes (Guthrie, 1998). Accruals allow for the capturing of full costs, thereby, supporting more effective decision making (Barton, 1999a; Blondal, 2003; Mellor, 1996). The effectiveness and efficiency of decisions increases, since more information is available, specifically regarding the cost of programs and services. Accrual accounting allows for the analysis of information and its effects on overall goals, objectives and costs 
of service. The ability to analyze the outcomes of various departments, projects and initiatives will lead to increased accountability over the quality, quantity and cost of inputs being used (Pallot \& Ball, 1996). The introduction of Resource Accounting in England, which is a management reform initiative that includes the use of accrual accounting, found that decision making was improved (HMT, 2001). One of the first benefits that New Zealand found from shifting to accrual accounting is the management of debtors and creditors. The increase in available information allowed managers to create savings, from improved cash management, through better accounting for and use of supplier credit and debt collections (Pallot \& Ball, 1997).

Finally, accrual accounting allows for more effective and efficient use of resources, especially regarding capital assets (Ellwood, 2003; Likierman et al., 1995; Mellor, 1996; Pallot \& Ball, 1997; Rowles, 1991; Saleh \& Pendlebury, 2006). Under modified accrual accounting, capital assets were expensed, resulting in great fluctuations in financial information, which could lead to poor capital investment decisions. This method introduces a negative bias with respect to capital expenditures (SCGOE, 2006). Alternative concepts of capital maintenance shape the nature of the information provided, therefore, shaping the behaviour of managers (Heald \& Georgiou, 1995). For example, a capital asset purchased for $\$ 1$ million with a useful life of 10 years, would be charged to operations at a rate of $\$ 100,000$ per year over the 10 years under accrual accounting. Under the modified accrual accounting system, the full $\$ 1$ million would be charged to operations the year it was purchased (Wong, 1998). Managers may avoid investing in capital assets, if they are expensed, because it would lower the financial results of their unit, possibly affecting how the unit's performance and consequently the managers' 
performance are viewed. The fluctuations in the financial bottom line from expensing capital assets would be eliminated and replaced with the systematic allocation of the asset to expense, over the life of the asset.

Accrual accounting better matches the cost of the asset to the benefits being received and forces the government to keep detailed asset registries (Pallot \& Ball, 1997). It enables the government to match real economic costs with the outputs being achieved and leads to better evaluation of performance (Evans, 1995). One paper concluded that many departments simply process cash and that accrual accounting would produce little changes in the department, whereas other asset rich departments, for example the Ministry of Defence, will be greatly impacted (Gillibrand \& Hilton, 1998). According to the Report of the Standing Committee on Operations and Estimates (2006, p. 13), the adoption of full accrual accounting could improve the management of capital assets, because it can:

- Provide context to debates regarding maintaining, renewing, replacing and funding assets

- Provide common measurement base for asset valuation

- Enable the evaluation of the physical condition of assets over the years

- Enable better costing of services to public that require the use of assets

- Disposition of surplus assets more efficiently at a better price

- Anticipate the deterioration of assets in order to maintain, renew, and replace them

The shift to accruals makes the true costs of government programs more transparent (Blondal, 2003; Mellor, 1996; Slamet, 1998). As well, accrual accounting forces tracking of capital assets, leading to greater accountability and control (Buckstein, 1999; Slamet, 1998; Stanton \& Stanton, 1997; Wong, 1998). According to Carlin (2005), 
transparency in accounting is a function of the believability and objectivity of the information produced by the accounting system. There is no literature in the public sector that refutes the notion of accrual accounting increasing transparency, but there are some studies indicating that there may be susceptibility in accrual accounting systems to diminished transparency (Carlin, 2005). In the United Kingdom, it was found that asset rich departments experienced the highest potential gains (Likierman, 2000).

According to Robinson, accrual accounting allows for the capturing of full cost only if the measure of full cost is full accrual costs, and depends on a range of factors, which include the valuation of assets and cost of capital (Robinson, 1998). Webster goes as far as to say, "only accrual accounting can provide cost base required to accurately cost products and services" (Webster, 1998, p. 24). Mellor argued that the use of accrual reporting in the public sector is appropriate, because it gives a complete picture of the government's financial position, disclosed the impact of policy over the long term, focuses attention on the management of total resources and obligations, and increases integrity of financial reporting by introducing discipline (Mellor, 1996). Robinson's (1998) rationale for the implementation of accrual accounting is that it provides the best measure of sustainability and intergenerational equity. Intergenerational equity is based on the notion, that taxpayers in each time period should finance all current expenditures and contribute to financing inherited productive assets, in accordance to the benefits they have received from those assets (Robinson, 1998).

While much of the literature suggests benefits that can be attached to accrual accounting, one study in the United Kingdom found that the introduction of accrualbased accounting initiatives failed to produce the claimed benefits (Mellett, 2002). 
Another study that interviewed senior managers, after the implementation of resource based accounting and budgeting, found that there was general dissatisfaction being experienced with the system (Pendlebury \& Karbhari, 1998).

\subsubsection{Public Sector Accrual Accounting Debate: Asset Valuations}

The literature regarding the debate over public sector accrual accounting is extensive and deeply divided centring on asset valuations and the appropriateness of accruals to the public sector (Carlin, 2005). A number of assets in the public sector are public domain, such as heritage and infrastructure assets, and do not exist in the private sector. Heritage and infrastructure assets include assets such as historical buildings, archaeological sites, roads, bridges, government buildings, railways, water sewage, gas and electricity reticulation systems, dams, docks, airports, parks, gardens, museums, monuments, and other network assets (Rowles, 1991). While these types of assets do exist in both public and private sector, they represent a significant portion of total government assets (Hone, 1997; Rowles, 1991). A major issue with heritage assets is that the value of these items are inherently cultural or social, not monetary, or that the asset was created long ago, making it difficult to cost (Awty, 2002; Blondal, 2003; Carnegie \& West, 2003; Carnegie \& Wolnizer, 1995; Heald \& Georgiou, 1995; Newberry, 2002). A cost assigned to such an item could be considered arbitrary, especially considering that some are not purchased, cannot be sold, or are never intended to be sold (Carnegie \& West, 2003, Heald \& Georgiou, 1995).

It is debated how these types of assets should be treated and even if they warrant special treatment (Likierman, 2000). This debate goes as far back as 1981, when Mautz 
postulated that these special types of assets should be thought of as liabilities, rather than assets, because they are required to be maintained across time and the controlling entity, the government, receives no economic benefit from controlling them. Another stream of thought on how to deal with these items is to recognize them as assets, but under different criteria than currently being used (Barton, 1999b, 1999c; Pallot, 1990). Some believe that certain heritage and infrastructure assets should be capitalized, while some assets, such as art and historical treasure collections should not. This argument for noncapitalization is based on the impracticality of obtaining fair values for these items and the high cost versus the benefits expected (Carnegie \& Wolnizer, 1995, 1997). Others believe that since the private sector controls a substantial proportion of these types of assets, and has accounted for them using accrual accounting, there is no need for any distinction when it comes to public sector accrual accounting (McGregor, 1999; Rowles, 1991).

On the other hand, some authors believe that certain types of assets should not be recognized in public sector balance sheets (Carnegie \& West, 2003; Carnegie \& Wolnizer, 1995, 1997, 1999, 2002). These authors believe that these items do not fit the criteria of assets (Guthrie, 1998). In addition, there is no demand by users of financial statements for them to be capitalized, and the capitalization of these assets is generally not practiced (Carnegie \& Wolnizer, 1995, 1999). Other authors argue that these types of items should not be included in financial statements, at an amount greater than what can be recovered from the asset through continued use and disposal. Infrastructure and heritage assets are not readily saleable, would not have a market value, and often do not generate revenue (Rowles, 1991). However, it has been suggested that whether or not the 
asset provides services can be used as the criteria for whether or not they generate future economic benefit instead of revenue; however, this point is debated in the literature as well (Carnegie \& Wolnizer, 1999; Hone, 1997; Micallef \& Peirson, 1997; Rowles, 1991). Of course, due to the contentious nature of this debate others have attempted to refute these arguments. Micallef and Peirson (1997) assert that these items do indeed fit the criteria of an asset as set out by the Australian Accounting standard setters. The debate as to whether or not these items can be considered assets centres on the following questions: Do these items have future economic benefits? Does the government have control over these items? Can the value of these items be determined? As well, the notion that users of the financial information do not demand this type of information is refuted through the argument that these items are paid for through tax dollars. The general public has a right to this information and these authors cite a multitude of examples where this type of information would be useful to decision makers (Micallef \& Peirson, 1997).

While the debate centres primarily on the feasibility of valuating assets, some authors point to the importance of asset valuations in terms of efficient public management. Hone (1997) cites three public management requirements that need the valuations of public collections. These requirements include the allocation of funds between competing uses, the evaluation of the performance of public sector managers, and the monitoring of public expenditure to ensure the legitimate application of public funds. Analyzing the rationale behind valuating assets helps determine if and how these assets should be evaluated. As evidenced by Table 1, the general adoption of public sector accrual accounting has increased, but there is still debate as to whether or not 
accrual accounting is being applied to certain items. Even among authors that agree that these assets should be capitalized, there is still debate over whether or not they should be depreciated, since some are considered to have infinite or extremely long lives (Rowles, 1991).

Some authors contributed to the debate, by applying the accounting standardsetting authorities' definition of an asset in their countries to these items, to determine whether public sector goods fit the criteria (Barton, 1999b, 1999c, 2002; Carnegie \& Wolnizer, 1995, 1997, 1999, 2002; McGregor, 1999; Micallef \& Peirson, 1997; Newberry, 2002; Pallot, 1990; Rowles, 1991; Stanton \& Stanton, 1997). In Canada, the CICA, the independent standard-setting body, has determined that these assets do indeed fit the definition of an asset. In Canada, the CICA handbook, an important body of relevant standards, defines assets as "economic resources controlled by an entity as a result of past transactions or events and from which future economic benefits may be obtained" (CICA, 2007, Section 1000, Paragraph 0.29). The essential elements of this definition are that, an asset must have future benefits, the entity can control access to the benefit, and the transaction or event giving rise to the entity's right to, or control of, the benefit has already occurred (CICA, 2007). According to this definition, heritage and infrastructure assets do fit the criteria for recognition as an asset. The government does have control over these items. These items do provide future benefits and the government can control access to these benefits. 


\subsubsection{Public Sector Accrual Accounting Debate: Appropriateness of Accruals}

There are two opposing schools of thought regarding the appropriateness of accrual accounting. One school, coined sector neutrality, argues that accrual accounting will work equally well for both private and public sectors (Carlin, 2005; McGregor, 1999; Micallef \& Peirson, 1997). This school of thought rests on the principle that the two sectors are fundamentally similar in their information needs; hence, the private sector accounting standards can be applied to the public sector with minor modifications. While there may be variances between such things as operating structure, source of funding, operating motives or sector location, the objective of financial reporting is the same throughout, that is, to provide financial information to assist users in decision making (McGregor, 1999). In addition, McGregor (1999) argues that the elements of financial statements are essentially the same between the two sectors (McGregor, 1999). Sector neutrality entails both sectors having the same accounting standards, and a common conceptual framework. However, Newberry (2001) points out that modern public sector accounting has not developed in accordance with this school of thought. The same conceptual framework that is used in the private sector may be applied to the public sector, but the conceptual definitions are interpreted by taking into account sector specific differences, resulting in two different conceptual frameworks actually being applied.

The alternative school of thought proposes that the public sector is fundamentally different from the private sector due to different markets in which the government operates, different objectives of public sector organizations and different kinds of assets and liabilities (Barton, 1999b, 1999c, 2002; Carlin, 2000, 2005; Carnegie \& West, 2003; Carnegie \& Wolnizer, 1995, 1997, 1999; Guthrie, 1998; Jones \& Puglisi, 1997; Mautz, 
1981; Newberry, 2002; Rusaw, 2007). For example, the objectives of a museum are to preserve and provide access to collections, and to increase the appreciation of, and public interest in, collections. A private enterprise would include aims that deal with income generation, wealth creation, or profitability (Barton, 1999c; Carnegie \& Wolnizer, 1995, 1999; Guthrie, 1998). Carlin (2000) gives an example of how the private sector is thought to be fundamentally more efficient than the public sector. This efficiency is because the public sector is designed to be fair, open, objective, and accountable, as opposed to efficient (Cole, 1988, as cited in Carlin, 2000), and that the purpose of public sector accounting is different from the private sector. The main objectives in the private sector are profitability, solvency, and capital structure. These points are irrelevant in the public sector (Carlin, 2005).

Another example of differences relates to the fact that public sector provisions are driven by supply in terms of available tax dollars instead of demand (Guthrie \& Parker, 1998). Allocation of scarce resources is not done solely through a cost/benefit analysis, but it can be determined by a variety of socioeconomic, public welfare and political constraints (Jones \& Puglisi, 1997). The private sector accounting standards have developed unique characteristics over a long period of time. The line of reasoning is that unless accounting standards are designed to suit the market in which the entity operates, the accounting system will not provide the information required by the users of the financial information (Barton, 1999c). It is under this rationale that some authors propose that accrual accounting methods need to be adapted before being applied to the public sector (Barton, 1999a). Some authors feel that the public sector is not only different from the private sector, but that it is also far more complex (Mautz, 1981). 
According to this line of argument, there are separate private and public goods markets, with the goods being supplied by public sector being public or social goods. Public goods are unique, as it is not possible to exclude others from using them, whereas private goods are based on the principle that one can exclude others from using them (Barton, 1999b, 1999c, 2002).

While most assets, with a few notable exceptions discussed above, are the same for both sectors, the markets in which the sectors operate are fundamentally different (Barton, 1999c). The bigger difference between the public and private sector is that in the public sector the owners of the assets are not the beneficiaries (Barton, 1999b, 1999c). As well, the fact that public sector goods cannot be offered by the private sector due to market externalities is further evidence that the private and public sector markets differ (Barton, 2002). Barton (1999a) argues that the private sector itself is a heterogeneous entity and that generalizations cannot be made throughout the private sector. The differences between the two sectors would then warrant different rules for each sector.

As the debate over the appropriateness of public sector accrual accounting continues, the question as to the impact that accrual accounting has had on public sector organizations emerge. The adoption and implementation of an accounting system across the public sector requires significant effort and resources. A government is unlikely to dismantle this infrastructure once it has been put into place in the near to medium term (Carlin, 2005). A government working within the framework of a new accounting system can find ways to gain the most benefit out of the system, and a government going through the process of implementing can try to do so at the lowest possible cost. 


\subsection{Development of Accrual Accounting in the Canadian Federal Government}

\subsubsection{History of Accrual Accounting in the Canadian Federal Government}

There have been discussions surrounding the adoption of accrual accounting in the Federal Government, starting in the early 1960 's with the Diefenbaker Government's Royal Commission on Government Organization, better known as the Glassco Commission. It was in response to the cabinet's concerns over losing control over the growing bureaucracy (O’Neal, 1994). The commission recommended replacing rigid controls with performance evaluations to ensure accountability and increasing efficiency and effectiveness. Although it recommended the adoption of accrual accounting for financial reporting, it stopped short of recommending that appropriations be based on accrual accounting. The report concluded that accrual accounting "... makes accounting reports more objective and comparable over any period of time" (Royal Commission on Government Organization [RCGO], 1963, p. 109). These recommendations were not implemented.

The Trudeau Government appointed the Royal Commission on Financial Management and Accountability, known as the Lambert Commission, in 1976. The commission's mandate was to determine the best approach for financial management. It had two goals: ensure financial management and control at all levels of government and develop effective administrative accountability (O’Neal, 1994). The report, issued in 1979 , stated that there was a "hodge-podge of accounting methods used in assembling the financial statements of the Government of Canada" (Royal Commission on Financial Manageme IAccountability [RCFMA], 1979, p. 247). As well, the commission found that ounting methods used in departments and in most agencies result in both 
inaccurate estimates of the cost of implementing a proposal and inaccurate reports of the costs of carrying out the activity" (RCFMA, 1979, p. 248). The commission did not specifically recommend accrual accounting, but recommended cost-based accounting, which essentially requires the use of accrual accounting. The Glassco Commission commented that accrual accounting, "... lays the basis for, but does not necessarily imply, cost accounting" (RCGO, 1963, p. 109). By recommending cost accounting, the Lambert Commission implied that accrual accounting needs to be put into place. These recommendations were not implemented.

It was not until the 1995 federal budget plan that the Canadian Federal Government announced that it would move to full accrual accounting for budgeting and accounting. The 2002-2003 financial statements in Public Accounts and the 2003 federal budget were done on a full accrual accounting basis (TBS, 2006, as cited in SCGOE, 2006). According to a backgrounder on the implementation of accrual accounting in the Federal Government, implementation was a response to concerns raised by the OAG regarding proper accounting for capital assets, environmental liabilities, and investments in Crown Corporations (DOF, 2007). While the OAG does not have the ability to mandate change, the $\mathrm{OAG}$ is a source of influence, especially with its ability to provoke public pressure (Baker \& Rennie, 2006). However, Canada has not yet adopted an accrual budgeting system (SCGOE, 2006). Table 2 outlines the different accounting bases employed for different levels of administration for both budgeting and reporting. As the table shows, both government-wide and departmental budgets and appropriations, 
as well as departmental reports are managed on a cash basis.

\begin{tabular}{|c|c|c|}
\hline \multicolumn{3}{|c|}{ CURRENT STATUS OF ACCRUAL ACCOUNTING IN GOVERNMENT } \\
\hline & Government-wide & Departmental \\
\hline \multicolumn{3}{|l|}{ BUDGETING PURPOSES } \\
\hline Federal Budget & Accrual & - \\
\hline Departmental Budget/Estimates & Near-Cash & Near-Cash \\
\hline Appropriations & Near-Cash & Near-Cash \\
\hline \multicolumn{3}{|l|}{ REPORTING PURPOSES } \\
\hline Summary Financial Statements & Accrual & - \\
\hline Departmental Financial Statements (unaudited) & - & Accrual \\
\hline Departmental Performance Reports & - & Near-Cash \\
\hline
\end{tabular}

Table 2: Current Status of Accrual Accounting in the Government. Source: OAG, 2006, as cited in SCGOE, 2006.

The literature suggests that, internationally, public sector accrual accounting adoption experience differs significantly between jurisdictions and that each implementation experience is unique (Carlin, 2005). For example, the Hong Kong Special Administrative Region government ran its cash and accrual systems concurrently before switching to the new system (Awty, 2002). In Canada, implementation was done using a phased-in approach (DOF, 2007) led by the Treasury Board of Canada Secretariat (TBS). The phased-in approach entails departments switching to the new system in phases, with all departments not switching at the same time and TBS running both the old and new systems during this phasing. TBS provided direction and advice while monitoring and facilitating implementation.

In the past, all financial transactions were processed centrally by Public Works and Government Services Canada and maintained in the central accounting system. The government's annual financial statements were prepared from this centralized information. For management information purposes, many departments and agencies maintained duplicate information in their own management information systems. Under 
the new system, financial management and accounting are decentralized. Departments are now responsible for processing and maintaining detailed financial transactions in their own financial systems. Departments submit only the summary information required for government-wide reporting and analysis to the new central systems (Office of the Auditor General of Canada [OAG], 1999).

\subsubsection{Key Organizations in Development and Functioning of Accrual}

\section{Accounting}

There are many organizations, both within and outside the Canadian Federal Government that have influenced and continue to influence the accrual accounting system. Standard setters influence the decision to adopt accrual accounting and the characteristics of the accrual accounting system. Important standard-setting authorities in the Canadian landscape include the Public Sector Accounting Board (PSAB) and TBS. The OAG plays a role in influencing the development and adoption of standards, as well. An important international standard setter is the International Public Sector Accounting Standards Board (IPSASB). Within the Federal Government, three departments have been instrumental in the functioning and developing of the accounting system. These departments have been the TBS, the Receiver General, and the Department of Finance.

The OAG audits the Federal Government and provides the Parliament with independent information, advice, and assurance, with the objective of making the government accountable for its stewardship of public funds. It conducts financial audits of the government's financial statements (public accounts) and performs special examinations and annual financial audits of Crown Corporations (OAG, 2007). The 
OAG is also influential in the standard-setting process. Through the course of its auditing, the OAG will often make recommendations that touch upon accounting standards. These recommendations can influence the development of accounting standards. One example is the Federal Government Reporting Study of 1986, a joint initiative between the OAG and the Comptroller General of the United States. This study found that users of government accounting information wanted accrual accounting and proceeded to recommend a model for financial reporting using it (Baker \& Rennie, 2006).

The PSAB is an influential standard-setting authority. In 1981, a research study by the Canadian Institute of Chartered Accountants (CICA) found that government statements were complex and varied. The study's report led to the creation of the PSAB. The Canadian Federal Government is sovereign and cannot be forced to comply with recommendations made by this board, but often does so voluntarily. Eventually, the CICA Public Sector Accounting Handbook was created (Skinner \& Milburn, 2001). Its mandate is to improve and harmonize accounting and financial reporting in the public sector (Jun Lin, Baxter, \& Murphy, 1993). The standards encompassed in this handbook represent the generally accepted accounting and reporting principles for the public sector (SCGOE, 2006). The PSAB is an independent accounting standards-setting body for the public sector, which is important in order for the public to perceive the financial information as credible and not subject to political or economic pressures (SCGOE, 2006).

The IPSASB focuses on the accounting and financial reporting needs of national, regional and local governments, related governmental agencies, and the constituencies 
they serve. It addresses these needs by issuing and promoting benchmark guidance, conducting educational and research programs, and facilitating the exchange of information among accountants and those who work in the public sector or rely on its work. The board produces a handbook, which states that public sector financial statements should be presented on the accrual basis of accounting. This board is an important standard setter in terms of international public accounting standards (International Public Sector Accounting Standards Board [IPSASB], 2008). These standards currently do not apply to the Canadian public sector, although the CICA is represented on the international standards board.

The TBS is another important authority that provides advice and support to Treasury Board Ministers in their role of ensuring value for money. It also provides oversight of the financial management functions in departments and agencies (TBS, 2004). TBS issues Treasury Board Accounting Standards. These standards are part of the Financial Management and Accounting Policy Directorate. Its mandate is to stimulate awareness and effective decision making through government-wide excellence in financial management, accounting, and financial reporting. Many of the relevant standards are encompassed in the Financial Information Accounting Manual, which provides explanation and guidance on the adoption and use of accrual accounting along with accompanying accounting principles (TBS, 2004).

Under the old accounting system the Receiver General, the TBS and the Department of Finance shared the responsibility of the central accounting within the system. The Receiver General is part of Public Works and Government Services Canada. It maintained and operated the government-wide system. The TBS was responsible for 
accounting policies, and determining the form and content of financial statements. The Department of Finance held the responsibility for matters relating to the financial affairs of Canada. It assessed and analyzed the government's financial position and relates that information through its annual report (Buckstein, 1999). This modified accrual system was also a fairly centralized system. TBS led the implementation of accrual accounting in the Canadian Federal Government. The accrual accounting system adopted by the Canadian Federal Government is more decentralized compared to the previous system. Both the Receiver General and departments no longer produce the same accounting information. The Receiver General has now become responsible for managing the central management reporting system and producing government-wide consolidated reports (Buckstein, 1999).

\subsection{Wider Reform Initiatives in the Canadian Federal Government}

\subsubsection{Relation to Accrual Accounting in the Canadian Federal Government}

There is an international trend towards adopting accrual accounting (Awty, 2002) fuelled by the need for increased transparency and accountability, the growing size of the public sector, growing government debt, and questions about the nature of information being provided within government to assist in good decision making (Naik, 2005). These factors require more than implementing a technical accounting change. They need to transcend to a strategic level. This strategic rationale for adoption is evidenced in Canada by the fact that accrual accounting adoption is part of larger change initiatives. These larger change initiatives are strategic in their objectives and go beyond technical requirements. Accrual accounting is not adopted as an end in itself, but as a means to 
achieving wider reforms (Carlin, 2005; Carlin \& Guthrie, 2001; Evans 1995). However, it must be noted that accounting is not merely a neutral process that just records a preexisting reality, but can be used to actively shape that reality (Hopwood, 1984).

Carlin (2005) created a framework to depict the interconnection of management reforms to financial management techniques, as seen in Figure 2. The Precursor category in the framework is where the adoption of accrual accounting would fall. This category includes techniques necessary for the subsequent implementation of a range of other techniques. The next section, the Hub, includes activities carried out by the public sector agency as the production of measurable outputs. An example is accrual budgeting, which

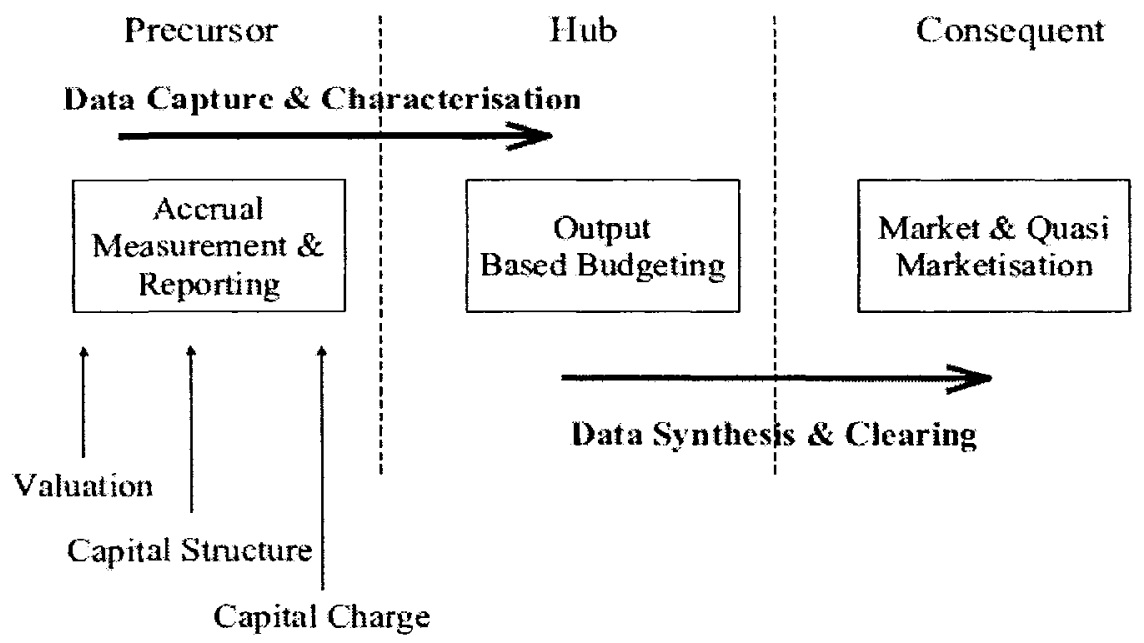

Figure 2: The Public Financial Management Reform Environment. Source: Carlin (2005) p. 321.

has not been the case as of yet in Canada, but is being seriously considered. According to Carlin (2005), the Hub will then transmit this data into the markets in which outputs are traded. The Consequent section depicts the markets and quasi-markets where the outputs are traded. It was found in the UK that accrual accounting was a result of management initiatives that occurred before it (Likierman et al., 1995). In other countries, such as 
New Zealand, it was found that a coherent framework of ideas to guide systems design was more effective than making incremental changes to the existing system (Pallot \& Ball, 1996, 1997).

\subsubsection{Past Reforms in the Canadian Federal Government}

Major reforms in the Canadian Federal Government include the Results for Canadians framework, which is an overall framework for the management of government. Under this framework, there are several major initiatives, including the Modern Comptrollership Initiative. Comptrollership, which is not a new concept to the government, has traditionally focused on financial controls and accounting (Independent Review Panel, 1997). The modernization of comptrollership has more far reaching objectives. One objective is to modernize how inputs and processes are managed. The Financial Information Strategy (FIS) was created in order to achieve this objective. One element of this strategy is to implement accrual accounting systems for financial reporting purposes.

The hierarchies of the various reforms are outlined in Figure 3. Since implementation is done concurrently and in support of these wider initiatives, it is difficult to isolate the effects that are attributable to accrual accounting. Despite the large body of literature that pertains to public sector accrual accounting, there is a gap in studying implementation within the context of other related public management reforms (Carlin, 2005). As well, the simultaneous implementation of a group of reforms makes it more difficult to gather evidence of the links between a particular reform being studied and its impact on the environment being studied (Carlin, 2005). It may also be due to the 
difficulty of gathering evidence regarding the linkages between a particular reform and related changes in performance in a complex environment (Carlin, 2005). A review of the pertinent initiatives will inform the discussion on accrual accounting.

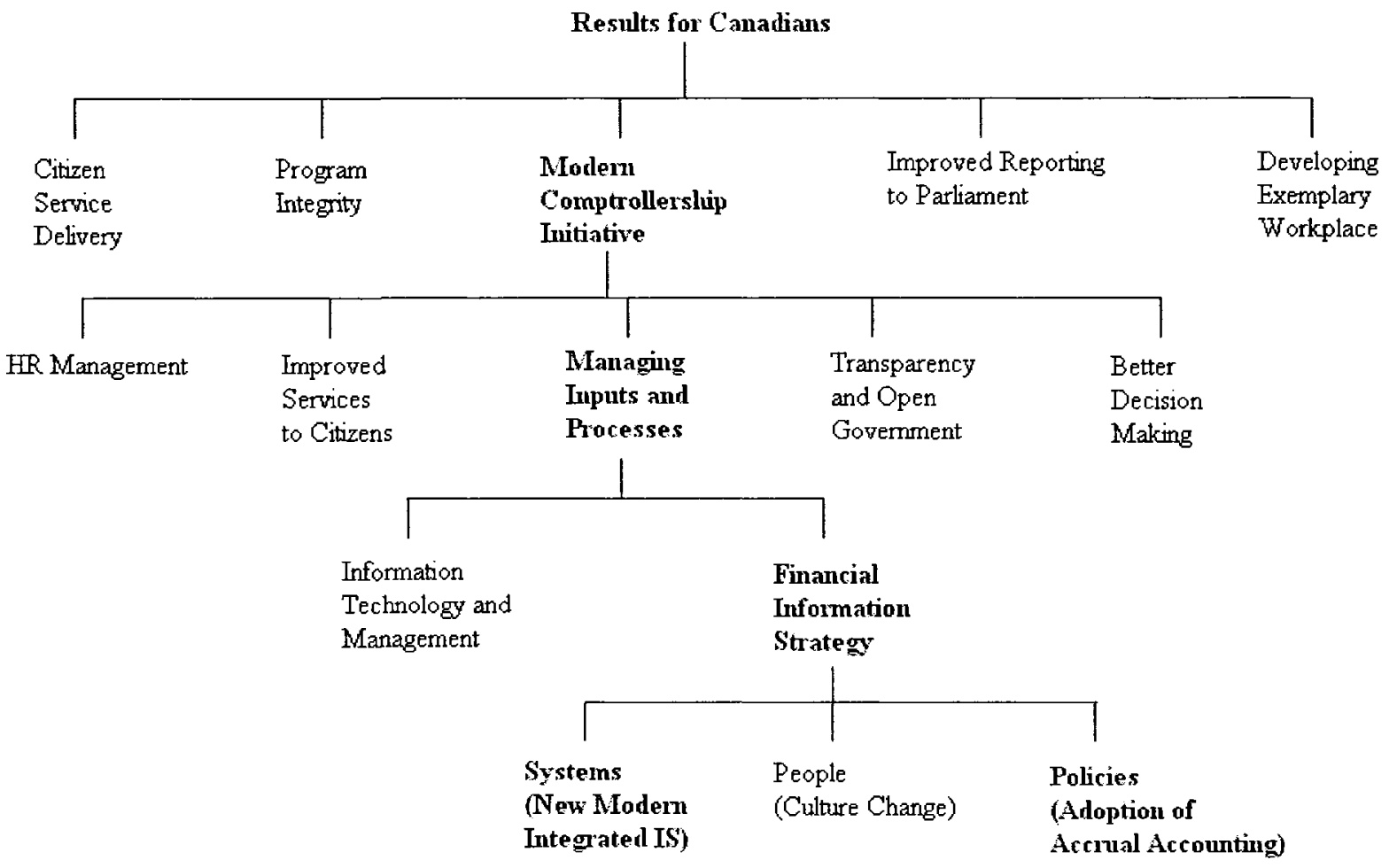

Figure 3: Hierarchy of Government Reforms in the Canadian Federal Government. Source: Adapted from Independent Review Panel (1997) and TBS (2002a, 2002c).

The Results for Canadians framework for management in government, includes the concepts of citizen focus, sound public service values, achievement of results for Canadians, and value for money. A focus on results includes measuring and evaluating results of work. It requires management to look at the impact or effects of programs. It also requires a clear definition of results to be achieved, delivery of programs or services, and measuring and evaluating performance. Responsible spending is another area relevant to the adoption of accrual accounting. It includes the information, financial and 
non-financial, needed to make decisions. This information links expected and actual results, effective management of risk, establishment of a proper environment of control, and cross-departmental information on expenditures and results (TBS, 2002c). Modern Comptrollership Initiative (MCI) is one relevant initiative among many initiatives under this framework.

The MCI is designed to provide managers with integrated financial and nonfinancial performance information, a sound approach to risk management, appropriate control systems, and shared values and ethics (Colman, 2004). These objectives rely on information flowing from the FIS. The MCI includes numerous components, including human resource management, improved services to citizens, transparency and open government, better decision making, and managing inputs and processes. The need to change how comptrollership is viewed stems from the growth and complexity of the government, technology, and management philosophy and tools (Independent Review Panel, 1997). There are two major initiatives under managing inputs and processes: FIS and the Information Technology and Management.

The FIS is a modern comptrollership initiative that is being led by TBS. The mandate of the FIS is to establish detailed policies on capital assets and departmental financial statements (Colman, 2004). The FIS simultaneously focuses on systems, people, and policies. These three branches of FIS are interdependent on one another for success. Accrual accounting was introduced by FIS in order to get complete and accurate information (Colman \& Fletcher, 2003). Along with accrual accounting, the FIS will establish a new chart of accounts for government-wide reporting, decentralize responsibility for accounting records, to departments with centrally produced 
consolidated financial statements, and modernize central information systems (TBS, 2002a). Although the focus of this research is on the adoption of accrual accounting, it must be noted that these three initiatives are interdependent and must be implemented in tandem. A modernized information system and chart of accounts are key elements that need to be in place in order to successfully implement accrual accounting.

Some of the proposed benefits under the FIS are the integration of financial and non-financial information, relevant information on results of past decisions, greater emphasis on advisory and less on control, better information on business planning and performance measurement, and comparative trend analysis over multiple years (TBS, $2002 \mathrm{~b}$ ). The FIS is putting in place the tools to produce better financial information and better financial analysis to aid in the decision making process, with the ultimate goal of improving government's performance in the management of resources. This improvement supports the modernization of the comptrollership initiative, which is concerned with the sound management of resources.

There is a precedent in other countries for the adoption of accrual accounting to be entwined in larger change initiatives. In England, Resource Accounting and Budgeting (RAB) was introduced. Resource accounting involves a set of accrual accounting techniques. It is a framework for analyzing expenditure against department aims and objectives, and relating them to outputs. Resource budgeting is planning and controlling public expenditures on a resource accounting basis (HMT, 2001). Examples of the benefits of the RAB include better information on the use of resources to meet objectives, value for money, and better information leading to enhanced accountability (HMT, 2001). In Australia, the Brisbane city council undertook concurrently the 
development of a new financial management framework, policies for accrual accounting, and new financial systems and reporting formats. In order to accomplish these tasks, the city council had to create training programs for its staff, amend the law to support its initiatives, and create groups to look into specific issues (Webster, 1998). The council found that undertaking these major tasks concurrently created a complex developm schedule and anxiety for the personnel involved (Webster, 1998).

\subsubsection{Accrual Budgeting and Appropriations}

Budgeting involves the allocation of resources within an entity. Appropriations are spending authorities granted through legislation by the parliament (TBS, 1995). Budgeting in the Canadian Federal Government is still done on a partial accrual basis. There are risks to applying accrual accounting to financial reporting and not budgeting. Firstly, the budget is a key management document in the government. Accountability is based on the ability to implement the budget as approved by the legislature. In order to assess government spending plans, it is important that budget and estimate documents are clear and transparent, requiring the disclosure of all relevant information in a timely and systemic manner. It is done through a consistent accounting basis selected for reporting and budgeting (SCGOE, 2006). According to Mr. Ronald Salole, Vice-President, Standards, CICA, accrual accounting enhances transparency and accountability because "It's telling it the way it is - not the way people want it to be or the way people like it to be, but the way it is" (SCGOE, 2006, p. 6). If the budget is on a cash basis of accounting, then making the switch to accrual financial reporting is a purely technical exercise (Blondal, 2003). Accrual-based budgeting is used to shift the emphasis of the 
budgetary process away from cash towards outputs and outcomes (Carlin \& Guthrie, 2001). The objective of accrual-based accounting is not simply to provide better information, but also to change behaviour (Wright, 1995). However, Mellor (1996) exerts that accrual accounting will not bring about changes in behaviour, that will result in benefits of accruals, unless budgeting is also on an accrual basis.

Secondly, performance measurement becomes complicated when budgeting and financial reporting are done using different bases of accounting. Comparability issues arise between budgeted and actual results, making them difficult to measure and compare (Blondal, 2004; Hepworth, 2003). Accrual budgeting is necessary in order to ensure symmetry between accrual financial reporting and budgeting (Blondal, 2004). If an organization is using both accrual-based accounting and budgeting, it is able to process transactions it plans to undertake during the year. It forecasts the results of potential scenarios to decide if it is satisfied with the outcome (Webster, 1998). According to Mr. Ronald Salole, Vice-President, Standards, CICA, “....research shows that financial reporting prepared on the accrual basis of accounting, historically, also happens to be the best predictors of what is likely to happen in the future." (SCGOE, 2006, p. 7).

Furthermore, if the objective of the government were to provide better services and not to spend more money, then linking resources to services would be an important component of budgeting (Likierman, 2000). An example of how cash budgeting in an accrual environment may not be appropriate is that accrual accounting introduces a new range of costs such as depreciation or employee leave entitlement. These types of costs are not budgeted for under cash based budgeting (Webster, 1998). The advantage to accrual- 
based budgeting is that it allows resources used to be related to services provided, making it easier to link the results of an expenditure to that expenditure (Pallot \& Ball, 1996).

However, the experiences of the Government of Ontario in implementing accrual accounting for appropriations, as conveyed by Mr. Bruce Bennett, Acting Controller for the Government of Ontario, were that accrual accounting offers, "A better measurement of program expenditure ... and there is an improved basis for year-over-year comparisons of program expenditures." (SCGOE, 2006, p. 7). How budgeting is viewed under accrual-based budgeting system would change as well. Cash would no longer be the predominant focus (Boxall, 1998). Other benefits claimed for accrual-based budgeting are that it has a greater customer focus, based on supply or services/products, separates purchaser and owner, reflects full accrual costs, gives clear choices to the buyer, provides sound basis for internal resource allocation, and focuses on outputs and outcomes (Carlin \& Guthrie, 2001). Within the literature these benefits have simply been stated and not explained, or are not apparently obvious. There is a lack of literature that analyzes these benefits in detail.

\subsubsection{A Potential Accrual Budgeting Reform in the Canadian Federal}

\section{Government}

The TBS has engaged an independent contractor to conduct a study of accrual accounting and to determine whether it can be applied to budgeting and appropriations. In addition, the TBS has consulted departments on implementation strategies and explored the impact of accrual-based budgeting and appropriations for capital assets. It 
must be noted that the TBS has been studying the implementation of accrual-based budgeting since 1998 and has not yet come to a conclusion (OAG, 2006).

As well, the House of Commons Standing Committee on Government Operations and Estimates began extensively studying the implementation of accrual budgeting. It made, in December of 2006, its recommendations that the Government of Canada adopt full accrual accounting for budgeting and appropriations (SCGOE, 2006). In this report, the House of Commons Standing Committee identified several expected benefits, by switching from cash budgeting to accrual budgeting. These benefits included improved efficiency, greater transparency, improved financial management, and better accountability. These expected benefits were based on expert testimonies of individuals such as the OAG, important CICA personnel, provincial Auditor Generals, etc. (SCGOE, 2006).

However, it must be noted that the concept of accountability, both in terms of its meaning and the extent to which various reforms have furthered it, has been found to be highly problematic (Olson, Guthrie, \& Humphrey, 1998). Improved financial management would be achieved through improved cost information being available to decision-makers and improved management of capital resources (Blondal, 2004). They are also perceived benefits of accrual accounting, which would indicate that both systems aim for the same objectives. Additional benefits of accrual accounting proposed by Blondal (2004), include highlighting the long-term consequences of public finances, through the incorporation of the balance sheet into the budgeting framework, thus acting as a catalyst for other management reforms. 
The adoption of accrual-based budgeting is not without debate and there are differing views on the desirability of implementing accrual-based budgeting in the public sector (SCGOE, 2006). Reasons for not embracing accrual-based budgeting, proposed by Blondal (2003, 2004), include risking budget discipline and legislatures resisting adoption. Budget discipline involves ensuring the political decision to spend money should match with what is reported in the budget. Under accrual-based budgeting, only the depreciation would be reported instead of the cash outlay. It is feared that reporting only depreciation would lead to increased spending. The fact that assets and liabilities may accrue in one period, but be expensed or amortized in another, raises the prospect of granting multi-year appropriations or acquiring assets with amortization periods that go beyond the Parliament's mandate (SCGOE, 2006). These issues also lead to concerns over budget discipline. It is felt that these issues could be used as a way for parliamentarians to fund projects through an indirect form of taxation, since a capital project will have to be paid for throughout its useful life and not just in the current year (Aiken \& Capitanio, 1995).

The other issue is that legislators resist adopting accruals for budgeting because of the perceived complexity of accrual accounting (Blondal, 2003, 2004; SCGOE, 2006). As well, it has been proposed that the implementation of accrual-based budgeting is not feasible due to the increased sophistication of an accrual-based budgeting system. Those involved with the new system will not be able to handle the new information, thus confusion and potential misuse could arise (Likierman, 2000). There is a much greater degree of acceptance internationally of accrual-based accounting than for accrual-based budgeting (Blondal, 2004; Pallot \& Ball, 1996, SCGOE, 2006). In 2004, three OECD 
member countries adopted full accrual budgeting with others adopting accruals for specific transactions in their budgets, as seen in Table 3.

\begin{tabular}{|c|c|c|c|c|}
\hline & Cash basis & $\begin{array}{c}\text { Cash, } \\
\text { except certain transactions } \\
\text { on accruals basis }\end{array}$ & $\begin{array}{l}\text { Accruals, } \\
\text { except for capitalisation } \\
\text { and depreciation of assets }\end{array}$ & Accuals basis \\
\hline Australia & & & & $x$ \\
\hline Austria & $x$ & & & \\
\hline Belgium & $x$ & & & \\
\hline Canada & & $x$ & & \\
\hline Czech Republic & $x$ & & & \\
\hline Denmark & & $x$ & & \\
\hline Finland & & & $x$ & \\
\hline France & $x$ & & & \\
\hline Germany & $x$ & & & \\
\hline Greece & & $x$ & & \\
\hline Hungary & $x$ & & & \\
\hline Iceland & & & $x$ & \\
\hline Ireland & $x$ & & & \\
\hline Italy & $x^{1}$ & & & $x^{1}$ \\
\hline Japan & $x$ & & & \\
\hline Korea & & $\mathrm{x}$ & & \\
\hline Luxembourg & $x$ & & & \\
\hline Mexico & & $\mathrm{x}$ & & \\
\hline Netherlands & $x$ & & & \\
\hline New Zealand & & & & $x$ \\
\hline Norway & $x$ & & & \\
\hline Poland & $x$ & & & \\
\hline Portugal & & $x$ & & \\
\hline Slovak Republic & $x$ & & & \\
\hline Spain & $x$ & & & \\
\hline Sweden & & $x$ & & \\
\hline Switzerland & $x$ & & & \\
\hline Turkey & $\mathrm{x}$ & & & \\
\hline United Kingdom & & & & $x$ \\
\hline United States & & $x$ & & \\
\hline
\end{tabular}

1. To be verified.

Table 3: Use of Accrual Budgeting in OECD Member Countries. Source: Blondal (2004) p. 118.

Organizations that have adopted accrual-based budgeting have experienced difficulties due to the lack of clarity and measurability of outcomes and the lack of a performance measurement system that would provide feedback from the new budgeting system (Carlin \& Guthrie, 2001). Another issue that arises with the implementation of accrual budgeting is the cost of implementing the system and the increased annual 
operating costs of the system. The preparation of additional financial statements and new items in the budgeting and appropriations processes will incur costs that are not incurred in the current budgeting system (SCGOE, 2006).

\subsection{Accrual Accounting Implementation in the Canadian Federal Government}

\subsubsection{Enterprise Systems}

ES is also known as Enterprise Resource Planning Systems (ERP). According to Watson and Schneider (1999), ERP is a generic term for an integrated enterprise computing system (cited in Kumar, Maheshwari, \& Kumar, 2002). It is a software-based system that can handle the majority of an enterprise's information requirements in all functional areas, such as finance, human resources, manufacturing, sales and marketing (Miranda \& Kavanagh, 2005). It attempts to integrate all information in one central database that allows information to be retrieved from many different organizational positions (Dechow \& Mouritsen, 2005). The adoption of ES represents a move from functional to process-based IT infrastructure (Al-Mashari, 2003). ES facilitates the flow of information among all functions within an enterprise. It sits on a common database supported by a single development environment. The concept of ERP has advanced from the Manufacturing Resource Planning systems (MRP) in the 1970's and the MRPII systems in the 1980's (Al-Mashari, 2003). Some authors make the distinction between ERP as a technology of database modules, and ERP as a system. ERP becomes a system through design and use (Deschow \& Mouritsen, 2005). Early ES implementers in the public sector were driven by technical objectives such as the millennium bug, while 
currently organizations are investing in technology with more strategic objectives (Miranda \& Kavanagh, 2005).

There are benefits unique to the government from the use of ES. Benefits to government organizations include integrated real-time information, better administration, and the ability to manage based on results (Kumar et al., 2002). These benefits are congruent with the objectives of accrual accounting implementation and larger initiatives, such as Results for Canadians. ES-enabled standardization is a vital means to integrate dispersed organizational systems, provide seamless access to organization-wide information and make informed decisions on strategic and daily business matters (AlMashari, 2003). A key benefit of ES that is often cited is the organizational integration of both business processes and data, which in turn reduces processing time and increases control over operations (Volkoff, Strong, \& Elmes, 2005).

ES implementation is driven by its standardization and integration capabilities, flexible client/server architecture, and its ability to drive effective business process reengineering and management of core and support processes (Al-Mashari, 2003). It is this ability to drive business process re-engineering and management of processes that is critical to the implementation of accrual accounting, since processes need to be altered. Grant (2003) summarized the opportunities afforded by ERP implementation, which can be found in Table 4. This table organizes the opportunities ES implementation affords based on the level that is being impacted, and includes strategic, organizational, operational, and technological opportunities. While there is a consensus over what ES is capable of achieving, there is still debate regarding whether ES actually delivers expected benefits (Miranda \& Kavanagh, 2005). Some literature suggests that it will have a 
positive impact only if it is installed correctly, which could account for the debate over whether or not ES is actually successful (Deshow \& Mouritsen, 2005). Field studies suggest that ES has only a relatively moderate impact on the character of management accounting and the work of management accountants. However, these studies have been criticized as adopting a static approach and not exploring accounting processes (Scapens \& Jazayeri, 2003).

Accrual accounting would require ES to summarize and integrate financial information from various sources, as well as to track assets that have previously gone unrecorded. The ES would have to be updated and enhanced to meet these new information needs. The Hong Kong Special Administrative Region government found that it needed to implement new systems to support the adoption of accrual accounting and cited a customized enterprise resource-planning package as the optimal solution. Many governments worldwide have come to this same conclusion, including the United Kingdom, the US, Australia, New Zealand and Singapore (Awty, 2002; Slamet, 1998).

\begin{tabular}{|c|c|}
\hline Type of impart & Opportunities \\
\hline Strategic & $\begin{array}{l}\text { Support globalization, strategic alliances, mergers and acquisitions } \\
\text { Improve responsiveness to competitic pressurs and market opportunities } \\
\text { Support the supply chain, selling chain and clectronic business processes } \\
\text { Support eonsolidation of the IT infrastructures across business units }\end{array}$ \\
\hline Organizational & $\begin{array}{l}\text { Create a plation for business process re-engineering } \\
\text { Support the introduction of best practices in business processes } \\
\text { Improve communication and coordination between and across business units } \\
\text { Support the rationgtization ('right sizing") of organizational infrastructures }\end{array}$ \\
\hline Operational & $\begin{array}{l}\text { Improve the transaction-prosessing ability } \\
\text { Improve operational efficiency by incegrating operational and transaction data across operating units } \\
\text { Improve the quality and visibility of organizational information } \\
\text { Improwe the decision support capabilities }\end{array}$ \\
\hline Technological & $\begin{array}{l}\text { Improwe the processing power across the organizational network } \\
\text { Introduce more cost-effective TT architectures } \\
\text { Standandize ISTT operations for developing focused IT competencics } \\
\text { Overeeme systems challenges such as year } 2000 \text { and Euro compliance }\end{array}$ \\
\hline
\end{tabular}

Table 4: Opportunities Afforded by ERP Implementation.

Source: Grant (2003), p. 161. 
In the United Kingdom, it was found that after the implementation of the RAB, departments were required to re-assess and invest in new management information systems in order to utilize the resource based information (HMT, 2001; Pendlebury \& Karbhari, 1998). A change in information technologies was required in Australia as well, when accrual accounting was implemented (Guthrie, 1998). The change in information technologies has resulted in accounting personnel becoming more involved in the design and management of IT systems (Caglio, 2003).

Accrual accounting implementation in the Federal Government must be studied in parallel with ES implementation, since ES enables implementation of business practices (Al-Mashari, 2003), and several departments have used ES to implement accrual accounting and other strategic initiatives. Likierman et al. (1995) concluded that the ability to implement accrual accounting can now only be achieved because of reduction in the cost of technology. ES provides the technology that enables the use of accrual accounting. This enabling is partly done through the automation of many tasks that had previously been time consuming, allowing accountants more time to perform analysis, interpretation, and consultation (Caglio, 2003). These systems lay the foundation for transforming government into lower cost, higher performing organizations that focus on customer service (Miranda \& Kavanagh, 2005). This transformation is in keeping with the wider government initiatives, of which accrual accounting is an integral part.

ES attempts to integrate information in one central database, allows information to be retrieved from many different sources, and can allow any organizational objective to be visible (Dechow \& Mouritsen, 2005). These abilities are key to the implementation of accrual accounting in such a vast organization as the Canadian Federal Government, 
where departmental information must be collected centrally to produce government financial statements. ES also impacts the functioning of accounting systems and changes the role of accountants within the organizations. Part of the changing role stems from accounting literacy becoming easily transferable to non-accountants through ES. As such, ES contributes to the diffusion of accounting knowledge throughout an organization (Caglio, 2003).

ES applications have the ability to lock operating principles and processes of the organization into software systems (Kumar et al., 2002). While it may not be an accounting change driver, ES has the ability to facilitate the change (Scapens \& Jazayeri, 2003). ES also has the ability to decrease diversity in operations, practices and behaviours, and give emphasis to consistency and uniformity across an organization. It accomplishes these goals by embedding business practices, even when management of organizational data, information, and knowledge is decentralized (Caglio, 2003). These abilities of ES facilitate the adoption of accrual accounting.

The Service Oriented Architecture Strategy in the Canadian Government recognizes that it is imperative to address the demand for consistency and interoperability across the government, as more and more services require information from multiple sources. Increased interoperability cannot be achieved with a collection of nonhomogeneous products, tools and applications, but requires large-scale changes. One goal of this strategy is to facilitate the manageable growth of large-scale ES (TBS, 2006a). In the Canadian Federal Government, larger departments use SAP with a few exceptions using Oracle. The shared systems initiative allows departments and agencies to choose one of the seven approved financial management systems. Five of these 
systems, Freebalance, Oracle, SAP, G-MAX and AMS, are commercial applications while two, CDFS and CMS, were internally developed by Public Works and Government Services Canada and Human Resources Development Canada, respectively (Buckstein, 1999). Each of these systems has unique attributes that can either facilitate or hinder the accrual accounting implementation processes to different degrees.

\subsubsection{Organizational Culture}

Organizational culture reflects underlying values and interests, and impacts structures, processes and people by prescribing acceptable work styles, methods and behaviours (Rieschi, 2007). It is the pattern of values and beliefs held by members of an organization (Driscoll \& Morris, 2001). Culture is the driving force within any organization (Marc \& Farbrother, 2003) and is a key to organizational performance (Driscoll \& Morris, 2001). However, one author holds the view that behaviour is what affects performance and behaviour is affected by more than just culture (Ryan \& Lewis, 2007). Social, emotional, and behavioural aspects of the workplace must be considered when any kind of organizational change is being purposed (Marc \& Farbrother, 2003). Any significant change in size, scope, or direction can have an impact, often unintended, on culture (Rieschi, 2007). Organizational change is a "comprehensive, collaborate, and planned process of solving problems through altering foundational assumptions and beliefs of individuals in order to improve work content, structures and relationships in organizations" (Rusaw, 2007, p. 349).

Studies have shown that, in order for an organizational change to be achieved, there are a number of factors that must be considered. These factors include a framework 
that allows the organization to paint a picture of what it wants to achieve, namely alignment between political and senior administration, organizational and individual commitment to the change, and active involvement by everyone (Marc \& Farbrother, 2003). The research to develop this particular framework was performed on Canadian Municipal government, but the same principle could still apply to the Canadian Federal Government.

Broadly, change management literature contains two types of change models. The first is the rational model that places importance on planning, problem solving, and execution. The second type of model explores changing, rather than change, and emphasizes the uniqueness and contextual richness of each situation (Stewart \& Kringas, 2003). More specifically, three common change management models include Strategic Information Systems, Theory of Constraints, and Organizational Development. The Strategic Information Systems model uses information systems in order to achieve business change. Theory of constraints is based on the idea that multi-phased processes can only proceed at the pace of the lowest process. This model emphasizes finding and supporting the limiting factor. Finally, organizational development focuses on processes and organizational learning (Ritson \& O’Neill, 2006).

Another study examined four approaches to changing public organizations. These models are means-end, incremental, pluralistic, and individual. The means-end model focuses on finding the root cause of existing problems, developing a range of strategies, selecting and implementing a strategy. The incremental model involves making minor changes in the existing system. The pluralistic model tries to cultivate multiple stakeholder input, resources, and commitment in order to resolve a problem. The 
individual model focuses on learning through training and development programs (Rusaw, 2007). One study found that most organizations use a process-centred approach to change. This approach is done through defining and documenting new processes (Oakland \& Tanner, 2007). The author notes that these models are not mutually exclusive and may be used in conjunction with each other. Generally, there is a lack of clarity and exploration of processes in the literature pertaining to change management in the public sector (Stewart \& Kringas, 2003).

Research in the private sector also emphasizes ensuring employee commitment and involvement, primarily through frequent effective communication (Rieschi, 2007). Change communication increases the employee's positive change receptivity (Frahm \& Brown, 2007). Stakeholders within an organization need to understand the need for the change and feel a sense of urgency in order to unfreeze the organization (Neal \& Taylor, 2006). Inappropriately, management changes can confound positive change initiatives (Rieschi, 2007). The alignment between organizational culture and employees' values and interest is essential, and when this alignment is threatened, employees perceive it as a betrayal (Rieschi, 2007). Understanding the cultural shift helps engage employees and prevents culture related problems (Rieschi, 2007). One study found that when a cultural change was driven from the top down, employees conformed to what was required of them without any real attitudinal or cultural change (Driscoll \& Morris, 2001). As well, when the big bang approach to change is utilized, organizations can experience problems with resistance. In a more incremental approach, staff learn as they go (Stewart \& Kringas, 2003). 
Accounting and management changes can be seen as social phenomena situated within a social setting (Guthrie, 1994, as cited in Guthrie \& Parker, 1998). In order to introduce accrual accounting into government departments, cultural changes are required (Guthrie, 1998). According to the literature, any major organizational change is difficult, unless the underlying value and belief systems of the organization's members also change (Driscoll \& Morris, 2001). Other authors feel that the introduction of accrual accounting will produce a fundamental cultural change (Buckstein, 1999). The ability to change culture within an organization is extremely debatable, however (Driscoll \& Morris, 2001). Driscoll and Morris (2001) found three streams of thought in cultural literature. These streams include that culture can be managed and thus directed and controlled, culture should not be managed since culture may be manipulated, and finally that culture exists and changing it is beyond management. Further complications for implementing are experienced if the implementation involves new technology such as ES.

In a literature review of important variables for successful merger and acquisitions, communication was found to be crucial (Appelbaum, Lefrancois, Tonna \& Shapiro, 2007). It is expected that this need for communication will be true as well for the successful implementation of a new accounting system. Communication and staff involvement are essential for overcoming resistance to change, along with effective leadership and change management strategies (Appelbaum et al., 2007). Communication is not only important during the implementation process, but also in establishing a consensus before implementation actually begins (Stewart \& Kringas, 2003). Leadership is also thought to be an important variable in successful change (Stewart \& Kringas, 2003). 


\subsubsection{Implementation Challenges}

Other countries that have adopted new accounting systems found the implementation process to be marked with significant difficulties (Pendlebury \& Karbhari, 1998). Organizational change, no matter how well, planned often has unintended consequences (Stewart \& O'Donnell, 2007). Changing managerial culture is a difficult task. One study of IT implementations found that there was often a lack of attention paid to "softer" management change practices, such as culture change, organization development and user involvement (Maguire \& Redman, 2007). Studies of accounting systems implementation seem to find similar results.

One major implementation issue is to ensure that the shift to accrual accounting is not just seen as a technical exercise, but that the adoption fosters a change in the organizational culture (Blondal, 2003; Hepworth, 2003; Likierman, 2000). One author found that after resource accounting was implemented in the UK managers felt there was no use for the accrual accounting information (Pendlebury \& Karbhari, 1998). Resistance to change can be a major problem (James, 2006). Resistance can be anticipated if proposed organizational changes alter values and visions relating to the existing order. Managing resistance should be part of the implementation strategy (Trader-Leigh, 2002). Studies have found that consultation with stakeholders was key in an implementation change program (Oakland \& Tanner, 2007; Stewart \& O'Donnell, 2007).

The implementation of accrual accounting is not just a better way of costing, but also a better way to understand and use that information. Some countries have found that implementation was impeded because of a lack of desire from senior management to 
learn and adapt (Connolly \& Hyndman, 2006). Leadership is key in inspiring change throughout the organization and ensuring that the change is implemented (Oakland \& Tanner, 2007). Webster (1998, p. 24), in his study of the adoption of accrual accounting in the city of Brisbane, found that it was crucial "to embrace accrual accounting from day 1." In fact, other studies of implementation have found that even when considerable resources were put into training and preparing, an organization culture shock was still experienced (Webster, 1998). The ability to understand the accrual information was also an issue (Pendlebury \& Karbhari. 1998).

For the implementation to be successful, good communication must be an essential element of the implementation strategy (Oakland \& Tanner, 2007). Other countries that have moved to accrual accounting cited more and better communication was a greatly underestimated component of implementation (Blondal, 2003). Studies in the private sector have found that, frequent communication was a powerful tool in ensuring that change initiatives are successful, by building acceptance and ownership among employees (Rieschi, 2007). Employees who experience organizational change use communication in order deal with uncertainty concerning the outcomes of the change, the rationale behind the change, and the implementation process (Allen, Jimmieson, Bordia, \& Irmer, 2007).

A major challenge is to ensure that the technological aspects of the ES system reconcile with the needs of the government initiatives (Kumar et al., 2002). The appropriate technology must be in place to facilitate the use of accrual accounting information (Blondal, 2003). Studies performed in other countries found that underdeveloped information systems led to information that was slow to produce and 
complex to understand (Connolly \& Hyndman, 2006). As well, it was found that organizations outgrow their financial systems and that their needs are no longer being met. Often these financial systems were adequate when first installed, but as accounting becomes more complex, these systems are unable to meet the new demands (Webster, 1998).

Lack of accountancy skills was found to be another roadblock in the implementation process (Blondal, 2003; Likierman, 2000; Pallot \& Ball, 1996). There needs to be trained accountants in accruals, as well as, training for the average managers on how to use the new accrual information. One study found that the need to train people on the new accruals was the single biggest challenge (Jones \& Puglisi, 1997). It was found that, once accrual accounting was implemented, the information produced was too complex and that there was a lack of understanding among the users of the information (Connolly \& Hyndman, 2006). However, the implementation of accrual accounting in New Zealand, was accompanied by an increase in information available to the Parliament, for ministers to make informed choices (Pallot \& Ball, 1997). An addition, it was found that, after implementation, some governments did not have the ability to cost accurately the costs of implementation (Connolly \& Hyndman, 2006). A challenge of implementing the system is the ability to ensure that the costs and benefits of implementation are justifiable. This justifying the system is not possible without accurate costing information. In addition, it is especially important to consider the cost involved in reporting, especially for smaller departments (Pallot \& Ball, 1997).

Along with the previously mentioned issues, there are also a number of technical accounting issues that accompany the implementation of accrual accounting. Accounting 
for infrastructure and heritage assets is challenging as previously discussed. Military assets also present a challenge for valuations (Gilllibrand \& Hilton, 1998; Neal \& Taylor, 2006). A challenge that comes with the implementation of accrual accounting is recognizing the values of these assets (Awty, 2002; Blondal, 2004; Evans, 1995; Jones \& Puglisi, 1997). Inappropriate accounting practices for these assets can distort financial information, send incorrect signals to decision makers and lead to poor resource allocation (Rowles, 1991). One jurisdiction moving to accrual accounting abandoned the attempt, in part because it was found asset valuation was too difficult (Likierman et al., 1995). Prior to implementation, one report claimed that asset valuation would be one of the most difficult implementation challenges that the Canadian Federal Government would experience (Buckstein, 1999).

Finally, challenges can relate to valuation of liabilities and revenues. There is a general lack of focus in the literature pertaining to the valuation of liabilities, which can be just as difficult (Heald \& Georgiou, 1995). As previously mentioned the PSAB has issued guidelines to deal with this issue. These guidelines set out steps for compliance with full accrual accounting for capital assets. The Treasury Board Accounting Standards also makes recommendations on how to deal with valuation issues (Wong, 1998). Recognition of tax revenue is another technical challenge of implementation, specifically the timing of recognition and the amounts to be recognized (Mart, 2006; Pallot \& Ball, 1997; Webster, 1998). Canada's tax system is one of self-assessment, which raises difficulties because the amount of taxes collected is not known until the following fiscal period. 


\subsection{Conclusion}

In this chapter, the relevant literature, pertaining to the implementation of accrual accounting was reviewed. First, background information was presented. The Canadian Federal Government has adopted a full accrual accounting system, which is a shift away from the former modified accrual accounting system. In doing so, it has joined an increasing number of countries that have adopted full accrual accounting instead of traditional cash or modified accrual accounting. While there is an abundant amount of literature available concerning the potential benefits of implementing accrual accounting, in both the public and private sector, there appears to be a lack of literature to explain how these benefits are actually achieved. There are studies available in several jurisdictions that have already implemented accrual accounting, but the benefits cannot be assumed to apply without study to the Canadian landscape, since there are fundamental differences across jurisdictions. Furthermore, public sector accrual accounting literature is deeply divided regarding implementation benefits. One side advocates the adoption of accrual accounting in the public sector, while the other opposes it. Authors on both sides of the debate are adamant with respect to their positions. While both sides have merit, it must be noted that once a government, having spent considerable time and resources, has adopted accrual accounting, it is unlikely to revert to the former system.

Secondly, the development of accrual accounting in the Canadian Federal Government was discussed. The history of accrual accounting in the Canadian Federal Government dates back to the Royal Commission on Government Organization in the early 1960s. However, the decision to implement accrual accounting did not occur until 
much later, when it was announced in the 1995 federal budget and implemented in fiscal year 2003. This decision was partially due to urging from the OAG. The OAG also plays a key role in the accrual accounting standard setter process, along with the PSAB, the TBS and to a lesser degree the IPSASB. The Receiver General, the Department of Finance, and TBS all play a vital role in the functioning of the accrual accounting system in the Federal Government.

Thirdly, through the literature review, it was discovered that accrual accounting has been implemented in the context of larger reform initiatives such as the FIS, Modern Comptrollership, and Results for Canadians. Being part of these larger reforms affects the accrual accounting system and how it is implemented. Along with these past reforms, there is a potential reform, accrual budgeting, which is currently being discussed in the Federal Government. While there are problems with the current system of accounting being on a different basis than budgeting, there is no general consensus in the literature that accrual-based budgeting should be adopted in the public sector. Advocates of accrual-based budgeting claim many benefits from its adoption, but as with the accrual accounting literature, there is a lack of depth to this discussion.

Finally, accrual accounting implementation in the Canadian Federal Government was explored in terms of ES, organizational culture, and implementation challenges. ES is a generic term for an integrated enterprise computing system that handles the majority of an organization's information requirements (Watson \& Schneider, 1999, as cited in Kumar et al., 2002). ES must be studied in parallel with accrual accounting, since these two systems are integrated, and ES is often used to implement strategic initiatives. The other influential factor that must be studied in parallel is organizational culture. 
Organizational culture is a pattern of beliefs held by an organization (Driscoll \& Morris, 2001). Organizational culture change needs to be managed for any kind of system implementation to be successful. The literature that studies implementation of accrual accounting in other public sector jurisdictions found that implementations did experience many challenges. These challenges were both technical and cultural in nature. 


\subsection{Research Model and Questions}

This section examines theories useful for adoption of accrual accounting systems that comprise the theoretical foundation for this study. Based on the findings of the literature review, an a priori model was created that forms the basis of this study's research questions. This section explains the research model, which is an adaptation of Kumar, Pollanen, and Maheshwari's (2007) ERP Systems Effectiveness model in implementing internal controls, and Markus and Tanis's (2000) Enterprise System Experience Cycle. The latter part of this section contains the research questions.

\subsection{A Priori Model}

The implementation processes for accrual accounting can be framed using emergent process theory. An emergent process takes into account the unpredictable reactions between people in an organization and the environment. It assumes that people try to achieve goals, but that the outcomes are not always those intended. The strength of this type of theory is that it accounts for mutual influences, but its weakness is that it is explanatory rather than predictive in nature (Markus \& Tanis, 2000). That does not mean that materiality is not taken into account when studying the implementation of accrual accounting. According to De Cock and Sharp (2007, p. 238), “... all processes exist as the interaction of agency with materiality. That is to say materiality and process cannot be considered separately but only together." An example of an emergent process theory relevant to this discussion is the Enterprise System Experience Cycle in Figure 4. This theory consists of four stages: the Chartering Phase, the Project Phase, the Shakedown Phase, and the Onward and Upward Phase. The Chartering Phase includes all the 
activities and challenges up to the point when a decision is made to fund the system. The Project Phase comprises activities and challenges in the creation of the system, and the Shakedown Phase is a period from when the system is created until normal operations are achieved. The final phase, Onward and Upward, continues fine-tuning the system after normal operations are achieved. While this model was developed to describe the enterprise system (ES) implementation processes by Markus and Tanis (2000), it has been applied successfully with some modifications to other contexts, such as supply chain partnerships (Maheshwari, Kumar, \& Kumar, 2006). It is expected that this model will also apply to accrual accounting system implementation in general. Upon collection of the empirical evidence, this model will be modified in order to address the public sector accrual accounting environment.

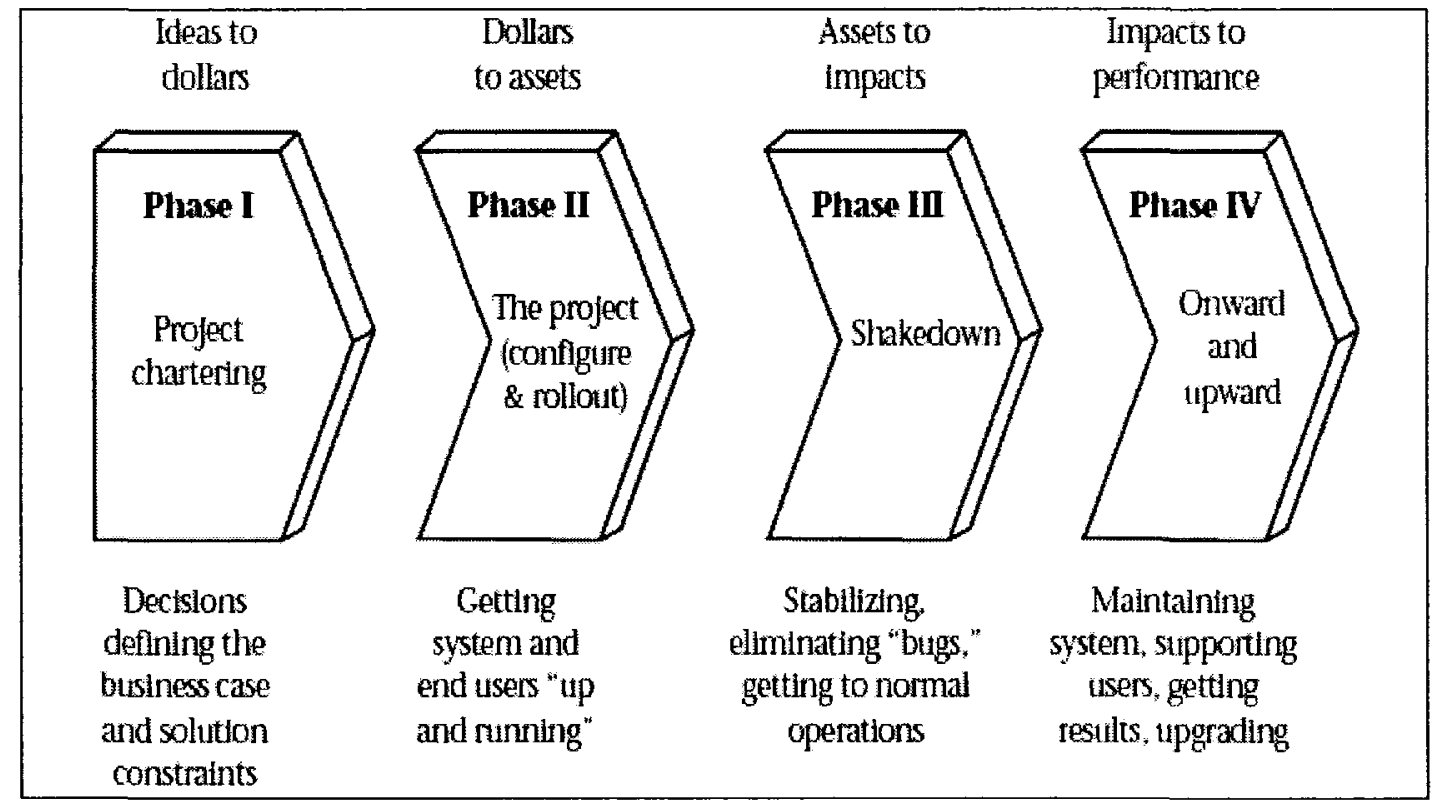

Figure 4: Enterprise System Experience Cycle.

Source: Markus and Tanis (2000), p. 189. 
While the influence of ES on accrual accounting adoption has not been studied directly, Kumar et al. (2007) developed a model of ERP Systems Effectiveness in implementing internal controls, as seen in Figure 5. This model identifies the system characteristics and required functional features of ES that would benefit implementation, the actual implementation processes, and the associated benefits of the system. As described by Kumar et al. (2007), the functional ES features outline the information needs in typical accounting systems, for example, budgeting, transaction processing, monitoring, and reporting. The technical ES features provide a technological infrastructure and technical tools, for example, common databases and integrated information, for implementing the functional features. Both the functional and technical features can work seamlessly as enablers of effective internal control implementation. Control implementation follows six processes depicted in the model: scoping and planning, appraisal of design and operating effectiveness, trial and documentation, implementation, reporting on internal control effectiveness, and external audit of internal control effectiveness. These processes have commonly been used to implement regulatory internal controls, such as those required by the Sarbanes-Oxley Act (US Congress, 2002). Although the major stages are sequential, minor modifications to previous stages may be necessary throughout the successive stages as learning occurs. Effective internal controls, implemented using ES, can result in several operational and strategic benefits, for example, systems and process efficiency, improved organizational performance, regulatory compliance, and positive employee behaviours and stakeholder reactions. Feedback and lessons learned can be used to further improve systems and processes and ultimately achieve sustainable longer-term benefits and organizational 
effectiveness. It is expected that this model will at least partially apply to the accrual accounting implementation.

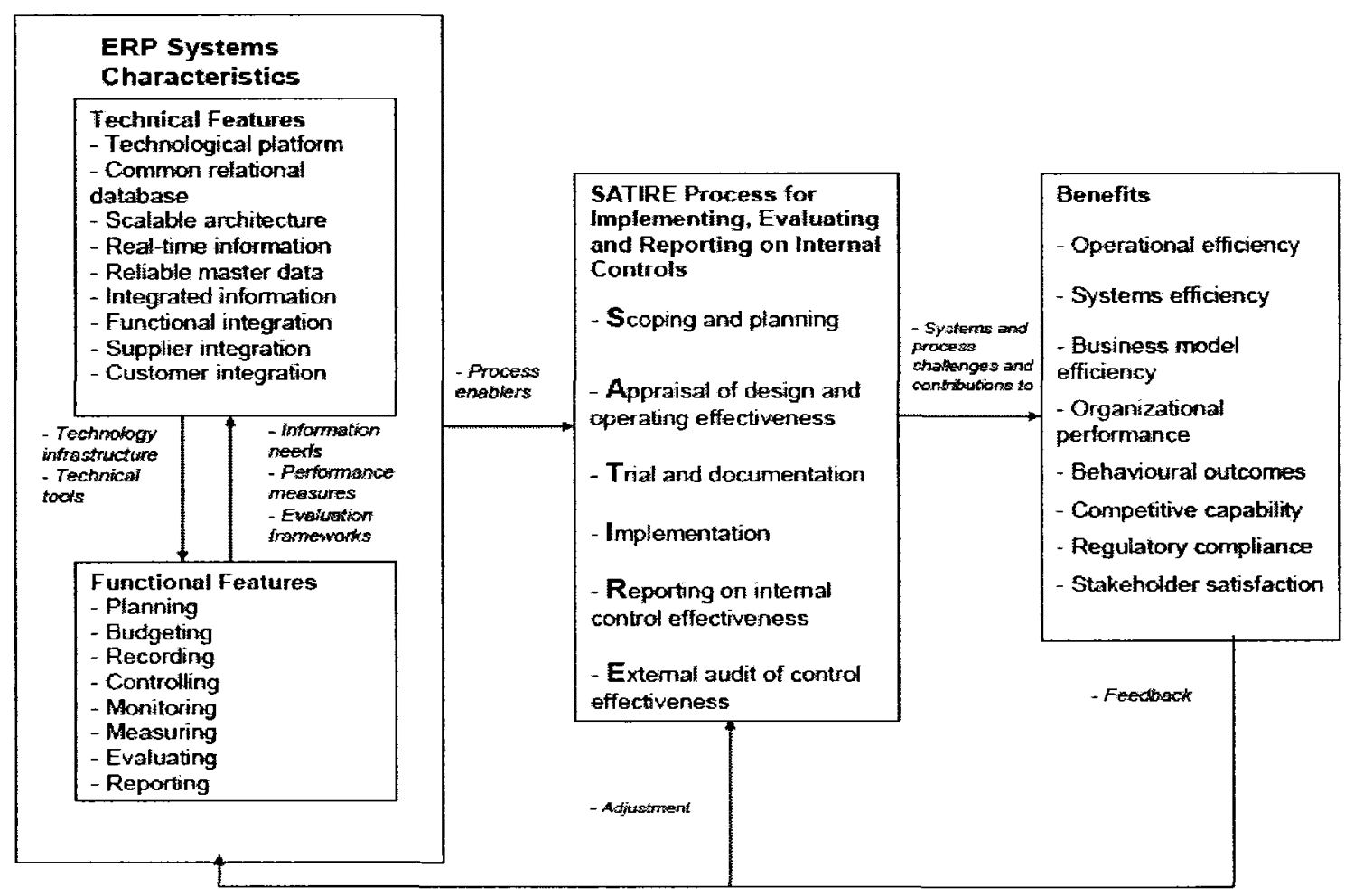

\section{Figure 5: SATIRE Process Model of ERP Systems Effectiveness in Implementing Internal Controls.}

Source: Kumar, Pollanen, and Maheshwari (2007), p. 21.

Based on the above-described two models, a new a priori model is developed for use in this study. The a priori model, shown in Figure 6, consists of three main areas. One major area focuses on accrual accounting implementation processes and the benefits that stem from these processes. These processes, activities, and challenges are based on Markus and Tanis' Enterprise System Experience Cycle (2000) and consist of four phases. The Chartering Phase is also termed the Ideas to Dollars Phase. This phase is comprised of all activities leading up to the funding of the system. Key activities proposed by Markus and Tanis in this stage that would apply to accrual accounting 
implementation include building a business case, approving budget and schedule, and identifying project leadership.
Cultural Aspect
- Lack of desire to learn and adapt
- Implementation viewed as a technical exercise
- Poor communication
- Lack of required knowledge and skill
- Reconciling system with organizational needs

\section{Modern Comptrollership Initiative Financial Information Strategy}

Process for Implementing
Accrual Accounting
- Project Chartering (Ideas to
Dollars)
- The Project (Dollars to
Assets)
- Shakedown (Assets to
Impacts)
- Onward and Upward
(Impacts to Performance)

\section{Benefits}

- Operational efficiency

- Systems efficiency

- Organizational performance

- Behavioural outcomes

- Stakeholder satisfaction

- Comparability of

information

- Improved decision

making

- Accountability

- Compliance with

standards

- Integration of financial and non-financial

information

- Improved management control systems

- Improved management of capital assets

\section{ES Characteristics and Support}

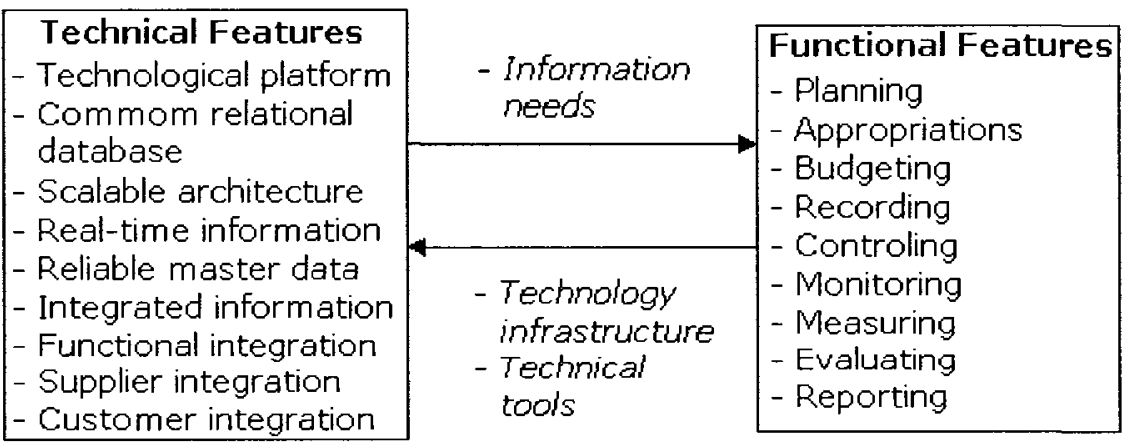

Figure 6: $A$ Priori Model of Accrual Accounting Implementation.

Source: Adapted from Kumar et al. (2007) and Markus and Tanis (2000). 
Common challenges were also identified at each phase of implementation. During the Chartering Phase challenges include incomplete or faulty business cases, underestimation of the amount of organizational and business change required, and undefined metrics and objectives.

The next phase is the Project Phase or the Dollars to Assets Phase. In this phase, the actual asset, Accrual Accounting System, is created. Activities are centred on getting the system up and running. Key activities in this phase include ensuring functional software that supports accrual accounting and data integration is in place, testing, training, and rollout. Challenges at this stage include lack of necessary knowledge and skill, inadequate training and testing, and lack of desire to learn and adapt. The third stage is the Shakedown or Assets to Impacts Phase. During this stage, the government will acclimate to the new system, and the phase will end when normal operations have been achieved. Key activities in this stage will include system performance tuning, retraining, and staffing. Examples of challenges at this phase of implementation include personnel working around the system and operational personnel not gaining the necessary knowledge.

The final implementation phase is Onward and Upward or the Impacts to Outcomes Phase. It is during this phase that the government is expected to begin receiving the benefits of the accrual accounting system. As well, during this phase, a post-implementation review should be performed along with continuous system improvements and additional user skill building. An example of a challenge faced at this stage is the loss of knowledgeable personnel. Decisions made at each stage will impact 
future stages of implementation. For instance, providing limited training at the Chartering Phase might hinder the government's ability to utilize the system.

The benefits that stem from the implementation processes have been adapted from the Kumar et al. (2007) model and from the relevant literature applicable to implementing accrual accounting in governments. These benefits are both operational and strategic in nature. Benefits are the outcomes of the processes previously discussed. Benefits included in the a priori model, which are based on the Kumar et al. (2007) model, are operational efficiency, systems efficiency, organizational performance, behavioural outcomes, stakeholder satisfaction, and compliance. However, in the case of accrual accounting implementation, compliance is with the relevant standards set by the standardsetting authorities and not compliance with regulations.

Benefits included in the model, that are specific to accrual accounting implementation and gathered from the literature, include increased comparability, better decision making, and better management of capital assets. These examples are taken from the literature pertaining to the adoption of accrual accounting in other countries, such as New Zealand, Australia, and the United Kingdom (Ellwood, 2003; Lye et al., 2005; Saleh \& Pendlebury, 2006). The experience of the implementation process in other countries is taken as a basis point to begin studying the implementation within the Canadian Federal Government. It must be recognized that it may be difficult to isolate the benefits attributable to accrual accounting implementation in the Canadian Federal Government, because the implementation occurred as part of larger change initiatives, such as the Financial Information Strategy (FIS) and the Modern Comptrollership Initiative. Possible benefits in this section include some of the relevant benefits from 
these larger change initiatives that are integrated with accrual accounting. Examples of benefits that relate to larger change initiatives include accountability, integration of financial and non-financial information, and improved management control systems (TBS, 2002b). This list of benefits is not exhaustive and more are expected to be uncovered during the interview process. As well, the interview process will also serve to identify which of the $a$ priori model benefits apply to the accrual accounting implementation in the Canadian Federal Government. The experience of short-term benefits and overcoming challenges provide feedback that can be used to improve the systems and processes and to achieve longer-term benefits.

The second major area of the model outlines the ES characteristics, both technical and functional, that are relevant to accrual accounting implementation. They are the same characteristics used by Kumar et al. (2007) with the exception of "appropriations" which is an additional functional feature. Appropriations are spending authorities granted by the Federal Government (TBS, 1995). They are a unique feature of the government sector and must be included in this model. The technical features of an ES provide the infrastructure and tools for implementing the functional features of the system. The functional and technical features of ES serve to enable the implementation of the accrual accounting system and the information needs of the accrual accounting system drive the technical characteristics of the ES (Kumar et al., 2007).

The final area of the model deals with the cultural aspects that influence the implementation of accrual accounting in the Canadian Federal Government. Organizational culture can be defined as a pattern of basic assumptions and beliefs, developed by a given social group throughout its history of internal integration and 
external adaptation. This pattern has worked reasonably well in the past to be considered by the group as valid and important enough to be passed on to new members, as the correct way of interpreting the organization's reality (Cabrera, Cabrera, \& Barajas, 2001). For any type of transition to be successful within an organization, people need to buy in and be committed. Individual interests, values, and competencies must be aligned with the organization's vision, culture, and capabilities (St-Amour, 2001). If the innovation's design does not fit with the current organizational structure and culture, then the organizational structure and culture need to be redesigned (Cabrera et al., 2001). Examples of cultural issues that could affect the implementation of accrual accounting in the Canadian Federal Government include lack of desire by managers to learn and adapt (Connolly \& Hydman, 2006), implementation being viewed as a technical exercise (Blondal, 2003; Hepworth, 2003), poor communication (Blondal, 2003), reconciling the system with organizational needs (Blondal, 2003; Connelly \& Hyndman, 2006; Kumar et el., 2002), and lack of required knowledge and skills within the organization (Blondal, 2003).

This model has been set within the context of FIS and the Modern Comptrollership Initiative. The contextual setting is necessary because accrual accounting was not implemented in isolation. These other reform initiatives within the Canadian Federal Government impact all areas of the above-mentioned model. The features of this model are neither all-inclusive, nor exhaustive, and serve more as examples than as a comprehensible list. As the a priori model is based upon a literature survey, aspects of the model will be modified upon collection of the data, tailoring it to fit 
with the unique circumstances of accrual accounting implementation in the Canadian Federal Government.

\subsection{Research Questions}

The focus of this study is on the implementation of accrual accounting in the Canadian Federal Government. Specifically, this study will focus on the implementation processes, challenges, benefits expected, and the role of ES and culture. The study is exploratory and the following general research questions will be addressed based on the main components of the model in Figure 6. These research questions are based on the relevant literature and are intended as a guide for this study. It is recognized that these questions may contain some overlap.

1. What processes has the Canadian Federal Government used in implementing accrual accounting and what challenges have arisen?

2. What benefits have resulted from accrual accounting implementation in the Canadian Federal Government?

3. What role has ES played in the implementation of accrual accounting in the Canadian Federal Government?

4. What role has culture played in the implementation of accrual accounting in the Canadian Federal Government?

5. For what purposes is accrual accounting information used, and considered useful, in the Canadian Federal Government? 


\subsection{Conclusion}

In this chapter, an a priori model was developed based the two key models available in the literature. The first model is Markus and Tanis' (2000) Enterprise System Experience Cycle. While this model was developed to explain ES implementation, it will be adapted for accrual accounting implementation. The second model is Kumar et al. (2007) SATIRE Process Model of ERP Systems Effectiveness in Implementing Internal Controls. Research questions were developed based on the $a$ priori model and they focused on implementation processes and challenges, benefits expected, and the role of ES and culture. 


\subsection{Research Methodology}

This section describes the research methodology used for this study. The first section contains the research design, followed by the section containing the data collection procedures. The third section contains the profile of the participants and the fourth section goes into detail regarding the data analysis methods. The next section discusses the research validity associated with this study. The final section contains the research methodology conclusions.

\subsection{Research Design}

In order to understand the design of this research, the assumptions, concepts, values, and practices of the researcher must be explored, since they affect consciously and subconsciously the direction the study will take (Creswall, 1998). One concept that shapes a researcher's study is how the researcher sees reality and the nature of being. The assumption in this study is that reality is subjective and differs based on the perceptions of the participants in the study. This assumption translates into the need to collect data from more than one participant since each would have different perspective. Another major assumption that affects research has to do with the nature and scope of knowledge. In particular, what is of concern to this study is the way in which knowledge is transferred. Due to the fact that reality is subjective, the researcher attempted to lessen the distance between the interviewer and interviewee, in order to understand how that participant saw the implementation process. The last assumption that will be discussed is the nature of values and value judgments. The researcher acknowledges that research is value-laden and, while all attempts are made to minimize subjectivity, biases are present. 
One bias present in this study is that the main researcher is an accountant and sees reality from an accounting perspective. As well, the researcher does have preconceived notions of the accrual accounting implementation process that stems from the available literature. These biases were addressed by allowing the interviewee to dictate the course of the interview and by analyzing the data based upon concepts that emerged from the interviews, instead of based upon the a priori model.

This study is exploratory, since there is little literature available that pertains to the Canadian Federal Government accrual accounting implementation. The research is also qualitative. Qualitative research is sometimes criticized in practice as being unscientific (Berg, 1998). Specific criticisms are that it does not usually fit with practical, managerial, applied, and outcome-driven research (Goulding, 2002). As well, critics say that since the researcher is pre-eminently the research tool, all data is filtered through the eyes of the researcher and, therefore, biased (Goulding, 2002). While there may be controversy surrounding the qualitative/quantitative divide, qualitative research is used frequently in practice. It is a methodological orientation that allows for the capturing of the nature or essence of things, as opposed to the quantity (Dabbs, 1982, as cited in Berg, 1998). Qualitative research allows "a researcher to build a complex, holistic picture" (Creswall, 1998, p. 15). The meanings, concepts, characteristics, and descriptions of processes and events are essential to the development of theory in this research. According to Creswall, the qualitative approach is appropriate when the research question is concerned with how in contrast to why (Creswall, 1998).

As previously discussed, this study is concerned with how the implementation processes unfolded. As well, qualitative research is suitable when a topic needs to be 
explored and theories need developing (Creswall, 1998; Goulding, 2002). The focus of this study is on theory development, as opposed to theory testing. The a priori model was developed based upon available literature, but the intention of this study was to further refine this model, as opposed to testing the correctness of the model. The aim is to produce a substantive theory as opposed to a formal theory. A substantive theory occurs before a formal theory and is closely linked with practical application because it is connected to empirical reality (Locke, 2001). The theory does not attempt to explain phenomenon, outside the immediate field of study, whereas, a formal theory has explanatory power across a range of situations (Goulding, 2002). This approach to research is an accepted practice when doing qualitative research (Berg, 1998; Locke, 2001).

In order to develop a model on the implementation of accrual accounting in the Canadian Federal Government, a grounded theory approach is used. The intent of grounded theory is to generate or discover theory, which is "an abstract analytical schema of a phenomenon, which relates to a particular situation." (Creswall, 1998, p. 56). The term grounded theory comes from the idea that theory should be grounded in data from the field (Creswall, 1998). The application of grounded theory is not without debate. This research will adopt grounded theory as described by Strauss (Strauss \& Corbin, $1990 \mathrm{~b}$ ). Grounded theory is thought to be particularly appropriate when developing process models (Locke, 2001), which is the objective of this research. The aim of data collection is to collect data until a category is saturated. Saturation occurs when additional data collected does not provide any additional insights. A category is a representation of a unit of information composed of events, happenings, and instances 
(Strauss \& Corbin, 1990a). Data is collected from individuals who have taken action or participated in the process under study (Creswall, 1998). In this study, that means interviewing individuals who participated in the accrual accounting implementation process.

This study uses a qualitative research approach, with a qualitative interviewing methodology. An interview can be simply defined as a conversation with a purpose (Berg, 1998). A qualitative design is useful when attempting to understand or uncover what lies behind any phenomenon about which little is known (Strauss \& Corbin, 1990a). A qualitative technique, also, allows researchers to share in the understandings and perceptions of others (Berg, 1998). It is often recommended that researchers combine multiple research methods, called triangulation. This triangulation ensures that the data collected is not being affected by the data collection design and as a means of mutual confirmation. In addition, it can provide the researcher different perspectives on the same element under scrutiny (Berg, 1998). While this study does not employ the triangulation of research methods, it does use data triangulation, by interviewing more than one participant on the same subject. The level of analysis for this study was the organization, since the research attempts to understand how the organization as a whole accomplished implementations, as opposed to how the individual navigated the implementation process. The fieldwork was carried out in Canadian Federal Government organizations.

The main data collection method used for this study is face-to-face semistructured interviews. This data collection method is preferable to surveying, due to the opportunity it provides to gain complete and accurate communication (Cannell \& Kahnm 
1968 , as cited in Berg, 1998). It allows the researcher to focus in on the participant's experiences with the implementation of accrual accounting. Relevant, publicly available, documentary information was also collected, to provide context and help integrate interview data. It is necessary to operationally define the concepts being studied, in order to concretize their intended meaning in relation to this study. The definition of concepts provides some criteria for measuring the empirical existence of the concepts under study (Leady, 1993 and Frankfort-Nachmias \& Nachmias, 1996, as cited in Berg, 1998). An example is that it was necessary to define the various stages of the implementation process as the researcher had categorized them. The interviewee and his/her organization may have categorized the implementation stages differently, but for the sake of consistency across interviews, these concepts were operationalized into specific stages. It is also important that the words in the interview be formalized in the vocabulary of the subject (Berg, 1998). All individuals interviewed, except two, had accounting backgrounds and were familiar with accounting terminology. The two participants who did not have an accounting background were only asked questions pertaining to his/her field of study, ES and budgeting, with which the participants were familiar.

The interview questions are included in Appendix A. This particular sample is written for departmental managers. The interview guide for the Treasury Board of Canada Secretariat (TBS) personnel is essentially the same, but the wording is changed slightly to be more appropriate. For example, instead of asking about "your department" the wording is changed to "the departments", where appropriate. The interview consists of a mix of open and close-ended questions. A semi-structured interview design is used for this research, since the research is still exploratory in nature. A semi-structured 
interview includes asking a number of pre-determined questions in a systemic and consistent order, but the interviewers can digress and probe further into the answer of the pre-determined and standardized questions (Berg, 1998). Participants were provided with the interview guide prior to the interview. A semi-structured interview allows a more flexible exploration of the issues and still provides rich detailed answers. Flexibility is important, because the interview needs to be tailored to the background of the interviewee. For example, in this study, one individual who was interviewed had primarily an accounting background and was not able to go into detail about the technical characteristics of enterprise systems (ES). This participant's interview focused solely on accrual accounting, whereas the majority of participants were knowledgeable about both ES and accrual accounting. This type of interview also gives a greater opportunity for clarification and detailed understanding (Ritchie \& Lewis, 2003).

The interview guide is divided into two main sections. The objective of the first section is to provide background information on the interviewee, providing context for their responses. As well, these questions were asked first, as they would be easy for the participant to answer, allowing the interviewer to develop a report with the participant. The second section contains four parts that pertain to the four research questions. In Appendix B, each question in the questionnaire is mapped to the model construct that it addresses. These questions begin open ended in order to invite detailed discussion (Charmaz, 2006). The interviewees were encouraged to discuss concepts and issues that were important to them and a conversational approach was adopted. The close-ended questions are reserved as prompts, to keep the discussion on track and to clarify the meaning of the open-ended questions, as necessary. An effort is made throughout the 
interview guide to avoid complex or double-barrelled questions, which are questions that ask the respondent to answer two issues in the same question.

\subsection{Data Collection}

The sample frame this study uses is the Canadian Federal Government and its employees that are knowledgeable about the accrual accounting implementation process and understand how ES is used in the implementation of accrual accounting. The sample was chosen using a combination of theoretical and snowball sampling. The grounded theory approach to sampling is theoretically driven (Locke, 2001; Goulding, 2002). The rationale behind theoretical sampling is to focus all data gathering efforts on gathering information that will aid the development of a theoretical framework (Locke, 2001). Sampling was chosen by targeting specific categories of individuals based on their ability to contribute to the evolution of theory. The way in which individual participants were recruited is through snowball sampling, meaning individuals who were contacted were asked to recommend other participants.

Tentative contact information was obtained through a personal contact for individuals at the OAG and TBS, upon the commencement of the research. These individuals were contacted and asked for a referral in each organization. While some of these individuals were no longer with the government of Canada and/or unwilling to participate, this information did lead to contact information of eventual participants. Contact information for the departments was not available before the commencement of the research. The Government Electronic Services Directory was also mined for potential participants. This service is provided by Public Works and is accessible on the 
Internet. This directory contains information such as name, position, department, and telephone number for the majority of Canadian Federal Government employees, but does not contain e-mail contact information. A query of this directory, based upon position in the organization, resulted in a list of potential participants and a contact person within the Federal Government provided the e-mail information.

E-mails were sent out to these individuals along with e-mails sent to the general enquiry e-mail address provided on department WebPages. Apart from automatic responses, the general enquiry e-mails resulted in no responses. More success was experienced with the contact information derived from the Government Electronic Services Directory. In order to avoid mass e-mailing departmental personnel, only one individual was contacted at a time. This method resulted with either the contact information of the appropriate departmental personnel or no response. If there was none or negative response from the suggested departmental personnel, no further enquiries were made into that department. If no response was received from the original e-mail, after sufficient time passed, another individual was contacted in that department. No response rates were calculated, since no statistical inferences will be made with the data and there is no way to truly tell the number of people being contacted since a snowball sample was used. Sample e-mails used to request contacts and participants are provided in Appendix C.

A pre-test was conducted in order to help identify any problems that might arise while conducting the research. As there were no apparent problems with the interview guide or methodology, the pre-test was treated as the first interview. The interview guide was refined to include e-mail contact information. One researcher conducted all 
interviews, ensuring a high degree of internal reliability. All interviews, with the permission of the interviewees, were recorded using audio equipment and then transcribed into a word document. Informed consent was obtained from all the participants before the data collection process began. An example of the Letter of Introduction/Letter of Consent can be seen in Appendix D. The following efforts were made to ensure full confidentiality of the participants of the study. Carleton University's Research Ethics Committee approved the research procedures. Neither individuals' names nor departments are mentioned in this paper, when presenting the full results. The results will be stored in a locked filing cabinet for three years. The data will not be used for other research purposes, and lastly, the data will be destroyed after three years by shredding. Due to the nature of the data collection, namely interviewing, it is not possible for the participant to be nameless, but efforts have been made to remove elements that may indicate the subject's identity.

A total of seven departments are represented in this study. The majority of the data collected was from individuals who were working during the implementation of accrual accounting. Multiple individuals currently working in the same department were interviewed, but with the exception of TBS, no two interviewees were working at the same department at the time of implementation. This variability in personnel's departments at time of implementation appears to be due to the high degree of mobility of government employees. The high occurrence of TBS participants stems from their enthusiasm for participating and providing contact information, for other TBS employees, as well as their involvement in the implementation process at a more macro level, making them knowledgeable in many areas relevant to this study. This department led the 
implementation process for the Canadian Federal Government, hence making it a focus for this study. The central agencies examined in this study were required to implement accrual accounting much the same way the departments were, but with added complexity, since these departments' mandates include responsibilities that deal with other departments and with the central systems. An example of this dual functionality is Public Works' Central Financial Management and Reporting System, which is responsible for trial balance submissions. A trial balance is a list of balances in all the accounts used in a period to test whether the accounts balance. All departments are required to send their trial balances periodically to Public Works.

A meeting was also held with an individual from the Office of the Auditor General (OAG). At that time, this individual informed the researcher that the OAG had no opinion beyond the official published documentations and any comment it would have would be encompassed in its official reports. The OAG's official publications have been substituted as a source of information in this study in lieu of interviews with OAG personnel. These publications contain the OAG's formal opinions regarding the objectives of this study and represent a wealth of information.

\subsection{Profile of Participants}

A summary of the organizations that participated in this study can be found in Table 5. These organizations are a mix of central and departmental agencies and include TBS, which led the implementation of accrual accounting in the Canadian Federal Government. The majority of departments interviewed used SAP as their ES with the exception of two departments. One department used an in-house developed system and is 
F

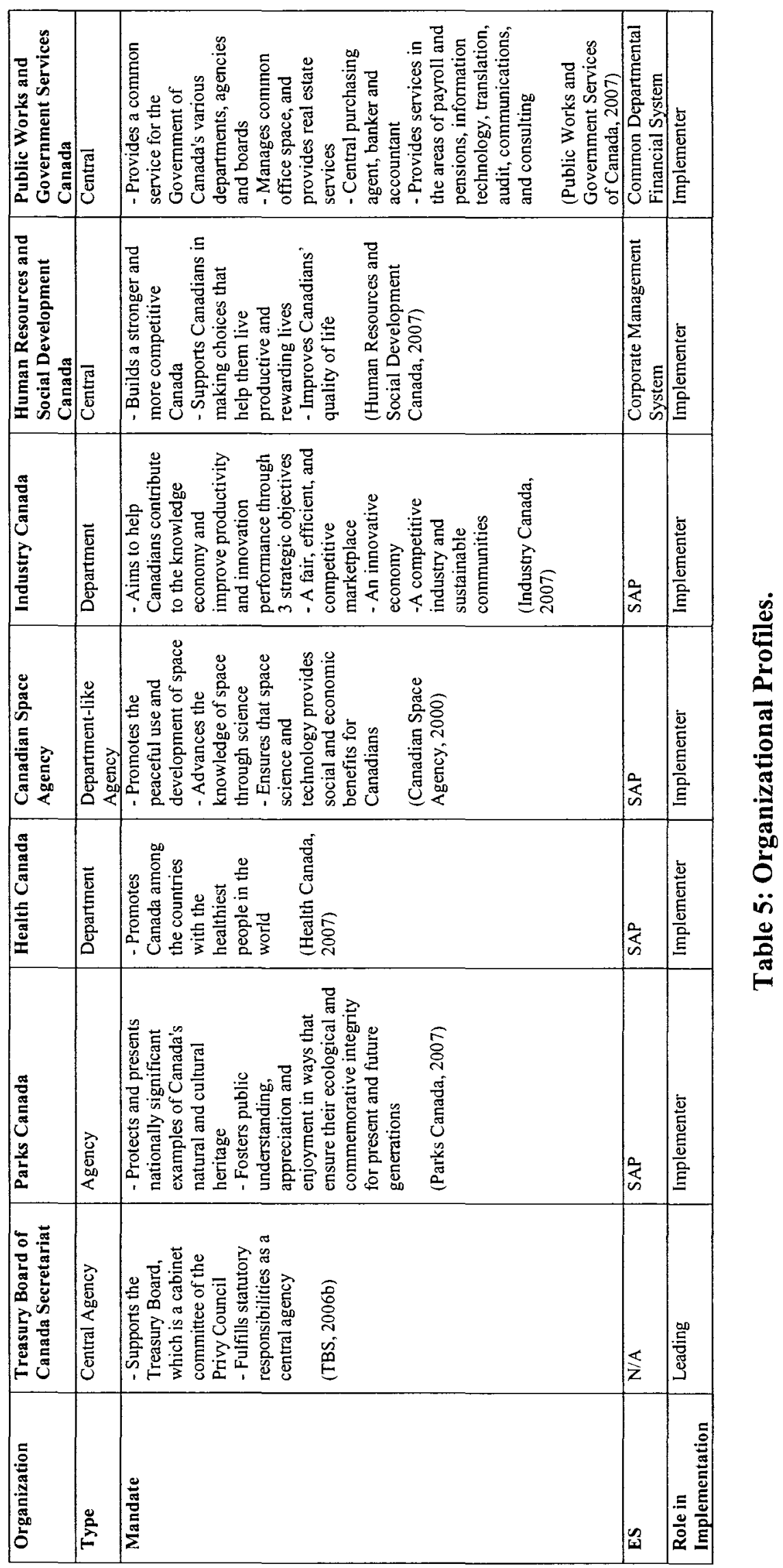


the sole department in the government to use this particular system. The other department used a system that was common among small government departments, but it is now moving towards SAP. Since the scope of the interviews with TBS focused on their role as leaders of the implementation, the ES used for their department is not applicable.

A total of nine participants were interviewed in a series of seven interviews. Some participants elected to be interviewed together for convenience reasons. Although some interviews contained more than one individual, each individual still brought a unique perspective and contributed individual data. These contributions were helped by the fact that in both cases, where more than one participant was interviewed at a time, the participants had either not been working in the same department at the time of accrual accounting implementation, or they were working on the implementation in different capacities. All individuals who did choose to participate in the study, with the exception of one person, had extensive experience working in the Canadian Federal Government, as can be seen in Table 6. The one participant, who had limited experience working in the Canadian Federal Government, had had previous experience in consulting for Canadian Federal Government departments during the implementation of accrual accounting. The majority of the participants are fairly high in the government organizational hierarchy, with one assistant deputy minister, four directors of various levels, two chiefs, and one manager. Interviewing individuals who are higher up in the organizational hierarchy, allows the interviewer to speak to individuals who are more involved with the big picture, as opposed to knowing simply the tasks that their job entails. Many of these individuals have extra qualifications, such as graduate degrees and/or accounting 
2

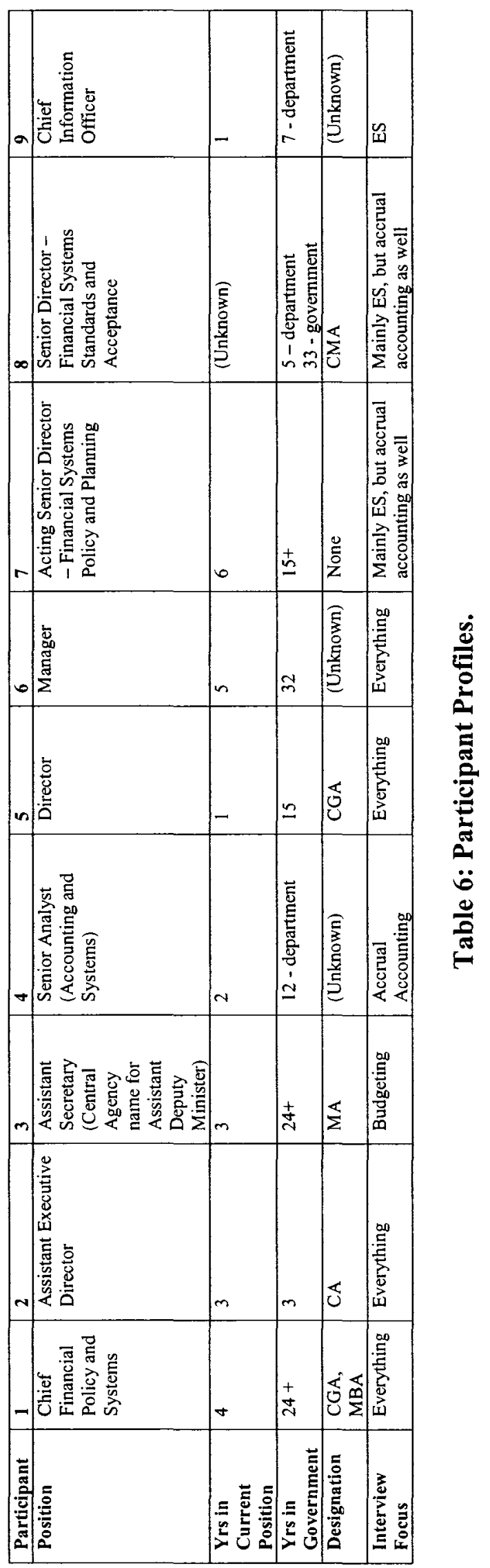


designations. As the focus of this research is on accounting, the majority of the participants have accounting backgrounds, with the exception of two participants; one comes from an information system background and the other specializes in public affairs. These participants played a large role in providing data regarding ES and budgeting. Two participants have a blended accounting and information systems background. They were not knowledgeable in depth with the technical side of ES, but worked extensively with these systems regarding planning, policy, systems standards, etc. The other participants had accounting backgrounds. The focus of each interview was tailored to the backgrounds of each participant, as can be seen in Table 6 . In all instances, interviews were held at locations of the participants' choice, which was either a participant's office or a conference room. These locations proved ideal in terms of privacy and reduced levels of noise, in order for the interviews to be clearly recorded.

\subsection{Data Analysis}

Data collected during interviews was taped and then transcribed, verbatim by the researcher, into word files. The analysis of the data is designed to follow the grounded theory strategy, which involves deriving theory from the data. Collected data was reviewed in its entirety initially in order to obtain a sense of the overall data. Then reflective notes were taken as part of a sorting-out process to identify major or recurring themes in the data. Using qualitative software called NVivo, codes were then developed. These codes are categories used to group data, based on their characteristics, which also serve as names given to the concept that the data represents. Coding in grounded theory relates potential indicators of concepts to concepts, in order to develop theory. Open 
coding was employed, meaning that data was broken down, examined, compared, and conceptualized in order to be grouped (Creswall, 1998; Strauss \& Corbin, 1990a).

All the collected data was then coded, which means the researcher went through all the data, assigning codes to various words, sentences and passages based on the meaning of the data. While coding was performed, new categories of analysis emerged and the data was then coded for these new categories. A list of codes and their descriptions used by the researcher can be found in Appendix E. The outcome of these processes was concepts, which were used to form the building blocks of theory. In essence, each interview was compared for similarities and dissimilarities or patterns. Comparisons entail assigning a common meaning to multiple data observations (Locke, 2001). These categories were then named in order to conceptualize and develop abstract meaning for the observations in the data. The label given to the category represents the researcher's interpretation of the data.

The second major activity after coding is integrating categories and their properties. At this stage, organization was brought to the conceptual categories, and relationships amongst various categories were clarified. The codes were organized into a hierarchical structure called trees, in order to clarify how the various concepts related to one another. These coding hierarchies can be found in Appendices F-I. At this point, it would have been optimal to continue further iterations of the data collection and analysis process (Locke, 2001), but, due to time and resource constraints, it was not possible. After the coding was arranged into trees, a revised model was then developed based upon the collected data. Coding acts as a pivotal link between collecting data and developing an emergent theory to explain the data (Charmaz, 2006). The model development was 
aided by the use of the Nvivo program, which allows the researcher to visually construct concepts and how they relate to one another.

A problem with coding is the possibility of losing the context of what the interviewee has said, since coding involves taking parts of text out of context. All efforts were made in the analytical process to ensure that the context of interviewees' words was not lost and pre-conceived notions were not imposed (Charmaz, 2006). These problems were partially addressed using software appropriate for qualitative research data, NVivo.

\subsection{Research Validity}

Research validity is the extent to which findings represent the phenomenon under study (Kervin, 1992). Validity can be broken down into internal validity, external validity, and construct validity. Variables that could potentially affect the validity of this research are discussed in this section.

Internal validity deals with causality. There are a number of variables that may have affected the internal validity of this study, one of which is time. In most departments, the implementation process occurred primarily in 2001 , resulting in a significant gap in time between the implementation and this study. This raises the potential of error in the participant's recollection of events and incidences, or simply memory lapses as to what occurred. In order to avoid this problem, multiple participants were interviewed in an effort to triangulate. Another potential problem deals with selection. Due to the fact that a snowball sampling method was used, the results of the study could be affected. Departments across the government vary greatly in size, purpose, and culture. As well, individual's experiences may vary greatly within the same 
department. In addition, it could not be determined whether there were different responses among non-participants. However, departments included in this study varied greatly from one another, minimizing non-response bias. Another problem deals with testing. Some of the responses may be attributable to the fact that respondents knew that the implementation process was being explored. Participants may have felt the need to place their answers in a certain light, to convey a level of success, as they were doing the implementing. Responses may have been sensitized and biased. In order to minimize this effect, it was made clear from the start of the interview that participant's responses would be kept confidential, and the interviewer assured the interviewee that they were not expected to be able to respond to every question. It must be noted that this study is primarily descriptive in nature. It is modeling how accrual accounting was implemented and does not focus primarily on causal relationships; therefore, internal validity is not a central concern.

External validity relates to the ability to generalize beyond the study in question. Due to the sampling method chosen and the small sample size, the results of the research may not be generalizable to the whole Canadian Federal Government. According to Glaser (1998), small sample sizes and limited data do not pose problems, because grounded theory aims to illuminate properties of categories, instead of being generalizable to the whole population (cited in Charmaz, 2006). As well, theoretical saturation may not be reached, since further iterations of this data collection process are not possible, due to availability of potential interviewees. Theoretical saturation occurs when sampling is carried out until a category has been saturated with data (Bryman \& Bell, 2003), and the model being studied is fully developed. However, the researcher has 
attempted to minimize any threats to external validity. One such problem is the occurrence of testing interaction. This interaction occurs due to the possibility of untruthful or incomplete answers on the part of participants, making the results not generalizable to other situations. However, it is unlikely in this case, since answers were confidential and there would have been no benefit to the participant in being untruthful or not forthcoming. Participants seemed quite open to share their experiences with the interviewer. Another potential problem is selection interaction. The type of respondent that participated in the study may also limit the generalization of results, because of the limit on the access to departments for interviewing. It is realized that there is a high degree of variability among governmental departments and agencies. For this reason, a number of departments were included.

Construct validity refers to the degree to which inferences can be made from the data collected in the study, to the theory being developed. In other words, does your construct measure what it intends to measure? It is recognized that many issues examined in this study are difficult to measure since they are intangible ideas. Due to this difficulty individuals involved with the actual implementation of accrual accounting were interviewed, and their retelling of their experiences used to measure the constructs under examination. The researcher also recognizes that some overlap does occur between constructs being examined, for example, some overlap between staffing and training. In order to address this issue, constructs should be analyzed within the scope of a larger study. Since no statistical analysis is performed on the data collected in this study, this overlap does not pose as great a concern. 


\subsection{Conclusion}

This chapter outlines the research methodology used in this study. The research design is exploratory and qualitative in nature. The intention of the design of the research is to further refine and develop the a priori model, as opposed to trying to test the model. To achieve this objective a grounded theory approach was used to generate or discover theory. The methodology chosen is face-to-face qualitative interviewing, due to its ability to uncover information about a phenomenon of which little is known.

The sampling frame used for data collection was Canadian Federal Government employees who are knowledgeable about the accrual accounting implementation processes. The sample was chosen through a combination of theoretical and snowball sampling. All interviews were carried out using one interviewer, ensuring a high degree of reliability, and all efforts were made to ensure full confidentiality of the participants. A total of nine participants spanning seven departments were interviewed. These participants were highly experienced and knowledgeable, with the majority having backgrounds in accounting.

The data collected was analyzed following the grounded theory approach. This analysis involved coding all the data in order to analyze the data for patterns and to develop theory. A software called NVivo was used to facilitate this process. The validity of the research was also examined in order to ensure that the findings of this study actually represent the phenomenon under study. Any deficiencies in the validity of the study were recognized and appropriately addressed. 


\subsection{Results}

The data collection results have been organized into four major categories that correspond to the proposed accrual accounting implementation model. These categories are the implementation process, technical challenges, cultural/people challenges, and accrual accounting benefits. The implementation process is divided into three phases of activities. The first phase is all activities undertaken by the Canadian Federal Government before the decision to implement accrual accounting. The second phase consists of all activities from the time of the decision until the system went live. The final phase is all activities that occurred after the system went live. Technical challenges have been divided into enterprise systems (ES) and non-ES challenges. Cultural/people challenges are organized into two major sections, resistance and support, followed by comprehension. Next, accrual accounting benefits have been organized under three major headings: integrated benefits, reporting and compliance, and managerial benefits. Integrated system benefits are those that depend on other initiatives and systems within the government. The reporting and compliance section deals with benefits stemming from departmental compliance and changes to the financial reporting process. Finally, the managerial benefits section discusses the benefits relating to how departments and managers manage their operations.

\subsection{Implementation Process}

\subsubsection{General Context}

Participants spoke of the Financial Information Strategy (FIS) as being interchangeable with accrual accounting implementation. As one participant said, "FIS 
was first and foremost about accrual accounting on a government-wide level." Accrual accounting was implemented within the larger context of the Modern Comptrollership initiative. The interview participants recognized this fact. This larger initiative comes with its own set of challenges and benefits. Some of the benefits discussed during the interviews were attributed to Modern Comptrollership instead of accrual accounting. An example would be accountability. Participants see accountability as an intended benefit of the Modern Comptrollership, as opposed to the implementation of accrual accounting.

There is also the recognition that it is difficult to isolate the benefits of accrual accounting from other changes occurring in the Canadian Federal Government, due to a lack of understanding of accrual accounting. However, it is recognized that these initiatives do depend on one another. Some participants see accrual accounting as a part of a larger strategy for change, as one participant said “...it was presented as a component of [a] bigger picture so people were well aware that this is one piece of the puzzle." Others see it as a prerequisite for other changes, as another participant said, "I would say it was a prerequisite for the other initiatives." According to one participant, accrual accounting laid the foundation for audited departmental financial statements and the CFO model, which is having a deputy minister as a properly trained accountant with the required supporting structure for decision making. Some participants described how accrual accounting was presented in an information session as being a component of a bigger picture, and that their department has regular meetings with their regions, in order to pass along information regarding new initiatives within the government.

Table 7 shows which interviewees discussed the topic, and how many paragraphs in each interviewee transcript were coded for this topic. It must be cautioned, however, 
that this table needs to be interpreted in the spirit of grounded theory. The frequency with which a topic surfaced does not necessarily translate into greater evidence. This format underscores the underlying complexity of the participant's responses and that they did not always have the same opinion discussing the same topic. As well, where one participant may discuss a topic at length, another participant may have only briefly mentioned the issue.

\begin{tabular}{|c|c|}
\hline \multicolumn{2}{|c|}{ Larger Change Initiatives } \\
\hline \multirow{2}{*}{ Interviewee } & \# Of Paragraphs \\
\hline $\mathbf{1}$ & 2 \\
\hline $\mathbf{2}$ & 2 \\
\hline $\mathbf{3}$ & 3 \\
\hline $\mathbf{4}$ & 1 \\
\hline $\mathbf{5}$ & 1 \\
\hline $\mathbf{6}$ & 1 \\
\hline $\mathbf{7}$ & 0 \\
\hline $\mathbf{8}$ & 0 \\
\hline $\mathbf{9}$ & 0 \\
\hline Totals & 10 \\
\hline
\end{tabular}

Table 7: Frequency of Larger Change Initiatives.

Just as other reforms affect the entire implementation process, so do the various personnel involved. In terms of functional areas, there was IT personnel, auditors, departmental financial staff, and people who worked in the field. In some departments, there were also change management personnel. Not everyone was involved in the entire process. For example, field personnel were required for the asset valuation activities as they had knowledge of the assets. Various types of engineers were called upon to access different types of technical assets. As well, both departmental and central agency personnel were involved at various stages. There was effort in some departments to get 
program managers involved. The frequency with which the topic of implementation personnel was discussed can be seen in Table 8 .

\begin{tabular}{|c|c|}
\hline \multicolumn{2}{|c|}{$\begin{array}{c}\text { Implementation Processes } \\
\text { Personnel }\end{array}$} \\
\hline Interviewee & \# Of Paragraphs \\
\hline $\mathbf{1}$ & 1 \\
\hline $\mathbf{2}$ & 1 \\
\hline $\mathbf{3}$ & 0 \\
\hline $\mathbf{4}$ & 1 \\
\hline $\mathbf{5}$ & 2 \\
\hline $\mathbf{6}$ & 2 \\
\hline $\mathbf{7}$ & 0 \\
\hline $\mathbf{8}$ & 1 \\
\hline $\mathbf{9}$ & 0 \\
\hline Totals & 8 \\
\hline
\end{tabular}

Table 8: Frequency of Personnel.

\subsubsection{Phase 1 Activity}

During the first phase of accrual accounting implementation, the activities undertaken by the Canadian Federal Government were examined. A number of participants, who had partaken in the decision making process, shared the reasons why the decision was made. This decision appears to have been driven by a mix of external and internal influences. Internally, there were a number of weaknesses identified in the Canadian Federal Government's financial reporting practices by the Glassco and Lambert Commissions. The recommendations of these commissions were seen by these participants to be the basis for FIS. As well, there was pressure from the Office of the Auditor General (OAG) to adopt accrual accounting and the public accounts committee, a standing committee of the House of Parliament, began to favour the implementation of accrual accounting. A major reason cited by two participants was the desire to comply 
with the PSAB, which was moving towards making accrual accounting the standard.

These participants felt that there was a pressure to follow suite. As one participant described it as follows:

... PSAB was moving towards making accrual accounting [the standard], so if we wanted a clean audit opinion, which ... you know was a good goal, but that was pushing us as well, so there was kind of a push to say get this clean opinion ...

Table 9 shows the total number of paragraphs in which a particular major activity was discussed by each interviewee. Each activity will be discussed in more detail in the remainder of this section.

\begin{tabular}{|c|c|c|c|c|}
\hline \multicolumn{1}{|c|}{ Phase 1 Activity } & $\begin{array}{c}\text { Problem } \\
\text { Identification }\end{array}$ & $\begin{array}{c}\text { Gaining } \\
\text { Understanding }\end{array}$ & $\begin{array}{c}\text { Cost/Benefit } \\
\text { Analysis }\end{array}$ & $\begin{array}{c}\text { Departmental } \\
\text { Involvement }\end{array}$ \\
\cline { 1 - 5 } Interviewee & 0 & 0 & 1 & 2 \\
\hline $\mathbf{1}$ & 0 & 1 & 1 & 1 \\
\hline $\mathbf{2}$ & 0 & 0 & 0 & 0 \\
\hline $\mathbf{3}$ & 1 & 1 & 2 & 1 \\
\hline $\mathbf{5}$ & 0 & 0 & 0 & 0 \\
\hline $\mathbf{6}$ & 0 & 0 & 0 & 0 \\
\hline $\mathbf{7}$ & 0 & 0 & 0 & 0 \\
\hline $\mathbf{8}$ & 0 & 0 & 0 & 0 \\
\hline $\mathbf{9}$ & 0 & 0 & 0 & 0 \\
\hline Totals & 1 & 2 & 4 & 4 \\
\hline
\end{tabular}

Table 9: Frequency of Phase 1 Activity.

The above description of why accrual accounting was adopted indicates that, during the primary stage of implementation, some problem identification activities occurred. Royal Commissions were formed to assess various aspects of management within the Canadian Federal Government and weaknesses were identified. As well, the 
OAG identified weaknesses and began to campaign for the government to address them.

One participant described the impact of the OAG campaign as follows:

In the 70 s ... the AG basically said our reporting was very poor so at a government-wide level we went to following more PSAB standards, externally set standards, as opposed to just creating our own standards as we went along

Another activity undertaken in this phase of implementation was gaining an understanding of how accrual accounting would apply in the Federal Government. One participant described some of the activity undertaken to accomplish this task. "They went through and sort of recast the financial statements under a full accrual basis." This recasting was not simply a shift from cash to accrual basis of accounting. The government was already on the modified cash basis, so there was a need to determine what and how the financial statements would change. The participant noted that the financial statements were recast to include other non-accrual accounting based changes, making it difficult to isolate the impact of just the accrual accounting changes on the analysis.

A cost/benefit analysis was performed before the decision to implement accrual accounting. According to one participant, "They took a few years to discuss about the cost and benefits of going accrual accounting." A monetary costing analysis performed on the required replacement of financial systems was balanced with an attempt to assess the administrative savings. Savings were to be derived from cleaning up processes and recording things centrally, thus cutting down on expensive duplication that is time consuming. Prior to the implementation of the new system, departments kept all the detailed transaction information and sent it to the Receiver General, who then held onto the information. Under the new system, departments still keep all the detailed 
information, but only send required summary information to be processed centrally.

When deciding to adopt accrual accounting, harder-to-quantify costs and benefits were also considered. For example, one participant talked about how there was discussion around Canada being a world leader in how it does its accounting, while another participant cited discussion around better asset management. While performing this analysis, there was definite awareness of the impact on perceptions of the Federal Government. One example of a hard-to-quantify benefit has already been mentioned, that of Canada being seen as a leader on the world stage. Another example comes from the perceptions of how well the government is doing fiscally. The participant stated, ... [The] real impetus was by putting the assets back on the books your bottom line got much better. This is your balance sheet since there is obviously no impact on annual surplus at the time, you know minor adjustments, but all of a sudden the accumulated deficit of Canada went way down because we have got all these assets on the books.

Virtually all the Phase 1 activity took place at the central level in the Federal Government. Departments were not consulted or involved in decision making. The decisions were made centrally and the departments were then required to comply. When one central agency participant was asked about departmental participation at this stage of implementation he replied, "it was a policy decision to do this and it was imposed on departments."

\subsubsection{Phase 2 Human Resource Activity}

All the activities relating to Human Resources discussed by the interviewees can be found in Table 10. In most departments, there was a need to hire consultants in the ES area during this phase of implementation. The reliance of consultants instead of hiring 
ES personnel was mainly due to the job market at the time. An SAP consultant would make more money than a government employee creating very little incentive for knowledgeable personnel to work full time for the Federal Government. Some departments actually experienced losses in this area as employees quit to go into consulting. According to one participant,

I know the SAP departments ... relied a lot on consultants, but that was because SAP consultants can make a lot more as consultants than as employees. So there was a lot of stress looking for competent people to do implementation system related work.

\begin{tabular}{|c|c|c|c|}
\hline \multicolumn{4}{|c|}{ Phase 2 Human Resource Activity } \\
\hline Interviewee & $\begin{array}{c}\text { Hiring } \\
\text { Consultants }\end{array}$ & $\begin{array}{c}\text { Hiring } \\
\text { Staff }\end{array}$ & Training \\
\hline $\mathbf{1}$ & 2 & 2 & 2 \\
\hline $\mathbf{2}$ & 1 & 2 & 1 \\
\hline $\mathbf{3}$ & 0 & 1 & 1 \\
\hline $\mathbf{4}$ & 3 & 1 & 2 \\
\hline $\mathbf{5}$ & 1 & 2 & 2 \\
\hline $\mathbf{6}$ & 1 & 0 & 4 \\
\hline $\mathbf{7}$ & 1 & 0 & 1 \\
\hline $\mathbf{8}$ & 1 & 0 & 1 \\
\hline $\mathbf{9}$ & 0 & 0 & 1 \\
\hline Totals & 10 & 8 & 15 \\
\hline
\end{tabular}

Table 10: Frequency of Phase 2 Human Resource Activity.

Systems implementation work requires people who know both the business and processes, and the systems. As stated by one of the participants, the government had people who knew the business and processes part, but lacked people who knew the systems part. The result was that obtaining competent people required spending more money on consultants than would have been spent on hiring new staff. In the words of one participant, "we got taken to the cleaners by consultants." Consultants were hired through contracts with large consulting firms. According to two of the participants, each 
consulting firm had different strengths, which were reflected in the way in which they chose to implement the systems. There was no overall central governance to ensure the various approaches consulting firms took coincided with one another.

Prior to implementation of accrual accounting, different departments had differing levels of accrual accounting expertise, creating different levels of activity surrounding hiring. Three of the participants found that the implementation in their department did not create a need to hire new people, but only some realignment of staff. As a participant said, “...I didn't see in the department an increased level [of] staffing due to FIS implementation." This contrasts dramatically with the central agency participants, who found that there was a huge lack of knowledgeable personnel at the departmental level. It was these participants' opinion that departments did increase their staffing levels during the implementation process. One participant said, “...increase in staff for sure to monitor things. Yeah you would see increase [d] resources in departments..." Central agency participants also found that additional personnel due to the implementation of accrual accounting were required. How departments went about hiring accounting personnel differed as well. Some departments involved Human Resource personnel while others did their own hiring. Overall, it was found to be difficult to attract knowledgeable personnel, since the government sector does not pay as well as the private sector, and there is an overall shortage of knowledgeable accounting personnel in all sectors.

Training activities were performed in all departments and central agencies interviewed. As well, the general consensus was that a lot of training had to be performed during this phase of implementation. Participants used words such as "demanding," "huge effort," "massive," and "lots and lots of training" when describing 
their training activities. There was centrally-led training by the Receiver General that dealt with how new processes would work in the new central systems. One participant described how general accounting courses were developed by one central agency for other departments. The content of these courses consisted of material, such as the difference between accrual and modified accrual accounting, how to do financial statements under the new system, and what the new processes are. Appropriation accounting is taken to mean modified accrual accounting in this context. Departments did their own training for new processes on their departmental systems. In the participant's words,

....as the central agency ... we developed sort of generic courses like here's introduction to accrual, here's the difference between accrual and appropriation accounting and [here is] what you are going to have to do, how do you do financial statements, that sort of thing; stuff that would apply to any [department], just very general training. Departments ... because, of course, they still have all their own systems, their own chart of accounts, if they wanted to do any training that was departmental specific that they had to do [it] themselves.

However, the department leading the implementation did offer services, such as putting the department in touch with technical training expertise. Some departments linked their internal training to local community colleges. There was a need to train on the basics of accrual accounting at the departmental level since, at least initially, transactions that are more complicated were dealt with centrally. Some departments would develop their own courses, based on their own specific needs, if their accounting requirements went beyond the basic. Some participants described the accounting training within their department as unfortunately being only simple accounting, whereas other participants said that the department provided training on a whole range of issues, such as 
capital assets, systems and processes, and new terminology associated with accrual accounting. Training was targeted mostly towards the financial community with the exception of people in budgeting, since it was felt that this implementation did not really affect them. Other users, such as clerical staff, who dealt with the new system were trained as well. Overall, training seemed to focus on both the new system and here is how to use it, as well as, basic accrual accounting.

Some departments indicated that there was a temporary requirement to hire additional training personnel in order to complete the required training. Some departments were quite satisfied with how training progressed, where others found training initially to be lacking, but rectified the issue during this phase. As one participant said, "we didn't know what we didn't know", when referring to initial training exercises. Initial training sessions revealed areas where expertise was lacking and new training sessions were developed based on that feedback. At least in some departments training was a fluid activity. The location and frequency of training activities was sometimes governed by practical considerations, such as time and expense. In departments spaced across Canada, training was a challenging exercise, and when selecting pilot sites, factors such as time zones and travel time had to be taken into consideration.

\subsubsection{Phase 2 Financial System Activity}

The frequency of Phase 2 financial activities can be found in Table 11. Testing of the system was another major activity undertaken during this phase of implementation. Departments were responsible for testing their own accrual accounting system, to ensure 
that it met their needs, apart from the centrally mandated requirement to produce financial statements of the public accounts and other reporting. Departments tested their own financial systems in terms of managing programs within the department. One department tested their system in a design development, which is a physical box where the software was tested before it became accepted. Once accepted, massive tests were performed before it was implemented within the department. As the participant described it,

What we did as a department, we test[ed] ... the development, which is a physical box where you test your software. When it was OK we move [d] it into acceptance to ... do massive tests and see if it was $\mathrm{OK}$ and then we move [d] it to production...

\begin{tabular}{|c|c|c|c|}
\hline \multicolumn{5}{|c|}{ Phase 2 Financial System Activity } \\
\hline Interviewee & $\begin{array}{c}\text { Testing the } \\
\text { System }\end{array}$ & $\begin{array}{c}\text { Chart of } \\
\text { Accounts }\end{array}$ & $\begin{array}{c}\text { Technical } \\
\text { Support }\end{array}$ \\
\hline $\mathbf{1}$ & 1 & 0 & 2 \\
\hline $\mathbf{2}$ & 0 & 0 & 0 \\
\hline $\mathbf{3}$ & 0 & 0 & 0 \\
\hline $\mathbf{4}$ & 1 & 2 & 0 \\
\hline $\mathbf{5}$ & 0 & 0 & 0 \\
\hline $\mathbf{6}$ & 0 & 1 & 0 \\
\hline $\mathbf{7}$ & 0 & 0 & 0 \\
\hline $\mathbf{8}$ & 0 & 3 & 1 \\
\hline $\mathbf{9}$ & 0 & 3 & 0 \\
\hline Totals & 2 & 9 & 3 \\
\hline
\end{tabular}

Table 11: Frequency of Phase 2 Financial System Activity.

The Receiver General tested the interfaces between departments and central agencies. Other departments had to ensure that their existing information systems could handle the accrual accounting requirements. Departments that were using the same systems formed cluster groups. These cluster groups aided in the implementation by 
providing technical support in the form of developing various patches to make the systems able to handle accrual accounting. One participant described how the implementation of the financial systems was actually done by financial services people as they understand the system requirements. There was still heavy involvement from IT people to handle the more technical aspects of implementation.

Another major activity undertaken, that pertains to the financial systems, is the adoption of a common chart of accounts. The work done on the chart of accounts enabled the departments to send summary information centrally. Prior to the use of a common chart of accounts, the Receiver General would receive all the detailed transactional data from departments, and then have to translate the data in order to integrate it. Under the current system, the departments perform the translation. Each department still has its own set of accounts, but the financial systems will map the departmental chart of accounts to the common chart of accounts. This chart of accounts allows departmental personnel to input the data to the departmental chart of accounts, but then switch to the government-wide chart of accounts, if needed.

Departments could configure their own chart of accounts based on their needs, as long as they used the common chart of accounts to communicate with the central agencies. As one participant put it, “...we didn't say how they had to do it except that we ... [said to] them this is the chart of accounts you need to communicate with central agencies, but what you do internally is up to you." Within the financial systems, this chart of accounts is a special purpose ledger that maps the departmental chart of accounts to the government-wide chart of accounts. Departmental chart of accounts are much more detailed than the summary common chart of accounts. The information collected 
using this common chart of accounts is then used by the Department of Finance to produce financial statements based on accrual accounting and for other purposes, for example, when Statistics Canada will use the information to understand how government impacts the economy. The departmental information is rolled-up on a monthly basis to the general ledger.

\subsubsection{Phase 2 Departmental Activity}

The activities that occurred in the departments during the second phase of implementation can be found in Table 12. While the decision to adopt accrual accounting was mandated for the departments, each department still had a variety of decisions to make surrounding when and how to adopt accrual accounting. These decisions were made within a control framework developed centrally. A phased-in approach was allowing the departments to choose one of three waves. A wave is an implementation time period. Departments had the choice of three years to begin their implementation. One participant explained that his department chose the third and final wave because they wanted the benefits and expertise of other departments, who would have adopted before them. Another major factor the participants cited in deciding when to implement the new system was $\mathrm{Y} 2 \mathrm{~K}$. Some departments had to upgrade their information systems because of $\mathrm{Y} 2 \mathrm{~K}$ and decided to begin implementing the new accrual accounting system at the same time. Many of the systems in the Federal Government were old and custom built. It was uncertain if these systems would handle the challenges Y2K presented.

Departments also decided how they wanted to implement the system. Departments were recommended by the department leading the implementation to run 
both systems in parallel before switching, yet the majority simply switched from the old system to the new. Central agencies, whose central financial functions changed, had to run both old and new systems in parallel since departments implemented in waves and for three years both systems were operational. Departments were also free to choose from one of seven approved financial systems. Prior to the implementation of FIS,

\begin{tabular}{|c|c|c|c|c|c|c|}
\hline \multicolumn{2}{|l|}{ Phase 2 Departmental Activity } \\
\hline Interviewee & $\begin{array}{c}\text { Decision } \\
\text { Making }\end{array}$ & Consultation & $\begin{array}{c}\text { Work } \\
\text { Groups }\end{array}$ & $\begin{array}{c}\text { Policy } \\
\text { Review }\end{array}$ & $\begin{array}{c}\text { Change } \\
\text { Management }\end{array}$ & $\begin{array}{c}\text { Valuating } \\
\text { Assets }\end{array}$ \\
\hline $\mathbf{1}$ & 2 & 1 & 1 & 1 & 0 & 1 \\
\hline $\mathbf{2}$ & 2 & 2 & 0 & 0 & 1 & 0 \\
\hline $\mathbf{3}$ & 0 & 0 & 0 & 0 & 0 & 0 \\
\hline $\mathbf{4}$ & 4 & 2 & 1 & 0 & 1 & 0 \\
\hline $\mathbf{5}$ & 0 & 2 & 1 & 2 & 0 & 1 \\
\hline $\mathbf{6}$ & 1 & 2 & 1 & 2 & 0 & 1 \\
\hline $\mathbf{7}$ & 0 & 0 & 3 & 0 & 1 & 0 \\
\hline $\mathbf{8}$ & 0 & 0 & 1 & 0 & 1 & 0 \\
\hline $\mathbf{9}$ & 0 & 0 & 1 & 0 & 0 & 0 \\
\hline Totals & 9 & 9 & 9 & 5 & 4 & 3 \\
\hline
\end{tabular}

Table 12: Frequency of Phase 2 Departmental Activity.

departments could choose which financial system they wanted, as long as they were able to translate their data, from what they were doing departmentally, to the Receiver General requirements, so, the government trimmed the number of financial systems it had from approximately sixty-three to seven. Departments also decided on how deeply they went with accrual accounting. On one end of the spectrum, one department elected to do a lot of accrual centrally instead of pushing it out to the departmental managers. On the other end of the spectrum, responsibility centre managers were held accountable on an accrual basis. As the one central agency participant described it, 
Departments had to make the decision on how deep they went with accrual. So particularly if you talk to [One Department] ... they talked about FIS light where they would do a lot of the accruals just centrally like their central reporting area would do all the accrual adjustments and they wouldn't push it out to departmental managers, whereas [Another Department] took the other approach. ... [which is] responsibility centre manager budgets were accrualbased.

Unlike Phase 1, there was extensive consultation during Phase 2 of the process.

Departments were consulted on how long they felt it would take to implement, what resources they would need, and whether they had personnel who could understand accrual accounting. According to one participant,

They were involved in how painful do you think this is going to be, how many years notice do you need, what kind of resources do you think you might need, do you have people who understand accrual accounting.

This consultation often took the form of a work group. These work groups were inter-departmental and had the objective of helping individuals better understand accrual accounting and solve problems that the departments may have been facing. Each work group was dedicated to specific purpose, for example, end-user understanding of accrual accounting or defining and applying accounting principles within different departments. These groups met on an as-needed basis usually when problems occurred. One participant said, "We had a lot of working groups, you know, [on] how do we treat this, how do we do that." These interdepartmental advisory groups supplied central agencies with input, as well. Accrual accounting policy was reviewed and developed. Some departments were more heavily involved than others with certain work groups, because they were more affected by certain issues. For example, departments that were major property holders were heavily involved with capital asset accounting. A physical count 
and valuation of assets had to be performed in order to switch to full accrual accounting. Prior to the implementation of accrual accounting, all assets were expensed in the period in which they were purchased. Many participants cited this task as a particularly difficult one in the implementation process. This valuation will be discussed in greater depth when discussing the challenges of implementation.

Other departments had specific needs and would have to work with central agencies on potential implementation issues. These departments provided a lot of insight to central agencies regarding how to deal with specific types of specialized transactions. They created work groups within the departments, since a variety of skills were required in order to implement. As well as work groups that focused on the accrual accounting implementation, there were also cluster groups that consisted of departments with the same ES. These groups also met during the implementation of accrual accounting. The changes that accompanied implementation were managed with varying degrees of success within different departments. Centrally, change management experts were brought in during this phase of implementation, when it was recognized that the current strategy was being met with resistance. As one participant described it, "we weren't selling it very well." Some departments made an effort from the onset to get users involved. One department trained a lot its managers and executive assistants on how to use the new system, in order to create some ownership of the new data coming from the system and encourage better use of the information. By understanding how the data was derived, it was hoped that there would be more trust in the data and more managerial involvement. Another department created a cross-functional, multidisciplinary team. A group of business experts was presented with proposed processes to 
gain feedback on how viable and effective they would be. Any challenges the team foresaw were then addressed. This approach was successful in getting user participation and acceptance of the new system. One thing that came out of this cross-functional team was different perspective on how things should be done. Some departments put together project plans that were discussed at bi-weekly meetings. It allowed changing the project plan in order to meet new challenges and for continual discussion of progress.

\subsubsection{Phase 3 Activity}

The third phase of implementation is an amalgamation of the third and fourth phases of the a priori model. Table 13 contains the frequency of Phase 3 activities. During this phase of implementation, the system went through a series of planned and unplanned modifications. The planned modifications revolved around devolving increasing amounts of accrual accounting responsibilities to the departments. Initially departments just took care of basic accrual accounting but subsequently they took on increasingly more complicated accounting functions. The ultimate goal is to "have the people with the expertise making the accounting decisions." Employees within departments know their business best and should be doing the accounting for it. In one participant's words, "When we first started we did all the accounting here, centrally, so you know environmental liabilities, pensions litigation, and we gradually started devolving some of it out to departments." The departments became more autonomous with regards to accrual accounting. An example is environmental liabilities being devolved to departmental personnel as they were in a better position to estimate these liabilities. Another example is that departments have become more autonomous with 
respect to forecasting annual salary information. This forecasting had been done previously by a central agency. As well, there was an indication of increased automation between central agencies and departments since the implementation of the new system. Other major new developments, since the initial implementation, include the requirement for departments to have audited accrual-based financial statements.

\begin{tabular}{|c|c|c|c|c|c|}
\hline Phase 3 Activity & \multicolumn{5}{|c|}{ 年ystem } \\
Interviewee & $\begin{array}{c}\text { System } \\
\text { Modification }\end{array}$ & Retraining & Staffing & $\begin{array}{c}\text { Implementation } \\
\text { Review }\end{array}$ \\
\hline $\mathbf{1}$ & 0 & 0 & 0 & 0 & 0 \\
\hline $\mathbf{2}$ & 4 & 1 & 0 & 0 & 1 \\
\hline $\mathbf{3}$ & 0 & 0 & 0 & 0 & 0 \\
\hline $\mathbf{4}$ & 2 & 1 & 0 & 0 & 0 \\
\hline $\mathbf{5}$ & 2 & 2 & 0 & 0 & 1 \\
\hline $\mathbf{6}$ & 2 & 1 & 1 & 0 & 1 \\
\hline $\mathbf{7}$ & 0 & 0 & 0 & 1 & 0 \\
\hline $\mathbf{8}$ & 0 & 0 & 0 & 0 & 0 \\
\hline $\mathbf{9}$ & 0 & 0 & 0 & 0 & 0 \\
\hline Totals & 10 & 5 & 1 & 1 & 3 \\
\hline
\end{tabular}

Table 13: Frequency of Phase 3 Activity.

Unplanned system modifications and improvements were also needed. The work groups were continued after the system went live to address problems that came up. Participants described a learning curve the first time financial statements had to be prepared under accrual accounting, and how the lessons learned the first year carried through to improvements in the second year. Some participants described the system functioning as expected, except that new functionality was continually being added, especially in terms of ES. Other Phase 3 activities surround further retraining of staff members. Personnel had to upgrade their skills in the areas in which there were 
modifications to the system. Some departments were still trying to hire new accounting staff to fill the void in accrual accounting knowledge that existed before implementing accrual accounting.

Finally, according to a participant at the central agency leading the implementation of accrual accounting, there was an informal review of the accrual accounting implementation process, and reviews done by the OAG staff to see what went right and wrong. These reviews helped the central agencies to determine what should be devolved to the departments. As the participant said,

Informally, there is an annual review that we ... sort of go through the results of our financial statement preparation, which is public accounts, ... also to go through with the Auditor General staff to see what went right [and] what went wrong, it is very much just a post-mortem informal. Every year we ask ourselves is there more stuff the departments can be doing that will result in better information.

As well, one of the participants described how their department went through an internal review process to determine what lessons could be learned from the experience.

\subsection{Technical Challenges}

\subsubsection{Enterprise Systems}

As previously discussed, the Canadian Federal Government uses a variety of ES, both commercial and homegrown legacy systems. The vast majority of information that participants provided relates directly to experiences with SAP. Table 14 shows the number of paragraphs within the interview transcripts in which the participant discusses ES challenges. 


\begin{tabular}{|c|c|c|c|c|c|}
\hline \multicolumn{6}{|c|}{ ES Challenges } \\
\hline Interviewee & Modification & Integration & User Interface & $\begin{array}{l}\text { Technical } \\
\text { Platform }\end{array}$ & $\begin{array}{c}\text { Miscellaneous } \\
\text { Challenges }\end{array}$ \\
\hline 1 & 1 & 0 & 0 & 0 & 2 \\
\hline 2 & 0 & 0 & 0 & 0 & 4 \\
\hline 3 & 0 & 0 & 0 & 0 & 0 \\
\hline 4 & 1 & 0 & 0 & 0 & 3 \\
\hline 5 & 1 & 1 & 0 & 0 & 3 \\
\hline 6 & 1 & 1 & 0 & 0 & 2 \\
\hline 7 & 2 & 1 & 0 & 0 & 3 \\
\hline 8 & 3 & 3 & 2 & 5 & 6 \\
\hline 9 & 3 & 0 & 0 & 0 & 2 \\
\hline Totals & 12 & 6 & 2 & 5 & 25 \\
\hline
\end{tabular}

Table 14: Frequency of ES Challenges.

Modification of the systems presented challenges. Many of the processes within ES had to be modified. One major modification made was the government-wide chart of accounts and mapping from the departmental chart of accounts. Another was the monthly trial balance being sent centrally instead of the detailed departmental transactions. The way interdepartmental transactions were handled was also changed within the systems. ES was not set up when purchased to handle them, but they have the capability for them. When first installed, the system had to be stripped of all their accrual accounting functionality, if the department was not yet on accrual accounting. When the department implemented accrual accounting, this functionality then had to be reinstated. As one participant described it,

In the initial place, yeah there were extensive modifications of the box product and then we basically had to go back in and undo everything we had done before in order to make it accrual accounting compatible. 
Integration was another issue. There was lateral integration between departments, because they have different ES. All information, including interdepartmental transactions, goes through the central agency first. However, there is vertical integration between departments and relevant central agencies, allowing for information, such as monthly trial balances, to be electronically communicated. This lack of horizontal integration is due to different departments using different systems, or using the same system configured in a unique way. Prior to implementation, there was no vertical integration and both the central and departmental systems had to be changed separately for them to remain in sync. There is also integration between different modules of ES. Modules can work with each other and sometimes with outside systems. Behind the scenes, managing integration is a big challenge since modules are patched together and not always technologically integrated. As one participant described it, ...one of [the] things we are trying ... is more open systems, you know, around the SOA architecture, so that, you know, these modules will actually work with each other right not only within the system but with other systems. Because right now SAP patches together, you know, different modules and it's a bit of smoke and mirrors there ... it is a big problem to manage integration.

The example used by one participant to explain technological integration is that all Microsoft products have the same software that runs spell check, instead of each product having its own spell check software. ES has internal code to manage integration, but according to one participant ES implemented within the federal government are running on a coding language that is not commonly used anymore, which causes problems. 
The user interface of the system was very important in getting the system accepted by users. New systems have some flexibility in this regard and can be configured to meet users' needs. For instance, labelling and language can now be changed to match the linguistic expectations of the users. The interface used to be limited in what could be changed creating problems with user acceptance. One participant described his frustration with user interfaces,

...before you were stuck with [it], it would drive people nuts, you had some title on some column you couldn't change it because that was what it was called in SAP or Free Balance or whatever. Now we can change that, if you want to call it something else we can call it something else, it doesn't matter [where] ... the table is coming from. That's very important, but these technological limitations were a real pain for us and we are gradually getting away from that...

There are issues with the technological platform on which these systems run that also presented challenges. They are currently running on old code that limits what can be done with the system. One example, given by a participant, is that under new platforms the ES module will run on any kind of background software and can use web-based tool kits. One participant worked with one of the commercial ES providers to develop a grantor module, since previously there had only been a grantee. A grantor module would be a module in SAP that contains the functionality to account for grants from the perspective of the organization giving the grant. Prior to this grantor module, there was only a module that accounted for grants from the perspective of the organization receiving grants. However, the Federal Government cannot actually use this module, because it does not have the right platform to run it on. As one participant described, 
...we helped SAP buil[d] a grantor module [since] they had a grantee module. When you get money from somebody you can manage it [through the grantee module], but they never had one ... for us in government. ... we have had all these scandals around this, we really want to manage this better, so we have ... worked with them to develop that, and we can't even use what they develop[ed] because we are not using the right platform of SAP.

Another challenge encountered was the continued use of spreadsheets to analyze data, instead of using the functionality of the ES. The full potential of the system was not being used, and analyzing was more time consuming. One participant described the consequences of this behaviour,

It is not the best way of doing things because you are replicating information that is already there and I know that for many years they still continued those spreadsheets rather than using the power of SAP to produce the report.

As well, there is controversy over who houses the detailed transactional information. Under the current system, central departments do not have access to this information, since it is stored at the department. Some participants feel this system causes inefficiencies when information is required at a government-wide level, and they cannot access the databases. Within the system, departments can code the same transaction, vendor, or item differently. For example, a vendor in one department may be labelled differently in another department or even in different areas of the same department. This inconsistency in coding makes access to information for any kind of analysis time consuming and expensive. Retroactive refitting of the systems to collect certain data is extremely expensive. The software challenges experienced required significant testing and retesting before the system could be up and running. Another issue is that ES foster a real lack of understanding of accrual accounting. It automatically does much of the accounting and removes the need to learn how accrual accounting 
works. One participant described the effect of ES automatically doing accounting, "They don't learn it, they don't even see the differences, it is just all magic." Commercial accrual accounting systems are not built to handle government modified accrual accounting, so challenges were also encountered setting up the system to work with the existing appropriation processes and handling interdepartmental transactions. Another challenge that these systems presented, as previously discussed, is the lack of expertise in the Federal Government in dealing with them, resulting in heavy reliance on consultants.

\subsubsection{Non-Enterprise Systems}

Non-ES technical challenges that will be discussed include budgeting, asset valuation, faulty or incomplete analysis, and underestimating the amount of change required. Table 15 outlines the various frequencies of these issues.

\begin{tabular}{|c|c|c|c|c|}
\hline \multicolumn{5}{|c|}{ Non-ES Challenges } \\
\hline Interviewee & Budgeting & Asset Valuation & $\begin{array}{c}\text { Faulty or } \\
\text { Incomplete } \\
\text { Analysis }\end{array}$ & $\begin{array}{c}\text { Underestimating } \\
\text { Change }\end{array}$ \\
\hline 1 & 4 & 5 & 3 & 1 \\
\hline 2 & 4 & 1 & 1 & 0 \\
\hline 3 & 1 & 0 & 1 & 0 \\
\hline 4 & 3 & 0 & 2 & 1 \\
\hline 5 & 5 & 2 & 1 & 0 \\
\hline 6 & 1 & 3 & 2 & 0 \\
\hline 7 & 1 & 1 & 1 & 0 \\
\hline 8 & 4 & 1 & 1 & 0 \\
\hline 9 & 1 & 1 & 0 & 0 \\
\hline Totals & 24 & 14 & 12 & 2 \\
\hline
\end{tabular}

Table 15: Frequency of Non-ES Challenges. 
A major technical challenge that was mentioned was difficulties related to accounting and appropriations not being on the same basis. Accrual accounting was implemented, but appropriations and department budgets remained on a modified accrual basis that more closely resembled cash accounting. Accrual budgeting and appropriations is a contentious issue, with many participants claiming, that there really is not much difference between the two bases for most managers. Tremendous amounts of work go into reconciling the federal budget, which is on full accrual basis, with modified cash appropriations. One participant said, "but you think about ... [the] work that goes into this [reconciliation], to get the federal budget full accrual [when] appropriations [are] modified cash, the reconciliation was just ridiculous." This reconciliation is important to the Federal Government in order to set fiscal expectations. What was actually spent is reconciled against appropriations and reported to parliament. One participant claimed that an invalid reconciliation was being made. This participant said that while the federal budget may be articulated, using full accrual accounting, the budgeting system is not on full accrual accounting. The budgeting starts on the cash basis and then is converted to the accrual basis. There is also the technical consideration of appropriations and budgeting going to full accrual accounting; how would that work? Unlike accrual accounting, there is no standardization in how that type of system would function. The Federal Government accrual accounting system is modeled on accrual accounting in the private sector and in other government jurisdictions. This modeling on the private sector does not work for budgeting since the budgeting process is far more complex in the government, compared to private industry, and each country's budgeting system differs. According to a central agency participant, the government is in heavy consultation with 
the departments in order to develop a model. Currently, because the budgets and accounting are on two different bases, there is need to keep two sets of information, creating added work and inefficiencies.

Asset valuation presented varying levels of difficulty, depending on the nature of the asset. Large assets, that had been designated crown projects, were subjected to special rules that required detailed reporting of costs. These assets have files detailing the costs of these projects. Other items, even costly ones, presented some difficulty. An example given by one participant was, "lots of building[s] that would be more than 40 years old and [it] was hard to figure out the right value for those buildings." There were not always records for these assets, and there were upgrades and enhancements that had to be taken into account.

In order to help other departments valuate their assets, one of the central agencies created a program to calculate the economic value of assets going back in time. Not all departments used this tool, and not all participants were aware of its existence. The OAG did approve this calculator so that its estimates could be used in financial statements. In order to value the assets, a physical count had to be performed. One participant described how the department found assets that they did not realize existed, and how the physical count of assets was lengthy, threatening to slow down the implementation process. Cooperation was required from the user community for both the physical count and the valuation of assets. It was decided that some assets, such as software with limited useful lives, would only be accounted for on a proactive basis. Other assets such as historical artefacts and land owned by Parks Canada were not valued at all, and do not appear in the Federal Government's financial statements. For capital projects, departments are now 
required to not only establish the cost of the asset upon acquisition, but the cost of maintaining the asset during its useful life, and the cost of disposing the asset at the end of its useful life.

The various rules that the Federal Government decided upon for asset valuation are contained in the Treasury Board Policy Manual. These challenges were overcome through heavy involvement of major property holders within the government. An example of a question departments struggled with was whether or not to capitalize the components of an IT system or the whole IT system. If done by component, the IT hardware did not meet the capitalization threshold, but if the whole system was valuated together, it would. Another difficulty came with trying to capitalize legacy systems. One participant described the complexity of certain asset valuations,

I remember a great discussion around how do you value the [Historic Building], it was built hundred and some years ago so market value is not there, historical value is not there, you have renovated it four or five times, you know it has a historical and cultural value far beyond it's physical value so they had to come up with a separate methodology for valuing different types of assets which forced them to look at the business and what does this really mean on the cultural side.

The initial analysis that departments and central agencies made before implementation was not always complete or accurate. One participant found that, within the department, the time required to implement was underestimated along with the need for communication. Another participant had the impression that the timeline to implement accrual accounting throughout the whole Federal Government was tighter than what was actually realistic. Yet another participant spoke of unexpected problems encountered using the system, and impacts that did not materialize. For instance, the 
expectation that the Federal Government would no longer need extra fiscal periods to close their accounting books was not realized.

In hindsight, one participant felt the route chosen to full accrual accounting might not have been the best one. The Canadian Federal Government chose to implement accrual accounting in financial statements at a consolidated level first and now is trying to get departmental accrual-based financial statements. Other countries and jurisdictions went with departmental accrual-based financial statements first, and then tried to get consolidated statements. The decision to implement consolidated statements first was due to efficiency, because it could be achieved faster, given higher levels of materiality. However, what was missing from the analysis is that better information could be obtained by completing the departmental implementations first, because of lower materiality levels. Another participant pointed to the fact that the decision was made to implement accrual accounting first, and the business case was made later. While participants never directly stated that the initial analysis was incomplete or faulty, they did cite examples such as, "I think the lack of what was really underestimated was more the state of the financial community." A key area of the analysis that was underestimated was the amount of change required to implement.

\subsection{Cultural/People Challenges}

\subsubsection{Resistance and Support}

Table 16 contains the number of paragraphs in which each of the topics related to resistance was discussed in the interviews. While all participants agreed that there was some resistance to change, some participants felt that it involved isolated incidences with 
certain individuals, while others felt it was a wide-spread organizational problem. Some people resisted the replacement of their legacy systems, because at the time they felt if offered more flexibility than the new standardized system.

\begin{tabular}{|c|c|c|c|c|c|}
\hline \multicolumn{6}{|c|}{ Resistance and Support Challenges } \\
\hline Interviewee & $\begin{array}{c}\text { Resistance to } \\
\text { Change }\end{array}$ & $\begin{array}{l}\text { Budgeting } \\
\text { Processes }\end{array}$ & $\begin{array}{c}\text { Top } \\
\text { Management } \\
\text { Support }\end{array}$ & Communication & $\begin{array}{c}\text { Organizational } \\
\text { Needs }\end{array}$ \\
\hline 1 & 2 & 1 & 1 & 1 & 1 \\
\hline 2 & 1 & 2 & 1 & 0 & 0 \\
\hline 3 & 0 & 2 & 0 & 0 & 0 \\
\hline 4 & 3 & 2 & 1 & 0 & 1 \\
\hline 5 & 1 & 0 & 0 & 3 & 0 \\
\hline 6 & 1 & 0 & 1 & 4 & 0 \\
\hline 7 & 1 & 0 & 0 & 0 & 0 \\
\hline 8 & $\overline{0}$ & 0 & 0 & 0 & 0 \\
\hline 9 & 0 & 0 & 0 & 0 & 0 \\
\hline Totals & 9 & 7 & 4 & 8 & 2 \\
\hline
\end{tabular}

Table 16: Frequency of Resistance and Support Challenges.

One central agency participant found that he was being yelled at or snubbed during inter-departmental meetings dealing with the implementation. This participant felt that part of the problem was due to the age of the financial community. In his words,

I remember going to meetings and just being either yelled at or snubbed because part of it was, and it is a continuing problem, was the age of [the financial community]... my interactions were with the financial community so it may have applied [to] other ones, but the financial community ... [is a] very old community and it's difficult going to somebody who has got three years until retirement and saying I am going to screw you over and change everything you do...

Many of these individuals were close to retirement and felt resentful that everything was being changed. As well, it was felt that the change had been poorly managed initially, especially considering that a change management specialist had not 
been brought in centrally right away. Within departments, there was resistance and push back being encountered. Again, the amount of animosity was not foreseen ahead of time. In one department, the participant found that the timing of the implementation is what caused most of the resistance. The implementation occurred during the busy time of year for the financial personnel, and there was a lot of resentment towards the increased workload. Some participants found that there was not necessarily overt resistance but a lack of interest outside the financial community. Some said that people were hoping to ride out the initiative, thinking it would just disappear as some other past initiatives. One participant who was involved with managing the change said, "... whatever system you had was a piece of crap until you get something else, then all of a sudden the old system is the greatest thing since sliced bread..." The amount of change required was underestimated, as well as the impact on individuals.

Many participants agreed that people within the Federal Government are not considering the accrual accounting information, because their budgets are still based on modified accrual accounting. There is no incentive for managers to look at accruals since they are being held accountable for the modified accrual budgets. As one participant put it, when describing attitudes towards accrual accounting, “... when you [are] asked to manage a budget it's modified cash. Why would you care?" The impact on planning and decision making is lessened because managers do not integrate the accrual information. As well, some participants feel that accountability will not increase until budgeting is on the same basis, because managers are not responsible for accrual information. Frustration was expressed at the length of time it is taking the government to implement accrual budgeting even though the government has not officially decided to implement it and still 
considers it under review. It is felt that balance sheet management falls outside managers' radar, because of the difference between accounting and budgeting systems. One participant said,

I think even now many users don't see much of a difference because as you know budgets are not on accrual basis so when people think about their budget they are thinking about their cashbased budget, which doesn't take into account depreciation of assets.

Having budgeting on the same basis as accounting will get departmental attention. Yet, there is disagreement on how much the way budgeting is done drives behaviour. Some feel it is a huge driver of behaviour, while others see the two bases as not being that different for the average manager. Another cultural problem with budgeting is misunderstanding of information being presented in the budgets, even under the present modified cash system.

Participants were also not in agreement concerning top management support. One participant, who mentioned it, felt that top management was really behind the initiative. They wanted to make the implementation happen and made the resources needed available. Another participant said, “... would say top management was really, I would say, anxious to make this happen so they put the resources we needed. We had very good support." As well, another mentioned working groups that consisted of top management, before even the implementation process commenced. Another participant said, as higher management were often not accountants, it was difficult to get senior engagement on the issue, especially considering that the implementation did not affect how they would manage their budgets. The sentiment was, "why do I care that you're doing this centrally." It was felt to be a central issue and did not concern them. One participant 
said that some of the sectors outside of the financial community might not have even known the initiative was occurring.

Participants were ambivalent about communication throughout the implementation process. One felt it was the thing that needed the most improvement, while another felt that communication was good and that they were made aware from the beginning what was occurring throughout the process and what was expected of them. As this participant said, "... it was upfront, people knew at the beginning what changes were need [ed] to be done to implement the accrual accounting." Both cluster meetings for ES and work groups helped promote communication between departments.

Support for the system also depended on whether participants felt that the organizational needs were being met. There was mixed response from participants regarding meeting organizational needs. One participant said, "I would say this new system has all the ingredients to meet the organization needs but the moment the budgets will be on accrual basis." Another participant felt that it was meeting their needs, since their needs consisted of complying with whatever was mandated for them. Whether or not accrual accounting benefits lived up to their expectations depended greatly on how the participants felt about accrual accounting before it was implemented. Some participants had higher expectations and feel that accrual accounting has yet to deliver them. Different reasons were cited for why accrual accounting had yet to deliver. One is that budgeting is still on a modified accrual basis instead of accrual basis. It is believed that without the budgeting component, accrual accounting has only been partially implemented, resulting in only partial benefits. Others felt that there just needs to be more time before the full benefits will be felt. 
Improvements are continually being made to reach the full potential of the systems. Some participants knew before commencing implementation that not all benefits would be realized right away. One participant felt that it was a generational process. Another described the implementation of accrual accounting as a "big boat to turn." Others' sole expectation of the accrual accounting implementation was that their department complied with what was mandated. As far as these participants are concerned, the accrual accounting system is producing the benefits that are expected. One participant felt that there were no realizable benefits from accrual accounting.

\subsubsection{Comprehension}

The activities in this section are outlined in Table 17. Most departments and central agencies felt that there were not enough people who were knowledgeable about accrual accounting in the Federal Government. According to one participant, there were not a lot of designated accountants in the government, and many of them had even lost their accrual skills from doing modified accrual accounting for so long. He said,

...the issue that people missed the most is ... [that] there was not a lot of designated accountants in government but even when there were, if you [have] been doing cash accounting for 30 years, you would be amazed ... [their skills were] just gone, it was a vacuum.

In many financial communities, accounting education was twenty to thirty years old. One participant described how fundamental this lack of knowledge was with an example of someone wondering, "how could you balance your books without single line entries." This example shows how some staff was missing one of the most fundamental concepts of accounting that it is based on double line entries. People did not know debits and credits and even depreciation was a new 
concept for them. For the non-financial community too, there was a problem with a lack of knowledge. It was a challenge getting people to understand the

\begin{tabular}{|c|c|c|c|}
\hline \multicolumn{3}{|c|}{ Comprehension Challenges } \\
\hline Interviewee & $\begin{array}{c}\text { Uniqueness of } \\
\text { Public Sector }\end{array}$ & $\begin{array}{c}\text { Lack of } \\
\text { Knowledge }\end{array}$ & Understandability \\
\hline $\mathbf{1}$ & 1 & 0 & 0 \\
\hline $\mathbf{2}$ & 2 & 2 & 2 \\
\hline $\mathbf{3}$ & 1 & 0 & 2 \\
\hline $\mathbf{4}$ & 0 & 3 & 0 \\
\hline $\mathbf{5}$ & 2 & 3 & 0 \\
\hline $\mathbf{6}$ & 0 & 0 & 0 \\
\hline $\mathbf{7}$ & 0 & 3 & 1 \\
\hline $\mathbf{8}$ & 1 & 2 & 2 \\
\hline $\mathbf{9}$ & 0 & 0 & 0 \\
\hline Totals & 7 & 13 & 7 \\
\hline
\end{tabular}

Table 17: Frequency of Comprehension Challenges.

differences between the old and new systems, especially when the individual did not have an accounting background. Operational managers really did not understand accrual accounting. Loss of knowledgeable personnel was not an issue on the accounting side, as there was never the knowledgeable personnel there to begin with. That is why there was a lot of basic training in accruals that occurred during the implementation of accrual accounting. Some participants felt there is still a lack of knowledge, and indicated that it would be difficult to comply with the mandate for audited departmental financial statements, because there was a lack of staff to help with the initiative.

This lack of knowledgeable personnel also applied to the use of ES. As previously discussed, it was more lucrative for people with this particular skill set to be 
consultants instead of government employees. This situation has not been resolved and as one participant put it,

... it is not acceptable to have the kind of volume of people with those kinds of skill sets in the government. It is expensive to train them and once they are trained they run off for bigger money in consulting ...

Apart from the lack of knowledge within the government to deal with accrual accounting, participants also mentioned an increased lack of understandability of the government financial statements produced for the general public and parliamentarians. One example is how the media discusses the governmental financial statements. Often, messages released regarding Federal Government financial information are actually false, for example, stating that the surplus pays down the national debt. This statement is not true, since the surplus is net income and not a cash number, and the implied national debt is really the accumulated deficit. This is due to a lack of understanding by the media concerning public sector accrual accounting. According to one participant, “... the average person in the public doesn't get accrual stuff, most parliamentarian[s] don't get it, so they try to make very simple messages." Another issue is that parliamentarians do not understand the simplified modified accrual accounting, so adding the complexity of accruals exacerbates the problem. The problem is sending parliamentarians away for training on accrual accounting is not feasible, since their positions are not permanent, and the process would be too time demanding.

Inability to train Members of Parliament is one example of how the public and private sectors differ. Participants mentioned how the public and private sector often differed creating issues concerning implementation. One example, previously mentioned, is how lease-versus-buy decisions, coming from the private sector, were not valid due to 
differences in cost of capital. Another big difference is how the media reports on government financial statements. Business reporters cover financial statements of large organizations. The same reporters who cover the question period in the House of Commons also cover the government financial statements. This results in differences in how the financial information is reported. As well, the financial requirements are stricter for the Federal Government, according to one participant. Another participant described how,

...the decision making process in a political system and a government system is much more complex and much more contentious than the equivalent that takes place in the large private sector organization and you have to look at the fact that it is a multi-layered process.

There are even differences in basic accounting. For example, according to one participant, the department has fourteen accounting periods in the year, whereas most private company would have only twelve. These extra accounting periods allow an overlap in the fiscal year, where during the thirteenth accounting period you are already in the first month of the next fiscal year. These periods allow personnel to finish left over work and make corrections after the year end. While the government may have additional accounting periods compared to the private sector, both entities have a twelvemonth fiscal year. Nonetheless, there is an acknowledgement that adopting accrual accounting does close some of the gaps between private and public sector. 


\subsection{Accrual Accounting Benefits}

\subsubsection{Integrated Accrual Accounting System Benefits}

Table 18 outlines the benefits called integrated benefits in this study. Some participants discussed benefits that they felt also depended on both larger change initiatives and the integration of accrual accounting systems with ES. Benefits that depended on larger reforms included accountability, relating financial and non-financial information, and costing. End-of-year reporting to the Parliament is now being done on an accrual basis. Departments have to submit a report to the Parliament on plans and priorities, describing what they have achieved and what resources were used. Not all participants agree on whether switching to accrual accounting has increased accountability. One felt that accountability was already in place, but in order to increase that accountability, both budgeting and appropriations would also have to be on the accrual basis. As well, there are larger change initiatives, such as the modern comptrollership initiative, that is also aiming to increase accountability in the government. As one participant described accrual accounting and its relationship to accountability, “... it is one of the wagons of the larger train, but the other elements are as important to deliver more accountability."

Other participants felt that the introduction of accrual accounting created a bigger danger for control because accrual accounting requires more use of judgment and estimates. A department exceeding their spending authority is considered to breach accountability requirements. When appropriations and accounting are done on a modified cash basis, it is very clear what gets charged to appropriations. Full accrual accounting introduces estimates and judgments to the budgeting process. 


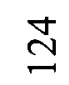

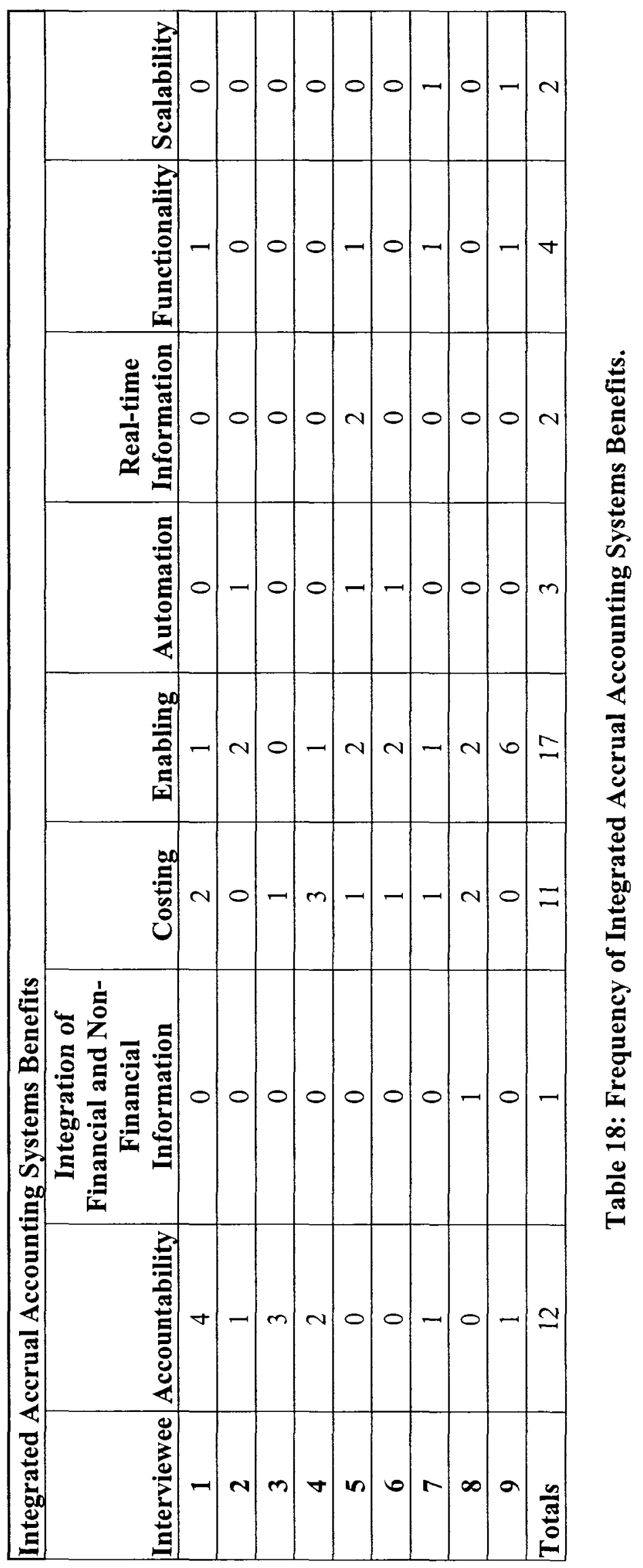


No participants indicated that there had been an increase in accountability due to the implementation of accrual accounting. However, some participants felt that accountability would increase with the introduction of accrual-based appropriations, although a few felt that it would decrease.

Relating financial and non-financial information is another proposed benefit that relates to larger change initiatives. The participant who mentioned this benefit perceived that the government did not do a good job and that, though financial information was being obtained, it was not being related to actual operations. As he said, ...we have been deficient in ... trying to relate financial and nonfinancial information. So managers really had good information on how they are doing [because] we do a fairly good job on getting financial information, but trying to relate that to actual operations is an issue.

It was felt that there was not a good understanding of program outcomes. As well, participants did not cite efficiency as a benefit of accrual accounting. However, they did say ES created efficiencies because of their added functionalities, increased automation, and the use of a central chart of accounts.

Costing does occur within the Federal Governments, but to varying degrees within departments. Departments are evaluated at the end of the year, when they report to the Parliament. Costs are accumulated for the report of plans and priorities by mission, and they are accumulated on an accrual basis. Again, costing is another area where the larger change initiatives have a great impact. When asked about costing information and accrual accounting, one participant replied, "I would say that what plays a role in that is more the new comptrollership division of government." Under the Modern Comptrollership Initiative, there is a focus on people reporting their achievements using 
measurable indicators for various targets. Departments are also expected to have a plan, whereby they link their activity to their targets, and then report on the indicators of target achievement. Centrally, the new accounting system produces better costing information that is being used. The use of costing information is not uniform across departments. Some departments are accumulating accrual information at a program level, whereas other participants said their department barely does any costing. How much costing a department does largely depends on its mandate. One participant observed that generally the government produced abundant reports and data, but that they are poor at acting on that information. The functionality is in place to do costing, but not all departments feel that it is beneficial to use the information.

ES facilitated the implementation of accrual accounting. Some departments had adopted new ES just before implementing accrual accounting, and others implemented them at the same time. The Shared Systems Initiatives is trying to standardize these systems in part by getting departments to adopt commercial software. Participants in the departments that implemented their ES before the accrual accounting system felt that the new accrual accounting system was easier for personnel to learn, since they were already familiar with the new system. The system "wasn't one more thing to learn." Personnel were already comfortable with the environment and many functions within the system stayed the same, with the changes being made behind the scenes without affecting the end user. Accounts receivable and accounts payable personnel would still be working with the same module. Personnel that dealt with assets would have to learn a new module. 
Repeatedly, participants pointed to the fact that these systems were built to handle accruals, therefore, making the implementation of accrual accounting easier. Many participants indicated that it would have been impossible to implement accrual accounting without ES, although, one participant felt that existing systems could have been reprogrammed to handle the implementation. In general, it was reported that ES within the department provided the tools that permitted accrual accounting to be implemented. An example is that the commercial ES allowed for the use of a special ledger within the system. This special ledger meant that departments could have both their own and the government-wide chart of accounts, and the departmental chart of accounts would be automatically linked to the government-wide chart of accounts. As well, ES could automatically create a monthly trial balance, which was necessary under the new system.

There is no clear consensus whether buying an off-the-shelf commercial ES was a better decision than reprogramming homegrown systems that already existed within departments. One participant pointed to the fact that since departments had seven financial systems to choose from, each department implemented the new systems in their own way, benefits from standardization were lost, and it may have been cheaper to modify the existing systems. It was also felt that there was a lack of consistency across departments. Other participants felt using commercial software increased the consistency across departments.

The automation that ES offers was found to be beneficial. For instance, previously departmental reports were being sent centrally as a hard copy every month, whereas now everything is done electronically. As well, some tasks, such as calculating 
depreciation, became automated. As one participant said, "I mean, just the notion of asset amortization schedules, to you and I it is pretty simple but to some people in departments that was, wow, I don't have to do this manually." Another technical feature that relates to automation is the ability to produce real-time information including monthly trial balances. These two features complemented one another and allowed for overall increased effectiveness and efficiency.

The functionality was found to be the most important feature of ES. For example, ES can handle amortization schedules that were previously done manually. ES was able to produce more views of information, making it easier to analyze financial data. The increased functionality also came with the fear by some participants that the system was being used without any real understanding of accrual accounting. Participants also found large increases in how much of the functionality has been used since the implementation of accrual accounting. Adding new functionality by using more features of an existing module is relatively easy to do, however it is relatively difficult to add new modules to the system. One participant felt that scalability was not important, since all modules that were needed were implemented. There was no need to scale the product after the fact. Instead of scaling ES, the focus for one participant was on using more of the functionality, as he said,

...we are finding more and more that we're using more of the capabilities of the product that we have. If we look, say we did a study, when I was with the program office a couple of years ago, I'm making the figure up but it's illustrative; when we first brought in SAP, we were using $50 \%$ of the functionality in the CO module, between the time we implemented and the time we did the study ... the product functionality may have grown by another $50 \%$. 


\subsubsection{Compliance and Reporting Benefits}

Accrual accounting benefits associated with compliance and reporting can be found in Table 19. A major benefit cited from the departmental perspective was compliance. The departments were mandated to produce certain information for the central agencies and the implementation of the accrual accounting system allowed the departments to meet those requirements. As one participant said, "Well the information is mainly used for managers to make sure that they meet the requirement of the department." For the government as whole, it was important to get a clean audit opinion on their full accrual statements. One participant said, "It is almost reverse benefits. The damage of getting an unqualified opinion, I mean, we got instant credibility in the world stage, because we have a clean opinion." The major benefit to the government as a whole is to be able to satisfy external financial reporting requirements. It allows the government to truly represent activity that occurred in the past year. Reporting became more timely and accurate. According to one participant, there is a certain amount of recognition and credibility that comes from Canada being the only G8 country that receives a clean audit opinion on their accrual-based, government-wide financial statements. A major reason why Canada is one of the only countries to get a clean opinion on government-wide statements is that Canada implemented audited accrual accounting financial statements on the consolidated level first, whereas other jurisdictions began with audited accrual-based departmental financial statements first. The materiality would be much smaller on the departmental statements, making it take longer to obtain a clean audit opinion. Canada is now moving forward with an initiative to implement audited departmental financial statements. When referring to financial reporting, one 
participant said, "... the first achieved objective, I will put it that way, was the financial reporting. Ok so we [have] got good statements."

\begin{tabular}{|c|c|c|c|c|}
\hline \multicolumn{5}{|l|}{ Compliance and Reporting Benefits } \\
\hline & & & & Financial \\
Interviewee & Compliance & Understandability & Comparability & Reporting \\
\hline $\mathbf{1}$ & 1 & 2 & 2 & 1 \\
\hline $\mathbf{2}$ & 2 & 0 & 2 & 1 \\
\hline $\mathbf{3}$ & 0 & 0 & 0 & 0 \\
\hline $\mathbf{4}$ & 0 & 0 & 1 & 2 \\
\hline $\mathbf{5}$ & 0 & 0 & 0 & 2 \\
\hline $\mathbf{6}$ & 0 & 0 & 0 & 0 \\
\hline $\mathbf{7}$ & 0 & 1 & 0 & 0 \\
\hline $\mathbf{8}$ & 0 & 0 & 0 & 2 \\
\hline $\mathbf{9}$ & 0 & 0 & 0 & 0 \\
\hline Totals & 3 & 3 & 5 & 8 \\
\hline
\end{tabular}

Table 19: Frequency for Compliance and Reporting Benefits.

One benefit cited by participants relating to financial reporting, is the increased understandability of the financial statements by both the public and parliamentarians. It was felt that accrual accounting brought the terminology of financial statements more in line with that used in private sector, with which the public and parliamentarians have more experience, as opposed to government jargon. As one participant said, "I would say that ... it gives you information in a format that larger part of the public will understand."

While most participants felt that the adoption of accrual accounting brings the government financial statements more in line with the private sector, there has been little or no comparisons of the financial information with the private sector. There are still major differences between the private and public sector that make the comparisons invalid. An example given by one participant was a buy-versus-lease proposal submitted by the private sector. However, the government's cost of capital is significantly lower 
than that in the private sector. Therefore, the proposal made sense in the private sector, but it did not work in the government sector. As well, according to another participant the reporting requirements for the public sector are much more vigorous than those for the private sector. Another talked about how private and public sectors have different roles, invalidating the comparison. For example, a comparison of bad debt expense would not be valid, since the government is not in the business of lending money for profit like a bank. One possibility for comparison may be with other government jurisdictions, especially if international standards for government accounting begin to be adopted. He said, “...we follow Canadian Public Sector GAAP, but if we ever move to international GAAP, you would see some comparisons." However, these comparisons are not currently being made.

\subsubsection{Managerial Benefits}

The frequency of managerial benefits can be found in Table 20. In terms of decision making, many participants said that there was not much difference between the accrual and the modified accrual accounting information. This lack of differences was particularly the case when the department was not capital intensive. One participant said,

I would say, yes, people do use it but they don't see a huge difference between accrual information and cash based information, because I would say, even with our cash based system the information was, I would say, quite in line with what people were spending during the year. The main ... distortion was the assets part, the rest was very close to accrual accounting.

As well, participants said that the accrual accounting information was not useful in terms of decision making, because the appropriations are still on a modified cash basis. 
Departmental budgets do not take into consideration accrual accounting items. Apart from capital assets, departments do not take into account accrual information when

\begin{tabular}{|c|c|c|c|c|c|}
\hline Managerial Benefits & \multicolumn{5}{|c|}{} \\
\hline Interviewee & $\begin{array}{c}\text { Decision } \\
\text { Making }\end{array}$ & $\begin{array}{c}\text { Compare } \\
\text { with Budget }\end{array}$ & $\begin{array}{c}\text { Asset } \\
\text { Management }\end{array}$ & $\begin{array}{c}\text { Behavioural } \\
\text { Outcomes }\end{array}$ & Efficiency \\
\hline $\mathbf{1}$ & 3 & 1 & 3 & 1 & 0 \\
\hline $\mathbf{2}$ & 5 & 1 & 6 & 1 & 0 \\
\hline $\mathbf{3}$ & 2 & 0 & 0 & 0 & 0 \\
\hline $\mathbf{4}$ & 4 & 2 & 3 & 0 & 0 \\
\hline $\mathbf{5}$ & 2 & 1 & 2 & 3 & 4 \\
\hline $\mathbf{6}$ & 0 & 1 & 0 & 0 & 2 \\
\hline $\mathbf{7}$ & 2 & 0 & 0 & 0 & 0 \\
\hline $\mathbf{8}$ & 2 & 1 & 2 & 0 & 0 \\
\hline $\mathbf{9}$ & 0 & 0 & 0 & 0 & 0 \\
\hline Totals & 20 & 7 & 16 & 5 & 6 \\
\hline
\end{tabular}

Table 20: Frequency of Managerial Benefits.

making decisions. Decisions are mostly made on a transactional basis by departments that are on modified accrual budgeting. So in terms of permission to do something, it is not predicated on accrual accounting information. As well, the majority of appropriations are statutory rather than voted, meaning that a high percentage of funds do not need to go through the Parliament to be voted, because they are automatic. This low percentage of voted funds means that accrual accounting has the potential to change decision making on a very small percentage of spending. However, there are some examples of the accrual accounting information being used for decision making. One is benefit amendments for veterans' pension plans. Another example is a sale-lease-back program, whereby one department sold nine of its buildings, and is currently leasing them back.

A major benefit of introducing accrual accounting, in terms of decision making, cited by most participants, is better asset management. It has allowed the government to 
realize the value of its assets. It forces the departments to pay attention to those assets and maintain them. As one participant said,

...for those who were asset rich I think there was a significant benefit because it forced them to look at their assets, it forced them to look at the aging, force[d] them to look at their replacement plans, their capitalization plans.

It forces the adoption of a life cycle approach to assets. Previously, only the cost of an asset must be established when evaluating capital projects, but now the cost of maintaining and disposing of assets must be taken into account as well. The new system also guards against the "rust out" problem, which is capital assets becoming outdated and not being replaced. Again, some participants explained that they felt the full benefits of accrual-based accounting concerning asset management would not be realized until the budget was on a full accrual basis, as well. It is felt that, under accrual-based budgeting, the department will be able to recognize the yearly cost of the asset.

As well, there is a tendency to hold onto assets under the present system because it is felt that they are not costing the department, and they would rather not fight to get it back in the future, if they should need the asset again. Some departments realized an increase in capital spending, since under the old system the whole cost of a new asset would go through the financial statements in the first year, making it difficult to acquire new assets. Under the new system, the cost is spread over the life of the asset. The new system also automated asset amortization schedules, which was thought to be helpful in terms of asset management. Departments that are capital asset rich, enjoyed these benefits the most, compared to departments that are comprised mostly of personnel. For personnel departments, there has not been a huge difference between modified accrual and full accrual numbers. 
Behavioural outcomes that resulted from accrual accounting included an increased focus on the balance sheet and away from just the current year. One participant said,

...when you are only on cash basis the focus for everybody is [the] current year, [but] when they started talking about accrual accounting and balance sheet, they discovered the balance sheet ... was containing valuable items and that we should pay attention to them.

Balance sheet items, such as receivables and liabilities, are better managed under the new system, but this opinion is not universal among participants. Some participants explained that liabilities were already being effectively managed before the new system. These participants said that the Canadian Government has always made an effort to be a good corporate citizen and pay its bills on time, in addition to the fact that departments get charged a penalty, if they do not pay their liabilities. However, participants overwhelmingly stated that, in order to change behavioural outcomes, there would have to be changes to accrual-based budgeting and appropriations, since it is the budget that drives behaviour in the government. Under the present system, one participant described how managers are overly cautious because of the minority government situation, and they fear that, if the government falls, even approved money for expenditures will not come through. The reason for major spending often occurring at the end of the year is to mitigate the risk of not getting funding even though it has already been approved. This participant indicated that accrual-based budgeting would be done a on a multi-year cycle, and it would allow for proper fund management. Another behavioural outcome mentioned is for the accounting personnel. University training for accountants is based on accrual accounting, and staff found it discouraging not to be able to use their 
education when they came to the government. This inability to apply university training to the job made it harder to attract new graduates to work for the government.

\subsection{Conclusion}

The data collected from the nine participants in the seven interviews is rich in detail. Participants discussed a variety of topics that were both predicted by the literature and unexpected. While multiple participants discussed some topics, others were specific to their department or area of expertise. Although the participant largely drove the discussion during the interviews, the results have been organized to make sense of the data in order to draw conclusions. The first area, implementation processes, focused on activities that were performed in the Canadian Federal Government in order to implement accrual accounting. These activities were divided into three phases based on how far along the government was in the implementation process. Participants described both activities in which they were personally involved, as well as activities that their departments undertook. In some cases, participants were also able to discuss activities in other departments.

The second and third major areas deal with challenges that arose, both expected and unexpected, during the implementation process. The challenges were categorized into technical and cultural/people challenges. Participants were very forthcoming about the challenges experienced. The final area focuses on the benefits of accrual accounting implementation in the Canadian Federal Government. These benefits varied among departments, just as challenges and activities varied among departments. The categorization of the results into the four main areas, discussed above, loosely 
corresponds to the a priori model. In the next section, these results will be used to develop a new model based upon this empirical evidence. This new model will incorporate the insights provided by these participants into the a priori model. 


\subsection{Discussion and Model Development}

The first part of the discussion will explore how the data collected in this study fits with the a priori model. In the second part of the discussion, a new model of the accrual accounting implementation process in the Canadian Federal Government, based on the data collected from the participants, is developed.

\subsection{A Priori Model}

\subsubsection{Implementation Processes and Benefits}

Collected data that is inconsistent with the a priori model or with the analyzed literature will be discussed in this section. The a priori model consists of four major areas: the implementation processes, accrual accounting benefits, cultural aspects, and Enterprise System (ES) characteristics and support, as reproduced in Figure 6. In accordance with Markus and Tanis (2000), the implementation processes deal with four phases. The first phase, called project chartering, was present for the government as a whole but not present in every department. The decision to proceed with accrual accounting was largely a central decision, with little or no involvement at the department level. Prior to the collection of data, it was realized that there were some key central agencies involved in the functioning of accrual accounting; however, it was not realized how centralized this first phase of accrual accounting implementation was. Some of the proposed activities at this stage were identified and included activities, such as building a business case, gaining an understanding of accrual accounting and assessing accounting needs. However, there is some evidence that the decision to implement accrual 
accounting was a political decision, instead of a managerial decision, emphasizing that

these implementation phases are distinct from those performed in the private sector.

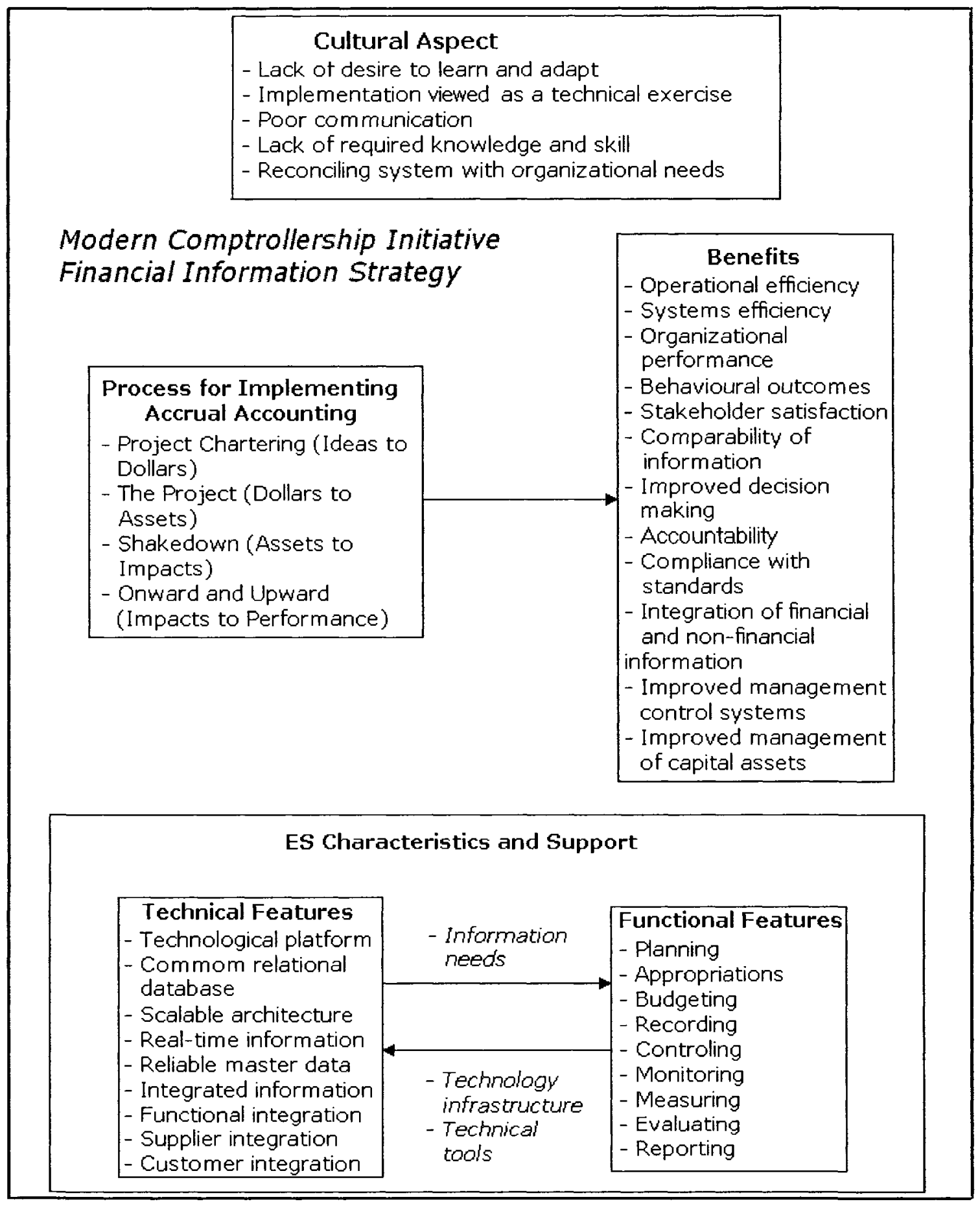

Figure 6: $A$ Priori Model of Accrual Accounting Implementation. 
As well, this study confirms the notion that, while the Federal Government of Canada is a sovereign identity, it does comply with the Public Sector Accounting Board (PSAB), which is an independent body. Along with PSAB, there are internal standardsetting bodies, such as the Treasury Board of Canada Secretariat (TBS), from which the departments receive guidance. While currently the Federal Government does not comply with international accounting standards, participants were well aware of their existence, and international factors were a factor in the decision to adopt accrual accounting. The next phase proposed in the a priori model was called The Project. Training seems to be a major activity undertaken at this stage of implementation as predicted by the a priori model. Other activities included hiring consultants, testing the system, and ensuring the IT was in place to support accrual accounting.

Participants did not distinguish between the third phase of the implementation, called Shakedown, and the next phase, called Onward and Upwards. During interviews, and upon further analysis of the data, it was realized that participants reject this conceptualization. They viewed all activity that happened after the system goes live as part of the same phase of activity. One participant felt that, once the system was operational, it was being used as it was intended. When asked about Phase 4 activities, he could not identify any processes at that stage. Another participant referred to the implementation of accrual accounting as being a generational process, when asked whether the benefits from this system had emerged as expected. This response would indicate that, at least according to this participant, the timeframe between Phase 1 and Phase 4, where the system is operating normally and the benefits are expected to be received, is rather lengthy. It also shows, according to this participant, that the Canadian 
Federal Government was still in the Shakedown Phase of implementing, yet this participant gave examples of activities in the Onward and Upwards Phase. These responses lead to the possibility that the accrual accounting implementation in the Canadian Federal Government may not have reached the last stage yet.

Other participants discussed how the full accrual accounting system has not been implemented yet, since accrual budgeting has not been adopted. This response also indicates that implementation has yet to reach Phase 4. It is also possible that participants do not distinguish between these two phases of activity, and that the separation is artificial to them. Activities identified in the a priori model at both of these stages were discussed. Participants spoke of tuning, improving and modifying the system after it went live. There was some evidence of retraining and post-implementation reviewing, although it was not done in a wide-scale systematic fashion. During the Onward and Upwards Phase, benefits of implementation are supposed to materialize. As will be discussed in the next section, there is no consensus as to what benefits have been achieved or the possibility for additional benefits. The Markus and Tanis (2000) model, upon which the processes in the a priori model were based, was developed as a framework for ES implementation in the private sector. The authors do not make any claims to the applicability of it in other sectors or to other types of systems; however, it appears that with minor modifications this model is applicable to the public sector and to implementing accrual accounting systems.

As discussed in the literature review section, benefits do not stem automatically from the implementation of accrual accounting, but result from managers acting on the information it provides (Evans, 1995). In the Canadian Federal Government, there is no 
uniform or consistent amount of benefits from accrual accounting that has been enjoyed in the various departments and agencies interviewed. As per the results section, part of this inconsistency stems from participants' perceptions of what accrual accounting benefits were expected to be before implementation.

A number of reasons were given for the absence of comparability as a benefit. They included the inappropriateness of comparing the Canadian Government to the private industry due to fundamental differences. This idea of fundamental differences between the public and private sectors adds to the debate in the literature over whether or not sector neutrality holds. Sector neutrality is the school of thought that the public and private sectors are fundamentally the same. The information collected supports the view that the two sectors are different and that this difference has an impact concerning the adoption and use of accrual accounting. Not all assets of the Canadian Federal Government were capitalized. Some assets were deemed to present insurmountable valuation issues. This non-capitalization provides further evidence that sector neutrality is not valid, since in the private sector, all assets are capitalized. However, this rationale given by participants does not account for the fact that comparisons are not presently being made between public sector jurisdictions. There was some evidence that there may be future benefits for comparability, if and when the government adopts international accounting standards. Then the Canadian Federal Government could be compared to other government jurisdictions.

While the literature shows strong support that accrual accounting supports effective and efficient decision making (Awty, 2002; Blondal, 2003; Boxall, 1998; H M Treasury, 2001; Likierman, 2000; Lye et al., 2005; Pallot \& Ball, 1997; SCGOE, 2006), 
there is not strong support for this idea among participants. There were two streams of rationale for this lack of support. One stream is that in many cases accrual and cash information are the same, and, therefore, accrual accounting does not impact decisions made by managers. In the literature, Figure 1 represented an accounting system spectrum. One end of the spectrum represents cash accounting and the other end accrual accounting. It appears that, while there are differences along this spectrum, the similarities between the points along the spectrum are much greater than anticipated. This is due to the fact that many departments do not have capital assets, which accounts for the major differences between the new full accrual system and the old modified accrual system. As well, some departments do not have a need for accounts receivable or liabilities, making accrual accounting similar to cash accounting. The second rationale, that even when the information could have an impact, managers do not utilize it, since their budgets are done on a modified cash basis. According to OAG (2002, p. 18), "Our most recent audit of the government's summary financial statements indicated that departments continue to face difficulty in making adjustments between accrual-based accounting for reporting purposes and cash-based accounting for budgeting and appropriations." The majority of the literature surveyed comes from countries, such as New Zealand, Australia, and the United Kingdom, which have implemented both accrual accounting and budgeting. The international nature of the literature could explain why there were not stronger benefits regarding decision making stemming from the implementation of accrual accounting in the Canadian Federal Government. Other countries could have been receiving benefits stemming from having both the budgeting and accounting system on the same basis. 
Decision making surrounding capital asset management is the only area that seems to have been impacted significantly, but only in areas that have a high degree of capital intensity. This conclusion is supported by the OAG, which found that accrual financial information was seen as most helpful to departments and agencies with a large number of capital assets, which consequently had to make more investment decisions regarding capital assets (OAG, 2005).

There was no strong identification of benefits related to larger change initiatives, which were included in the a priori model. If these benefits were mentioned at all by participants, it was always in relation to other initiatives. It appears that participants quite clearly delineate between benefits of related initiatives and accrual accounting. A benefit that was underestimated before the empirical research was compliance. It was thought that compliance would not be as important in the Canadian Federal Government, because it is a sovereign entity and is not required to comply with any external standards. However, departments felt that there were internal standards that they had no choice but to comply with, and that the Federal Government as a whole felt pressure to comply with international accounting standards. In the minds of some participants, compliance appeared to be the primary benefit of the implementation of accrual accounting. As well, the purpose of accrual accounting information does not differ from the benefits of accrual accounting information, as previously thought when formulating this study's research questions. 


\subsubsection{ES Characteristics and Cultural Aspects}

This section of the a priori model, which was adapted from Kumar et al. (2007), consists of technical features that provide infrastructure for implementing the functional features of the system. However, participants did not distinguish between the functional features of the system and the benefits. For example, if a participant found that reporting was a feature of the system they used, they talked about benefits in terms of financial reporting. If the system contained unused features, the participants did not refer to these at all. The discussion surrounding ES was on what benefits it allowed them to achieve. Participants did identify a number of technical features that either helped or hindered both the implementation and operation of the accrual accounting system. Integration was a feature of interest. The a priori model identified different types of integration such as supplier, customer, informational, and functional integration as being important. Of these three, the only one used in the Federal Government is functional integration. There are no attempts to integrate information between departments or any other entity. This lack of integration occurs due to the use of different ES. Within a department, functional models may be integrated and there is integration between departments and central agencies.

Interestingly according to Caglio (2003), ES would make accounting literacy easily transferable to non-accountants. While participants acknowledged that ES allows individuals to undertake accrual accounting tasks, there still remains a real lack of understanding. It appears that ES did not allow for greater accounting literacy, but instead enabled an individual who does not understand accrual accounting to undertake some of the accrual accounting processes. However, judging from the involvement of the 
participants in the management of the ES, it appears that accountants have had to become more proficient in the design and management of ES.

In terms of cultural/people challenges, accrual accounting was not completely embraced by all the users. Within the Canadian Federal Government, the OAG found that accrual accounting was largely an accounting exercise, not a management exercise, and that accrual financial information was not a priority for anyone other than financial managers at the year end (OAG, 2005). The participants supported this conclusion by the OAG in the interviews, when they talked about compliance as being the primary benefit. Compliance is a technical benefit, as opposed to a managerial benefit of accrual accounting. The participants are operating under the new system, because they have to, not because they see the benefits. There was mixed response regarding the desire of users to learn and adapt the system. The strongest support seems to come from the financial community, but even there resistance to change was felt. Many operational managers do not understand the benefits of accrual accounting. Repeatedly, participants spoke of a lack of understanding of accrual accounting to be a major cultural/people challenge experienced. While some felt that communication was well done throughout the implementation process, others talked about how some managers may not even be aware that change was occurring. According to the literature, employees should understand the need for change (Frahm \& Brown, 2007). Obviously, this understanding was not the case as some employees were not even aware that the change was occurring. It seems that there was an uneven level and quality of communication throughout the Canadian Federal Government. 
How participants felt about the accrual accounting system meeting their needs largely depended on how they viewed the accrual accounting system before implementation. Many participants had very little expectations and felt that it was meeting their compliance needs. According to Driscoll and Morris (2001), this focus on compliance could occur, because the change was driven from the top down, causing employees to conform to requirements, but without any attitudinal or cultural change on their part. Other participants felt that the system was capable of much more, but indicated that slowly these benefits were being realized. Resistance to change is cited as a major problem in organizational change literature and this resistance was clearly found in the implementation of accrual accounting in the Canadian Federal Government.

\subsection{Empirical Model}

\subsubsection{Implementation Processes and Benefits}

A revised model shown in Figure 7 was developed because the activities undertaken in the a priori model did not fit the collected data completely. This model applies both to the implementation of the accrual accounting system within departments and the implementation of the central system in the government as a whole. The implementation processes are broken down into three major phases, instead of four. Each phase corresponds directly to the a priori model, except for Phase 3 , which combines the Shakedown and the Onward and Upward Phases. This change was done because participants did not distinguish between the activities undertaken in these two phases, and the segregation of Shakedown and Onwards and Upwards was artificial. This lack of distinction between the third and fourth phase of implementation is not due to the high 
立

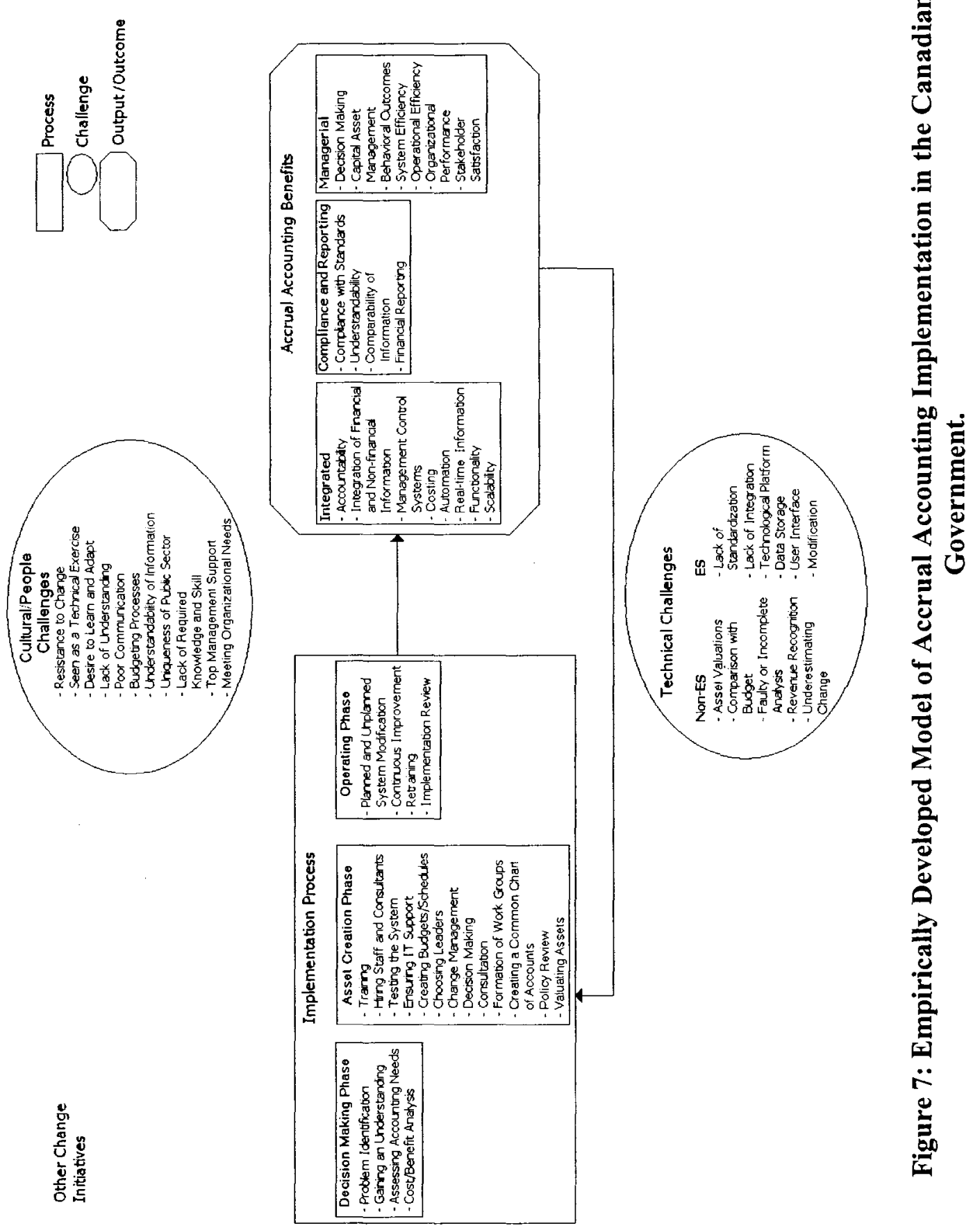


degree of mobility of participants between departments. Each department would still experience each phase of implementation, therefore, participants would have experienced later stages in their new departments. Since these phases have been modified from those proposed by Markus and Tanis (2000), the names of the phases are no longer used in the new model, but have been given new names. Another major difference in the empirical model is that these three phases do not consist of activities and challenges, but only activities. Due to the abundance of data concerning technical challenges, they were given a section of their own.

Key activities in the first phase, or the Decision Making Phase, not included in the a priori model included problem identification. The government established royal commissions to identify problems with the government's managerial system in the $1960 \mathrm{~s}$ and 1970s. These commissions identified the accounting system as a problem. It also serves to demonstrate the long time horizon needed by the Canadian Federal Government to decide to implement accrual accounting. Another activity during this stage was gaining an understanding of accrual accounting and how it would apply to the Canadian Federal Government. Gaining an understanding of accrual accounting was expected, but since it traditionally has been applied in the private sector, there was a need to understand how it would operate in the public sector. Government personnel recast their financial statements to see the impact that accrual accounting would have. They also performed a cost/benefit analysis, but some activities expected to occur in Phase 1 actually occurred in Phase 2. Activities such as creating a project budget and schedule, and choosing personnel to lead the implementation were undertaken during the second phase, at least from a departmental perspective. These activities were done in the second stage most 
likely, because departments were mandated to implement accrual accounting, and then they had to determine how to accomplish that goal.

By far, most participants identified activities of Phase 2, or the Asset Creation Phase. As previously discussed, Phase 1 activities in the a priori model actually occurred in Phase 2. All the expected activities such as training, testing, and software support did occur at Phase 2. Additional activities were undertaken, including change management activities designed to gain user acceptance. These activities were done to various degrees in different departments. Along with training, staff and consultants were also hired. A common chart of accounts was adopted, and decisions and activities surrounding implementation processes were made and performed. Extensive consultation was undertaken along with the formation of work groups. Unlike at the previous stage, there was extensive consultation with departments at Phase 2. Departments were told what reporting requirements were expected, but it was their decision how to implement and use the system. This autonomy in implementation resulted in a great deal of variability between departments in implementation experiences and the type and quantity of benefits they received.

Phase 3 activities, or the Operating Phase, are consistent with the a priori model's Shakedown and Onward and Upwards activities. Participants gave examples of how the system was fine tuned, along with examples of planned and unplanned modifications. There is a definite sense that the system is still continuing to improve. Review of the implementation was done, but only on a limited basis, which led to adjustments in the systems. Loss of knowledgeable personnel was not an issue as expected, since there was a lack of knowledgeable personnel in the first place. There was a definite divide in 
respondents' perceptions regarding the stage in which accrual accounting implementation was. Some felt that the Financial Information Strategy (FIS) has achieved its goals completely. Other respondents felt that FIS was still not functioning as it was intended. This divide in perceptions made it difficult to categorize activities into particular stages. The completeness of implementation according to participants was dependent on what the participant expected the system to achieve in the first place. However, the focus of this study is on the processes, and the categorization was used to break down a rather large topic into manageable discussion groupings. While these differing perceptions uncover an interesting point, it does not diminish the discussion on what activities actually occurred, even if they cannot be neatly categorized into a pre-existing model.

The second major area of the model is the benefits stemming from the implementation processes. As previously discussed, the Canadian Federal Government is not receiving all the benefits that were expected in the a priori model. Specifically, there was not much discussion surrounding increased operational efficiency, management control systems, and stakeholder satisfaction. While there was discussion around integrated benefits, there was weak support for benefits dealing with large change initiatives, such as accountability, costing, and integration of financial and non-financial information. That is not to say that some departments or agencies do not enjoy these benefits, or will not in the future but, among the participants interviewed, there was little support that these benefits were being realized due to the implementation of accrual accounting.

There was stronger support regarding benefits from the use of ES, such as increased functionality and real-time information. The discussion surrounding ES 
included how these systems facilitated the implementation of accrual accounting. It appears that ES were a key resource necessary for the implementation to be successful, especially due to their functionality surrounding accruals. Certain features of the system, such as automation and the ability to produce real-time information, were thought to be particularly useful under the new accrual accounting system.

There was mixed support depending on the department and the participant for the ideas of better capital asset management, decision making, systems efficiency, and changing behavioural outcomes. It must be noted that changes in behavioural outcomes usually related to capital asset management. There was strong support concerning the idea that accrual accounting allowed departments to comply with standards, and that it is useful for financial reporting. Financial reporting is a new benefit that must be considered. Many of the participants thought that new benefits would surface, the longer accrual accounting is in use, or if and when accrual budgeting is implemented. The list of benefits experienced is transitory in nature and contingent on other initiatives occurring within the Canadian Federal Government.

\subsubsection{Technical and Cultural/People Challenges}

The third major area of this model consists of the technical challenges experienced in implementing accrual accounting. In the a priori model, in this section consisted of ES Characteristics and Support, but this section fails to reflect the discussion surrounding the technical aspects of implementation. Technical aspects go beyond just ES and include accrual accounting technical difficulties, such as asset valuations. Instead of focusing on technical features and functional features of ES, as in the a priori model, 
this section will focus on technical challenges. These include both ES and non-ES challenges. Technical features of the ES are not included in the empirical model, because participants discussed these items in terms of the benefits and challenges that they presented. These features are thus included in the technical challenges and the accrual accounting benefits sections of the empirical model. The functional features are not included in the final model, because participants did not distinguish between functional features of the system and the benefits of the system. ES challenges are thought to apply both to departments that already have an ES and departments that are required to implement an ES in order to adopt accrual accounting. In both instances, ES work is required in order to implement an accrual accounting system. As well, it is clear that the implementation of an accrual accounting system within the Canadian Federal Government would not be possible without the presence of some kind of ES.

The implementation of accrual accounting in the Federal Government was not without major challenges. The OAG (2005, Section 8.1) stated, "We find that its progress on the use of improved financial information in departments and agencies, and improvements in its financial information systems supporting that information, continues to be very slow and, thus, unsatisfactory." These findings show that the OAG concurs, that the implementation process has indeed experienced some challenges. One of the biggest challenges found in the literature is the difficulty in valuating assets. The participants interviewed in this study found valuation of assets to be a difficult task as well, but a task that has been accomplished with a certain degree of satisfaction. Different stakeholders came together and came to resolutions over various asset valuation issues. 
Other non-ES issues included budgeting. While there was no consensus over the matter, many participants discussed the fact that budgeting and accounting performed on two different bases posed major technical difficulties in terms of trying to reconcile the actual figures to the budget. As well, in many cases, participants gave examples of how the initial plan or analysis was faulty or incomplete. While the literature cites revenue recognition as a technical problem in implementing accrual accounting, this challenge did not come up during the data collection stage, possibly due to the fact that Revenue Canada did not participate in the study. This particular challenge is not included in the empirical model.

ES did pose challenges as well. Two challenges discussed were the lack of standardization and integration, since there were seven different types of financial systems used in the implementation process, and departments using the same system often configured it differently. Another problem some participants discussed is how some employees would use spreadsheets instead of ES to manipulate and analyze data. Other challenges discussed in the results section deal with technological platforms and functionality due to difficulties with the user interfaces and accessing stored data.

All the cultural/people challenges included in the a priori model were relevant, due to participants reporting that these challenges did in fact occur. As well, this area of challenges has been relabelled cultural/people challenges to be more inclusive of the types of non-technical challenges being experienced. However, not all these challenges occurred in every department. Since departments had a lot of latitude over how to implement, there was much variability in the perceived cultural/people challenges. A cultural/people challenge that was discovered through data collection is the inconsistency 
of the budgeting and accrual systems. Since these systems are on two different bases, it has resulted in many participants feeling that the accrual accounting information is ignored in favour of modified cash information. Since managers' performance evaluations are based on the ability to carry out the budget, the managers will base their decision making on the information that is used in their evaluations. It is recognized that within and between both cultural/people and technical challenges there is the potential for overlap. When overlap was recognized, such as in the case of budgeting, the issue was included in both areas of the model.

Another challenge added to the empirical model is the understandability of the new financial information. This challenge differs from a lack of knowledge or skill, because it deals with external stakeholders, such as the media or parliamentarians, not understanding the accrual accounting information produced by the system. A final challenge that was discovered in the data collection process stems from the uniqueness of the public sector. Examples include the higher degree of sovereignty among departments and more complex and multi-layered budgeting and decision making processes than in private industry. While the participants of this study viewed the public sector as being unique, they did not reject the accrual accounting framework as being inappropriate for the public sector, but did indicate that the framework needed to be adapted to the public sector.

According to the literature, a key activity that should be undertaken for a successful organizational change to occur is getting everybody actively involved (Marc \& Farbrother, 2003). While this involvement appears to be the case in later stages, initially it was not done. The first phase of implementation was done centrally with very little 
consultation. This lack of consultation could explain some of the cultural/people challenges experienced during the implementation of accrual accounting. Broadly, it appears that the change model utilized in this situation is the rational model, which emphasizes the importance of planning, problem solving, and execution (Stewart \& Kringas, 2003).

\subsubsection{Larger Change Initiatives}

The empirical model is set within the context of other change initiatives, as was the a priori model. When speaking to participants, they used Financial Information Strategy (FIS), interchangeably with accrual accounting, even though, according to the literature, accrual accounting adoption is just one aspect of FIS. Participants saw the other aspects, namely the cultural change and new modern integrated information systems, as necessary components in order to achieve the adoption of accrual accounting. There was a definite recognition that accrual accounting was part of larger change initiatives, and that it can sometimes be difficult to isolate concurrent initiatives from one another. However, despite the positioning of accrual accounting in the literature as being part of a wider strategic change, it is not supported by the data, considering that many participants cited compliance as a benefit and did not feel it impacted decision making. It would indicate the system is not being used strategically.

The only difference between the empirical and a priori model is that these larger change initiatives are no longer identified, since during the interviews, participants identified numerous related change initiatives. Other change initiatives included audited departmental financial statements, the CFO model, the possibility of accrual-based 
budgeting, as well as, the previously identified larger change initiatives. The debate over the appropriateness of public sector accrual accounting is extensive in the literature. The debate in the Canadian Federal Government is no longer over the merits of implementing accrual accounting, but has shifted to the decision of whether to adopt an accrual budgeting system. This debate extends beyond whether it should be adopted to include what it would look like. Many of the same arguments found in the literature regarding the adoption of accrual accounting also apply to the decision to adopt accrual budgeting, such as whether or not it is appropriate, the differences between public and private sector, and how the system would work. While that topic is not the focus of this study, it came up frequently during interviews and is an issue that participants obviously considered important. Participants felt strongly on both sides of the debate, which affected their perceptions of the current accrual accounting system. Many of the problems identified in the literature regarding using a separate basis for accounting and budgeting, and fears surrounding the adoption of accrual-based budgeting, was also identified by the participants.

\subsection{Conclusion}

A summary of the points discussed concerning the empirical model of accrual accounting implementation in the Canadian Federal Government can be found in Figure 7. This model includes the items found in the literature along with items discovered during the empirical research. The fine-tuning and changes made to the a priori model serves to highlight the fact that the experiences of the private sector, and even the experiences of the public sector in other countries, cannot simply be applied to the 
Canadian Federal Government context. While there were many similarities between the experiences of accrual accounting implementation in the Canadian Federal Government and other sectors and governments, many issues were unique and needed to be uncovered.

An important realization that can be drawn from this discussion is that the implementation processes varied among the different departments and agencies. As a result of the variability in the implementation processes, different cultural and technical challenges were experienced by the various departments. While some departments may have had similar challenges, there were differences in the perceived severity of these challenges. As a result of these variances, departments and agencies are using the accrual accounting system in different ways and in different degrees, and they are consequently receiving different benefits in terms of both type and magnitude. Since experiences vary, it is important to note that all items included in Figure 7 do not necessary apply to all departments and agencies.

Another important conclusion is that the accrual accounting system within the Canadian Federal Government is not static. It is continually being impacted by other change initiatives, and departments are continually working towards attaining benefits from the system. Therefore, while the implementation of accrual accounting by the participants was discussed as if it were finished, the results of this study indicate otherwise. 


\subsection{Conclusions}

The objective of this study was to explore the implementation of accrual accounting in the Canadian Federal Government. Specifically, this study focused on the implementation processes, accrual accounting benefits experienced and/or expected, and technical and cultural/people challenges. The study is exploratory and questions were based upon an a priori model. However, the study resulted in the development of a new model based upon the empirical data of the implementation of accrual accounting in the Canadian Federal Government. A qualitative research approach using grounded theory was chosen, which is appropriate when the aim of the study is to develop theory, as opposed to testing theory. The data collection tool employed was semi-structured qualitative interviewing. The data gathered was analyzed using coding in quantitative software called, NVivo.

The results of the interviews generally supported the a priori model and the available literature, but the data did also present new concepts and ideas. The implementation processes within the Canadian Federal Government occurred in three different phases of activities. Activities found to occur in the Decision Making Phase included problem identification, gaining an understanding of accrual accounting, and cost/benefit analysis. The majority of activity reported by participants occurred at the Asset Creation Phase of implementation. This second stage included human resource activities, such as training and hiring, financial system activities such as testing, technical support, creating a new chart of accounts, and departmental activities, that included a wide range of activities, including valuating assets and change management. The Operating Phase consisted of activities, such as system modification and improvement. 
The technical challenges experienced by participants consisted of ES challenges and non-ES challenges. ES, according to participant's responses, played a large role in the implementation of accrual accounting. ES not only presented challenges, but also facilitated the implementation of the accrual accounting system, in large part through its technical features. Non-ES challenges relate to budgeting, asset valuation, analysis, and underestimating change. Challenges experienced by participants were also cultural and dealt with people, dealing with resistance and support, and comprehension problems. Resistance and support includes items that explain the level of resistance and support found in various departments. The comprehension issues dealt with differences in the public and private sectors, level of knowledge internally within departments, and the understandability of accrual accounting information by outside stakeholders. A major recommendation for future implementations would be to have dedicated change management plans and personnel both centrally and within departments. As well, the participation of the departments, in addition to the central agencies, in the initial Decision Making Phase would address some of these cultural and people issues.

Accrual accounting benefits discussed by participants were numerous and included integrated benefits. They can be actual and proposed benefits that stem from accrual accounting in conjunction with other change initiatives, as well as, benefits that stem from the integration of the accrual accounting system with the ES. Benefits also included compliance and reporting benefits. Financial reporting and compliance with standards were major objectives and therefore major benefits. The final area consists of managerial benefits. The discussion around this area included decision making, comparisons to budget, asset management, behavioural outcomes, and efficiency. 
With regards to the a priori model, the majority of expected processes did occur in the implementation of accrual accounting, but not always in the predicted phase. Some activities that were expected to occur in the first phase actually occurred in the second. There was also blurring between the third and fourth stages of implementation. Activities in the first phase of implementation were highly centralized and the timeframe leading up to the decision to implement accrual accounting was rather lengthy. As expected, the accrual accounting implementation did experience significant challenges. Many new challenges were discovered upon collection of the data, such as the budgetary process with resulting cultural and technical issues.

One important general finding is that departments did not undertake the same processes when implementing accrual accounting and notably they experienced different challenges and benefits as a result. This finding indicates that implementation processes can directly impact the benefits received from the system. Another interesting point uncovered is that many of the explanations provided by participants supported the notion that the private and public sectors are fundamentally different regarding how accrual accounting should be applied. There was very little support for sector neutrality.

In the course of this study, new activities, challenges, and benefits were discovered. Some of the proposed activities, challenges, and benefits stemming from other countries did not receive much support. This lack of support would indicate that the Canadian Federal Government's experience is indeed unique. As well, it appears that employees are able to delineate between accrual accounting and the larger reforms occurring simultaneously in terms of processes and benefits. 
The contribution of this study to the literature and academic research is the development of a model for the public sector implementation of accrual accounting. Currently, there is a need for a process model that describes public sector accrual accounting implementation. As well, while the literature cites a great many benefits and challenges experienced while implementing accrual accounting, it is neither apparent nor obvious whether these benefits and challenges apply to the Canadian Federal Government. This study determines the relevance of the literature to the Canadian Federal Government. As well, the literature does not always go into depth as to how benefits were achieved or challenges overcome. The results of this study include examples of how, and if, abstract benefits such as accountability, are achieved and how challenges, such as resistance to change are overcome.

A clearer understanding of the accrual accounting implementation process and obstacles will help accountants, within the government, to attain the expected benefits from the system. Departments implemented accrual accounting differently and thus are currently experiencing different benefits. Managers can, therefore, benefit from other departments' successes and challenges. As well, it is a distinct possibility that the Canadian Federal Government may embark on the implementation of accrual-based budgeting. The experiences and lessons learned of the accrual accounting implementation will help make the accrual budgeting implementation more effective and efficient. Managers will also benefit from an understanding of the role of ES and culture in implementing accrual accounting, as well as how these factors can be used in conjunction with accrual accounting to achieve organizational goals. As well, lessons learned might be applied to other public sector organizations such as provincial or 
municipal governments, as well as, other countries that are commencing the implementation process.

Limitations of this study include its sole focus on model development and not model testing. As well, development was based on information collected from specific departments and individuals that chose to participate in the study, which limits the generalizability of the model. The focus of this study is primarily on accounting and the results pertain particularly to accounting. This focus in no way denies that other aspects of the implementation, such as culture or ES, could also be explored in further depth. There is a tremendous opportunity for further research in this area of study. Firstly, the model developed in this study needs to be tested and further refined. This testing could be accomplished by applying the model to different public sector jurisdictions. Secondly, accrual-based budgeting is at the forefront of discussions surrounding public sector accounting. There needs to be further research into the appropriateness of implementing an accrual-based budgeting system, as well as, research into what the optimal accrualbased budgeting system for the Canadian Federal Government would look like. The results of this study also suggest many peripheral topics. One example is an exploration of how parliamentarians perceive accrual accounting information, particularly whether or not it enhances accountability and parliamentarian control. Another potential topic could be the exploration of the lack of knowledgeable accounting personnel within the Canadian Federal Government. 


\section{References}

Aiken, M., \& Capitanio, C. (1995). Accrual accounting valuations and accountability in government: A potentially pernicious union. Australian Journal of Public Administration, 54(4), 564-576.

Allen, J., Jimmieson, N., Bordia, P., \& Irmer, B. (2007). Uncertainty during organizational change: Managing perceptions through communication. Journal of Change Management, 7(2), 187-210.

Al-Mashari, M. (2003). Enterprise resource planning (ERP) systems: A research agenda. Industrial Management \& Data Systems, 103(1), 22-27.

Appelbaum, S. H., Lefrancois, F., Tonna, R., \& Shapiro, B. T. (2007). Mergers 101 (part one): Training managers for communications and leadership challenges. Industrial and Commercial Training, 39(3), 128-136.

Awty, A. (2002). Hong Kong moves on. Australian CPA, 72(1), 50-51.

Baker, R., \& Rennie, M. D. (2006). Forces leading to the adoption of accrual accounting by the Canadian Federal Government: An institutional perspective. Canadian Accounting Perspectives, 5(1), 83-112.

Barton, A. (1999a). A trusteeship theory of accounting for natural capital assets. Abacus, 35(2), 207-222.

Barton, A. (1999b). Land under roads - A financial bonanza or fool's gold. Australian Accounting Review, 9(1), 9-15.

Barton, A. (1999c). Public and private sector accounting - the non-identical twins. Australian Accounting Review, 9(2), 22-31.

Barton, A. (2002). Public-sector accounting: A common reporting framework? A rejoinder. Australian Accounting Review, 12(3), 41-49.

Berg, B. (1998). Qualitative research methods for the social sciences (3rd ed.). Needham Heights, MA: Allyn \& Bacon.

Blondal, J. R. (2003). Accrual accounting and budgeting: Key issues and recent developments. OECD Journal on Budgeting, 3(1), 43-59.

Blondal, J. R. (2004). Issues in accrual budgeting. OECD Journal on Budgeting, 4(1), 103-119.

Boxall, P. (1998). The revolution in government accounting. Australian CPA, 68(3), 1820. 
Bryman, A., \& Bell, E. (2003). Business research methods. New York: Oxford University Press Inc.

Buckstein, J. (1999). Getting it right - the financial information strategy in the Federal Government. Vancouver, British Columbia: Certified General Accountants Association of Canada.

Cabrera, A., Cabrera, E. F., \& Barajas, S. (2001). The key role of organizational culture in a multi-system view of technology-driven change. International Journal of Information Management, 21, 245-261.

Caglio, A. (2003). Enterprise resource planning systems and accountants: Towards hybridization? European Accounting Review, 12, 123-153.

Canadian Institute of Chartered Accountants. (2007). CICA standards and guidance collection Knotia Canada Limited Partnership. Retrieved March 17, 2007 from http://edu.knotia.ca.proxy.library.carleton.ca

Canadian Space Agency. (2000). Mandate and mission. Retrieved January 09, 2008 from http://www.space.gc.ca/asc/eng/about/mission.asp

Carlin, T. M. (2000). Measurement challenges and consequences in the Australian public sector. Australian Accounting Review, ll(2), 63-73.

Carlin, T. M. (2005). Debating the impact of accrual accounting and reporting in the public sector. Financial Accountability \& Management, 21(3), 309-336.

Carlin, T. M. (2006). Victoria's accrual output based budgeting system - delivering as promised? Some empirical evidence. Financial Accountability \& Management, 22(1), 1-19.

Carlin, T. M., \& Guthrie, J. (2001). Lessons from Australian and New Zealand experiences with accrual output-based budgeting. In J. Guthrie, L. Jones \& P. Steane (Eds.), Learning from international public management reform (pp. 89-100). New York: Elsevier Science Ltd.

Carnegie, G. D., \& West, B. P. (2003). How well does accrual accounting fit the public sector? Australian Journal of Public Administration, 62(2), 83-86.

Carnegie, G. D., \& Wolnizer, P. W. (1995). The financial value of cultural, heritage and scientific collections: An accounting fiction. Australian Accounting Review, 5(1), 3147.

Carnegie, G. D., \& Wolnizer, P. W. (1997). The financial reporting of publicly-owned collections: Wither financial (market) values and contingent valuation estimates? Australian Accounting Review, 7(1), 44-50. 
Carnegie, G. D., \& Wolnizer, P. W. (1999). Unravelling the rhetoric about the financial reporting of public collections as assets. Australian Accounting Review, 9(1), 16-21.

Carnegie, G. D., \& Wolnizer, P. W. (2002). A rejoinder. Australian Accounting Review, $12(3), 45-47$.

Charmaz, K. (2006). Constructing grounded theory: A practical guide through qualitative analysis. Thousand Oaks, CA: SAGE Publications.

Christensen, M. (2005). The 'third hand': Private sector consultants in public sector accounting change. European Accounting Review, 14(3), 447-474.

Colman, R. (2004). Ottawa's change agent. CMA Management, 78(7), 40-43.

Colman, R., \& Fletcher, D. (2003). Slow change to better governance. CMA Management, 77(4), 18-22.

Connolly, C., \& Hyndman, N. (2006). The actual implementation of accruals accounting: Caveats from a case within the UK public sector. Accounting, Auditing \& Accountability Journal, 19(2), 272-290.

Creswall, J. (1998). Qualitative inquiry and research design choosing among five traditions. Thousand Oaks, CA: SAGE Publications.

De Cock, C., \& Sharp, R. (2007). Process theory and research: Exploring the dialectic tension. Scandinavian Journal of Management, 23(3), 233-250.

Dechow, N., \& Mouritsen, J. (2005). Enterprise resource planning systems, management control and the quest for integration. Accounting, Organizations and Society, 30(7/8), 691-733.

Department of Finance. (2007). Implementation of full accrual accounting in the Federal Government's financial statements - backgrounder. Retrieved February 20, 2007 from http://www.fin.gc.ca/toce/2001/fullacc_e.html

Driscoll, A., \& Morris, J. (2001). Stepping out: Rhetorical devices and culture change management in the UK civil service. Public Administration, 79(4), 803-824.

Ellwood, S. (2003). Bridging the GAAP across the UK public sector. Accounting \& Business Research, 33(2), 105-121.

Evans, M. (1995). A change for the better? Accountancy, 115(1218), 92-92.

Frahm, J., \& Brown, K. (2007). First steps: Linking change communication to change receptivity. Journal of Organizational Change Management, 20(3), 370-387. 
Gillibrand, A., \& Hilton, B. (1998). Resource accounting and budgeting: Principles, concepts, and practice - the MoD case. Public Money \& Management, 18(2), 21-28.

Goulding, C. (2002). Grounded theory A practical guide for management, business and market researchers. Thousand Oaks, CA: SAGE Publications.

Grant, G. (2003). Strategic alignment and enterprise systems implementation: The case of Metalco. Journal of Information Technology, 18, 159-175.

Guthrie, J. (1998). Application of accrual accounting in the Australian public sector-rhetoric or reality. Financial Accountability \& Management, 14(1), 1-19.

Guthrie, J., \& Parker, L. (1998). 'Managerial' and marketisation' in financial management. In O. Olson, J. Guthrie \& C. Humphrey (Eds.), Global warning: Debating international developments in new public financial management (pp. 4975). Oslo, Norway: Cappelen Akademisk Forlag.

Hansen, D., Mowen, M., Senkow, D., \& Pollanen, R. (2004). Management accounting (Canadian Sixth ed.). Scarborough: Nelson.

Heald, D., \& Georgiou, G. (1995). Resource accounting: Valuation, consolidation and accounting regulation. Public Administration, 73, 571-579.

Health Canada. (2007). About Health Canada. Retrieved January 17, 2008 from http://www.hc-sc.gc.ca/ahc-asc/index_e.html

Hepworth, N. (2003). Preconditions for successful implementation of accrual accounting in central government. Public Money \& Management, 23(1), 37-43.

Her Majesty's Treasury. (2001). Managing resources: Full implementation of resource accounting and budgeting. Retrieved August 8, 2007 from www.hmtreasury.gov.uk/mediastore/otherfiles/rab30_03.pdf

Hodges, R., \& Mellett, H. (2003). Reporting public sector financial results. Public Management Review, 5(1), 99-113.

Hopwood, A. (1984). Accounting and the pursuit of efficiency. In A. Hopwood \& C. Tomkins (Eds.), Issues in public sector accounting (pp. 167-187). Oxford: Philip Allen.

Hone, P. (1997). The financial value of cultural, heritage and scientific collections: A public management necessity. Australian Accounting Review, 7(1), 38-43.

Human Resources and Social Development Canada. (2007). About Human Resources and Social Development Canada. Retrieved January 09, 2008 from http://www.hrsdc.gc.ca/en/corporate/about_us/index.shtml 
Independent Review Panel on the Modernization of Comptrollership in the Government of Canada. (1997). Report of the independent review panel on the modernization of comptrollership in the government of Canada, No. 0662-26179-8. Treasury Board of Canada Secretariat. Retrieved March 24, 2007 from http://www.acfoacaf.com/reports/rirp-e.pdf

Industry Canada. (2007). Mandate. Retrieved January 09, 2008 from http://www.ic.gc.ca/epic/site/ic1.nsf/en/h_00018e.html\#objective1

International Public Sector Accounting Standards Board. (2008). International public sector accounting standards board. Retrieved February 25, 2008 from http://www.ifac.org/PublicSector/

James, W. (2006). A processual view of institutional change of the budget process within an Australian government-owned electricity corporation. International Journal of Public Sector Management, 19(1), 5-39.

Jones, S., \& Puglisi, N. (1997). The relevance of AAS 29 to the Australian public sector: A cause for doubt? Abacus, 33(1), 1-18.

Jun Lin, Z., Baxter, G. C., \& Murphy, G. J. (1993). Improving government financial reporting in Canada: An evaluation of compliance with the PSAAC's accounting and reporting standards for governments. Financial Accountability \& Management, 9(4), 235-254.

Kansas Department of Administration. (1998). Policy and procedural manual. Retrieved April 27, 2007 from http://www.da.ks.gov/ar/ppm/ppm04030.htm

Kervin, J. (1992). Methods for business research. New York: HarperCollins Publisher.

Kieso, D., Weygandt, J., Warfield, T., Irvine, V. B., Silvester, W. H., Young, N., et al. (2002). Intermediate accounting (Sixth Canadian ed.). Etobicoke, Ontario: John Wiley \& Sons Canada Ltd.

Kumar, V., Maheshwari, B., \& Kumar, U. (2002). ERP systems implementation: Best practices in Canadian government organizations. Government Information Quarterly, 19(2), 147-172.

Kumar, V., Pollanen, R. \& Maheshwari, B. (2007). ERP system effectiveness in implementing internal controls in global organizations. Working Paper.

Likierman, A. (2000). Changes to managerial decision taking in U.K. central government. Management Accounting Research, 11(2), 253-261. 
Likierman, A., Heald, D., Georgiou, G., \& Wright, M. (1995). Resource accounting and budgeting: Rationale and background. Public Administration, 73(4), 561-570.

Locke, K. (2001). Grounded theory in management research. Thousand Oaks, CA: SAGE Publications.

Lye, J., Perera, H., \& Rahman, A. (2005). The evolution of accruals-based crown (government) financial statements in New Zealand. Accounting, Auditing \& Accountability Journal, 18(6), 784-815.

Maguire, S., \& Redman, T. (2007). The role of human resource management in information systems development. Management Decisions, 45(2), 252-264.

Maheshwari, B., Kumar, V., \& Kumar, U. (2006). Optimizing success in supply chain partnerships. Journal of Enterprise Information Management, 19(3), 277-291.

Marc, D., \& Farbrother, S. (2003). Changing organization culture, one face at a time. Public Management, 85(9), 14-17.

Markus, M. L., \& Tanis, C. (2000). The enterprise system experience: From adoption to success. In R. W. Zmud (Ed.), Framing the domains of IT management: Projecting the future through the past (pp. 173-207). Cincinnati: Pineflex Educational Resources Inc.

Mart, C. (2006). Accrual budgeting: Accounting treatment of key public sector items and implications for fiscal policy. Public Budgeting \& Finance, 26(2), 45-65.

Mautz, R. K. (1981). Financial planning: Should the government emulate business? Journal of Accountancy, 152(2), 53-60.

McGregor, W. (1999). The pivotal role of accounting concepts in the development of public sector accounting standards. Australian Accounting Review, 9(1), 3-8.

Mellett, H. (2002). The consequences and causes of resource accounting. Critical Perspectives on Accounting, 13, 231-254.

Mellor, T. (1996). Why governments should produce balance sheets. Australian Journal of Public Administration, 55(1), 78-82.

Micallef, F., \& Peirson, G. (1997). Financial reporting of cultural, heritage, scientific and community collections. Australian Accounting Review, 7(1), 31-37.

Miranda, R. A., \& Kavanagh, S. C. (2005). Achieving government transformation through ERP systems. Government Finance Review, 21(3), 36-42.

Naik, B. (2005). A cruel accounting. CA Magazine, 138(10), 44-46. 
Neal, D., \& Taylor, T. (2006). Spinning on dimes: The challenges of introducing transformational change into the UK Ministry of Defence. Strategic Change, 15, 1522.

Newberry, S. (2001). Public-sector accounting: A common reporting framework? Australian Accounting Review, 11(1), 2-7.

Newberry, S. (2002). The conceptual framework sham. Australian Accounting Review, 12(3), 47-49.

Oakland, J. S., \& Tanner, S. J. (2007). A new framework for managing change. The TQM Magazine, 19(6), 572-589.

Office of the Auditor General of Canada. (1999). 1999 report of the Auditor General of Canada - November - chapter 21. Retrieved April 22, 2007 from http://www.oagbvg.gc.ca/domino/reports.nsf/html/9921 ce.html

Office of the Auditor General of Canada. (2002). 2002 report of the Auditor General of Canada - December - chapter 5 - financial management and control in the government of Canada. Retrieved March 20, 2007 from http://www.oagbvg.gc.ca/domino/reports.nsf/html/20021205ce.html

Office of the Auditor General of Canada. (2005). 2005 report of the Auditor General of Canada - status report - chapter 8 - managing government - financial information. Retrieved March 21, 2007 from http://www.oagbvg.gc.ca/domino/reports.nsf/html/20050208ce.html

Office of the Auditor General of Canada. (2006). 2006 Auditor General report Office of the Auditor General. Retrieved April 04, 2007 from http://www.oagbvg.gc.ca/domino/reports.nsf/html/20060501ce.html/\$file/20060501ce.pdf

Office of the Auditor General of Canada. (2007). Office of the Auditor General of Canada. Retrieved April 03, 2007 from http://www.oag-bvg.gc.ca/domino/oagbvg.nsf $/ \mathrm{html} /$ menue.html

Olson, O., Guthrie, J., \& Humphrey, C. (1998). Global warning! International experiences with 'new' public financial management (NPFM) reforms: New world? Small world? Better world? In O. Olson, J. Guthrie \& C. Humphrey (Eds.), Global warning: Debating international developments in new public financial management (pp. 17-48). Bergen, Norway: Cappelen Akademisk Forlag.

O'Neal, B. (1994). Reorganizing government: New approaches to public service reform. Retrieved March 20, 2007 from http://dsppsd.communication.gc.ca.proxy.library.carleton.ca/Collection-R/LoPBdP/BP/bp375e.htm 
Pallot, J. (1990). The nature of public assets: A response to Mautz. Accounting Horizons, 4(2), 79-85.

Pallot, J., \& Ball, I. (1996). Resource accounting and budgeting: The New Zealand experience. Public Administration, 74, 527-541.

Pallot, J., \& Ball, I. (1997). What difference does resource accounting make? The case of New Zealand. In D. Corry (Ed.), Public expenditure: Effective management and control (pp. 237-252). London: Dryden Press.

Parks Canada. (2007). Parks Canada mandate. Retrieved January 09, 2008 from http://www.pc.gc.ca/agen/index_E.asp

Pendlebury, M., \& Karbhari, Y. (1998). Resource accounting and executive agencies. Public Money \& Management, 18(2), 29-33.

Public Works and Government Services of Canada. (2007). About PWGSC. Retrieved January 09, 2008 from http://www.pwgsc.gc.ca.proxy.library.carleton.ca/aproposabout/prps-bt-eng.html

Rieschi, G. (2007). Growing pains. CMA Management, 81(1), 15-17.

Ritchie, J., \& Lewis, J. (Eds.). (2003). Qualitative research practice: A guide for social science students and researchers. Trowbridge, Wiltshire: SAGE Publications.

Ritson, N., \& O'Neill, M. (2006). Strategic implementation: A comparison of three methodologies. Strategic Change, 15, 187-196.

Robinson, M. (1998). Accrual accounting and the efficiency of the core public sector. Financial Accountability \& Management, 14(1), 21-37.

Rowles, T. (1991). Infrastructure and heritage asset accounting. Australian Accountant, $61(6), 69-73$.

Royal Commission on Financial Management and Accountability. (1979). Royal commission on financial management and accountability final report. Ottawa, Canada: Supply and Services Canada.

Royal Commission on Government Organization. (1963). Royal commission on government organization final report. Ottawa, Canada: Queen's Printer.

Rusaw, C. (2007). Changing public organizations: Four approaches. International Journal of Public Administration, 30,347-361. 
Ryan, N., \& Lewis, D. (2007). Responses to public sector reform policy. Public Management Review, 9(2), 269-287.

Saleh, Z., \& Pendlebury, M. (2006). Accruals accounting in government - developments in Malaysia. Asia Pacific Business Review, 12(4), 421-435.

Scapens, R. W., \& Jazayeri, M. (2003). ERP systems and management accounting change: Opportunities or impacts? A research note. European Accounting Review, 12, 201-233.

Skinner, R. M., \& Milburn, A. J. (2001). Government. Accounting standards in evolution (2nd ed., pp. 653-671). Toronto: Prentice Hall/Pearson Education Canada.

Slamet, D. (1998). Looking to best practice: Taking a broad view. Australian CPA, $68(8), 60-62$.

St-Amour, D. (2001). Successful organizational change. Canadian Manager, 26(2), 2023.

Standing Committee on Government Operations and Estimates. (2006). Accrual budgeting and appropriations in the Federal Government. Ottawa, Canada: Communication Canada.

Stanton, P. J., \& Stanton, P. A. (1997). Governmental accounting for heritage assets: Economic, social implications. International Journal of Social Economics, 24(7/8/9), 988-1006.

Stewart, J., \& Kringas, P. (2003). Change management - strategy and values in six agencies from Australian public service. Public Administration Review, 63(6), 675688.

Stewart, J., \& O'Donnell, M. (2007). Implementing change in a public agency. International Journal of Public Sector Management, 20(3), 239-251.

Strauss, A., \& Corbin, J. (1990a). Basics of qualitative research: Grounded theory procedures and techniques. Newbury Park, CA: SAGE Publications.

Strauss, A., \& Corbin, J. (1990b). Grounded theory research: Procedures, canons, and evaluative research. Qualitative Sociology, 13(1), 3-21.

Trader-Leigh, K. (2002). Case study: Identifying resistance in managing change. Journal of Organizational Change Management, 15(2), 138-155.

Treasury Board of Canada Secretariat. (1995). Guide on financial arrangements and funding options. Retrieved April 23, 2007 from http://www.tbssct.gc.ca/pubs pol/dcgpubs/TBM 133/arral e.asp\#Foreword 
Treasury Board of Canada Secretariat. (2002a). Becoming FIS ready. Retrieved January 29, 2007 from http://www.tbs-sct.gc.ca/fin/sigs/FIS-SIF/ord-adp/READY_e.asp

Treasury Board of Canada Secretariat. (2002b). The benefits of FIS: Helping managers manage. Retrieved February 15, 2007 from http://www.tbs-sct.gc.ca/fin/sigs/FIS$\underline{\text { SIF/is-fi/bf-as_e.asp }}$

Treasury Board of Canada Secretariat. (2002c). Financial information strategy learning framework. Retrieved May 04, 2007 from http://www.tbs-sct.gc.ca/fin/sigs/FISSIF/tll-lf/fislearningframework/affected_e.asp

Treasury Board of Canada Secretariat. (2004). Welcome to the Treasury Board of Canada secretariat. Retrieved May 07, 2007 from http://www.tbssct.gc.ca/index_e.asp

Treasury Board of Canada Secretariat. (2006a). Government of Canada service oriented architecture strategy - statement of direction. Retrieved March 29, 2007 from http://www.tbs-sct.gc.ca/cio-dpi/webapps/architecture/sd-eo/sd-eo04_e.asp

Treasury Board of Canada Secretariat. (2006b). About us. Retrieved January 09, 2008 from http://www.tbs-sct.gc.ca/common/us-nous_e.asp

US Congress. (2002). Sarbanes-Oxley Act. Retrieved October 29, 2006 from http://www.sec.gov/about/laws/soa2002.pdf

Volkoff, O., Strong, D., \& Elmes, M. (2005). Understanding enterprise systems-enabled integration. European Journal of Information Systems, 14, 110-120.

Webster, A. (1998). Improving performance: Accrual accounting points the way ahead. Australian CPA, 68(3), 24-26.

Wong, S. (1998). Full speed ahead. CMA Magazine, 72(8), 18-23.

Wright, M. (1995). Resource budgeting and the PES system. Public Administration, 73, 580-590. 


\section{Appendix A: Sample Interview Guide Interview Guide for Departmental Managers}

\section{Section 1: Background Information}

1) Name of Department:

2) Address of Department:

3) Name of Interviewee:

4) Title/Designation of Interviewee:

\section{Years in Current Position: \\ Years with Department:}

5) Telephone Number for Contact with Interviewee:

6) Date of Interview: 


\section{Section 2: Draft Interview Questions}

The questions will be grouped into four main areas consisting of implementation processes, enterprise systems, purpose of accrual accounting information, and finally accrual accounting benefits.

\subsection{Implementation Processes}

The first few questions deal with four possible phases of implementing accrual accounting in your department along with the associated challenges.

\section{Phase 1}

The first phase of implementing accrual accounting involves all the activities undertaken before the decision to fund the implementation of the system is made.

1.1 What activities relating to the accrual accounting system did your department undertake during this first phase? Examples of some activities include, but are not limited to:
a) Analyzing the costs and benefits of implementing accrual accounting
b) Gaining an understanding of accrual accounting
c) Assessing accounting needs

\section{Phase 2}

The second phase of implementing accrual accounting involves all the activities undertaken while installing the system.

1.2 What activities relating to the accrual accounting system did your department undertake during this second phase? Examples of some activities include, but are not limited to:
a) Ensuring software is in place that supports accrual accounting
b) Testing
c) Training

\section{Phase 3}

The third phase of implementing accrual accounting involves all the activities undertaken immediately after the installation was completed.

1.3 What activities relating to the accrual accounting system did your department undertake during the third phase? Examples of some activities include, but are not limited to:

a) Modification of the system

b) Retraining 


\title{
Phase 4
}

c) Staffing

The fourth phase of implementing accrual accounting involves all activities undertaken while the system is fully operational.

1.4 What activities relating to the accrual accounting system were undertaken during this third phase? Examples of some activities include, but are not limited to:
a) Reviewing the implementation process
b) Continuing to improve the system
c) Additional training

1.5 What were some major challenges encountered in the different implementation stages? Examples of some challenges include, but are not limited to:

\section{Technical Challenges}
a) Incomplete or faulty analysis
b) Underestimating the amount of change required
c) Difficulty performing asset valuations
d) Timing and recognition of tax revenues
e) Adequacy of technical information systems

\author{
Cultural Challenges \\ f) Loss of knowledgeable personnel \\ g) Poor communication \\ h) Reconciling the system with organizational needs \\ i) Resistance to change \\ j) Administrative regulations \\ k) Top management support
}

1.6 What types of personnel were involved in the different implementation stages?

1.7 What did you learn from these implementation processes? 


\subsection{Enterprise Systems}

The next few questions deal with the role that enterprise systems played in enabling and supporting accrual accounting in your department.

2.1 How has enterprise systems facilitated implementation of accrual accounting in your department?

2.2 How has enterprise systems created challenges in implementing accrual accounting in your department?

2.3 What modifications were made in the enterprise system to accommodate the accrual accounting system implementation in your department?

2.4 What technical features of enterprise systems are important to accrual accounting implementation and operation in your department? Examples of technical features include, but are not limited to:
a) Technological platform
b) Common relational database
c) Scalable architecture
d) Real-time information
e) Reliable master data
f) Integrated information
g) Functional integration
h) Supplier integration
i) Customer integration
j) Other-specify 


\subsection{Purpose of Accrual Accounting Information}

The next few questions deal with what the purpose is of the accrual accounting information being used is and how it is beneficial to your department.

3.1 For what purposes are the accrual accounting information used in your department? Examples include, but are not limited to
a) Planning
b) Appropriations
c) Budgeting
d) Recording
e) Controlling
f) Monitoring
g) Measuring
h) Evaluating
i) Reporting
j) Other - specify

3.2 Which three of the purposes mentioned do you consider the most important?

3.3 Budgeting is still being performed on a modified cash basis. Has this discrepancy had an impact on the use of accrual accounting information in your department? 


\subsection{Accrual Accounting Benefits}

These final few questions deal with the benefits that have resulted, or expected to result, from accrual accounting implementation in your department.

4.1 What were the expected benefits of accrual accounting implementation in your department? Examples of expected benefits include, but are not limited to:
a) Operational efficiency
b) Systems efficiency
c) Organizational performance
d) Behavioural outcomes
e) Stakeholder satisfaction
f) Comparability of information
g) Improved decision making
h) Management of capital assets
i) Compliance with standards
j) Accountability
k) Integration of financial and non-financial information
l) Improved management control systems

4.2 How did/do actual benefits compare to the expected benefits you mentioned?

a) Which actual benefits exceed expected benefits?

b) Which actual benefits matched expected benefits?

c) Which actual benefits were less than expected benefits?

4.3 Which of the previously mentioned benefits can be primarily attributed to the adoption of accrual accounting in your department?

4.4 Which of the previously mentioned benefits primarily stem from larger change initiatives that have occurred, such as Financial Information Strategy?

4.5 What proportion of the total overall benefits achieved would you attribute to implementation of accrual accounting? 


\section{Appendix B: Questionnaire Mapping}

\begin{tabular}{|c|c|}
\hline Question Number & Model Construct \\
\hline 1.1 & Implementation Processes \\
\hline 1.2 & $\begin{array}{l}\text { Implementation Processes - Project Chartering } \\
\text { Activities }\end{array}$ \\
\hline 1.3 & $\begin{array}{l}\text { Implementation Processes - Project Chartering } \\
\text { Challenges }\end{array}$ \\
\hline 1.4 & $\begin{array}{l}\text { Implementation Processes - The Project } \\
\text { Activities }\end{array}$ \\
\hline 1.5 & $\begin{array}{l}\text { Implementation Processes - The Project } \\
\text { Challenges } \\
\text { Cultural Aspects - cultural challenges }\end{array}$ \\
\hline 1.6 & $\begin{array}{l}\text { Implementation Processes - Shakedown } \\
\text { Activities }\end{array}$ \\
\hline 1.7 & $\begin{array}{l}\text { Implementation Processes - Shakedown } \\
\text { Challenges } \\
\text { Cultural Aspects - cultural challenges }\end{array}$ \\
\hline 1.8 & $\begin{array}{l}\text { Implementation Processes - Onward and } \\
\text { Upward Activities }\end{array}$ \\
\hline 1.9 & $\begin{array}{l}\text { Implementation Processes - Onward and } \\
\text { Upward Challenges }\end{array}$ \\
\hline 1.10 & $\begin{array}{l}\text { Implementation Processes - Personal involved } \\
\text { in all phases }\end{array}$ \\
\hline 1.11 & $\begin{array}{l}\text { Implementation Processes - Lessons learned } \\
\text { form implementation process }\end{array}$ \\
\hline 1.12 & $\begin{array}{l}\text { Implementation Processes - Lessons learned } \\
\text { from implementation process }\end{array}$ \\
\hline 2.1 & ES Role - Facilitation \\
\hline 2.2 & ES Role - Challenges \\
\hline 2.3 & ES Role - ES modification \\
\hline 2.4 & ES technical features \\
\hline 3.1 & $\begin{array}{l}\text { Benefits - Expected Benefits of accrual } \\
\text { accounting implementation } \\
\text { Cultural Aspects - Potential changes to the } \\
\text { organizational culture }\end{array}$ \\
\hline 3.2 & Benefits - Expected versus actual benefits \\
\hline 3.3 & $\begin{array}{l}\text { Benefits - Separation of benefits from larger } \\
\text { change initiatives }\end{array}$ \\
\hline 3.4 & $\begin{array}{l}\text { Benefits - Separation of benefits from larger } \\
\text { change initiatives }\end{array}$ \\
\hline 3.5 & $\begin{array}{l}\text { Benefits - Separation of benefits from larger } \\
\text { change initiatives }\end{array}$ \\
\hline 4.1 & ES Functional Features \\
\hline 4.2 & Benefits of Accrual Accounting System \\
\hline
\end{tabular}




\title{
Appendix C - Sample E-mail
}

\author{
Individual Persons \\ (Name, Title)
}

(Name, Organization) has recommended you as a key participant in my MBA thesis research project at the Sprott School of Business, Carleton University. The research topic involves the implementation of the accrual accounting system within the Canadian Federal Government. It focuses on providing a better understanding of the processes and benefits surrounding the implementation of accrual accounting and the role that Enterprise Resource Planning Systems play in the implementation of accrual accounting in your department. The interview would be conducted in person at a location of your choice and is expected to last approximately 45 to 50 minutes. The interview questions would be e-mailed in advance. Attached is a letter of introduction discussing my research project in further detail.

Your participation would be greatly appreciated and I would be pleased to share the findings when my MBA thesis is concluded. If you are interested, please contact me at klseguin@connect.carleton.ca.

Thank you very much.

Sincerely,

\section{Persons who might have contacts}

(Name, Title)

(Name, Organization) has suggested you as an individual who may have contacts relating to my research project. I am currently working on my MBA thesis at the Sprott School of Business, Carleton University and am looking for individuals involved in the implementation of the accrual accounting system within their departments. Could you please forward this e-mail to your contacts who are, or have been, involved with accrual accounting implementation in their departments. My research focuses on providing a better understanding of the processes and benefits surrounding the implementation of accrual accounting and the role that Enterprise Resource Planning Systems play in that implementation. I have attached a letter of introduction that discusses my research project in further detail.

Any help would be greatly appreciated and I would be pleased to share the findings of the study when my MBA thesis is concluded. My e-mail address is klseguin@connect.carleton.ca.

Thank you very much.

Sincerely, 


\title{
Appendix D: Sample Letter of Introduction/Letter of Consent
}

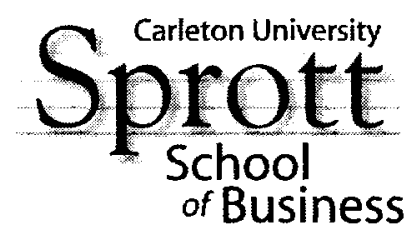

\author{
1125 Colonel By Drive \\ Ottawa ON K1S 5B6
}

[Date]

[Name]

Dear [Title, Name]:

You have been selected as a participant for a research study conducted by Kristin Lapointe Seguin, as her Masters of Business Administration (MBA) thesis research project at the Sprott School of Business, Carleton University, under the supervision of Professor Raili Pollanen.

The purpose of this research is to gain a better understanding of processes and benefits surrounding the adoption and implementation of accrual accounting in the Canadian Federal Government in the context of results-based management initiatives, and the role that Enterprise Resource Planning Systems play in implementation. Results of this study can help department managers improve departmental systems and processes, and thus contribute to more effective results-based management in general.

Your contribution is critical for the success of this study. Please provide us 30-45 minutes of your valuable time for conducting an interview at a time and location convenient to you. The interview consists of openended questions to guide discussion, allowing you to raise issues that are important to you. With your permission, the interview will be taped to facilitate data analysis. You will automatically receive a summary report of the results.

Please be assured that your responses will be strictly confidential. Only overall summary results will be reported, with no references made to individual responses, respondents, or departments. The data will be stored in a secured location and tapes will be destroyed after five years. Your participation in the study is voluntary, and you may withdraw at any time, or request that data collected be destroyed. You may decline to answer any questions at your discretion. You will be asked whether you are available for follow-up clarification questions, if necessary. There are no anticipated risks in participating in this interview.

The research procedures for this study have been approved by the Research Ethics Committee of Carleton University. If you have questions or concerns about research ethics or the nature of your involvement in this study, you may contact the Ethics Committee Chair, Prof. Antonio Gualtieri by telephone at 613-5202517 or by e-mail at ethics@carleton.ca. If you have questions about the research study itself, please contact the researchers directly.

Thank you very much for your time and consideration.

Sincerely, 
Raili Pollanen, $\mathrm{PhD}, \mathrm{CMA}$

Assistant Professor

E-mail: raili_pollanen@carleton.ca
Kristin Lapointe Seguin, BCom MBA Candidate

E-mail: klseguin@connect.carleton.ca

I, _ have read the above letter and understand that I have voluntarily agreed to participate in this research project. 


\section{Appendix E: Codes and Their Descriptions}

Bolded titles do not contain coding, but serve to organize the coding into sections.

\section{Context}

Description: These codes pertain to background information on the participants and their departments. They will not be included in the model, but are used in the methodology section to describe participants and their organizations.

Context/Background Information

Description: Information pertaining to organization under study

Context/Participant Information

Description: Information concerning the participants interviewed

\section{Implementation Process}

Description: Includes the coding relating to processes at the various stages and the personnel involved

\section{Implementation Process/Phase 1 Activity}

Description: Contains coding relating to all activity until the decision was made to implement accrual accounting

Implementation Process/Phase 1 Activity/Cost/Benefits Analysis

Description: Cost/Benefit analysis of accrual accounting implementation

Implementation Process/Phase 1 Activity/Departmental Involvement Description: Departments' involvement in the decision process

Implementation Process/Phase 1 Activity/Gaining Understanding Description: Efforts made to gain an understanding of what accrual accounting would be like

Implementation Process/Phase 1 Activity/Problem Identification Description: How and when were problems identified that lead to the consideration of accrual accounting

\section{Implementation Process/Phase 2 Activity}

Description: Contains all the coding relating to activities from the time the decision was made to implement until the system was operational

Implementation Process/Phase 2 Activity/Human Resource/Training Description: Training activities that occurred 
Implementation Process/Phase 2 Activity/Human Resource/Hiring Staff Description: Changes in staffing levels

Implementation Process/Phase 2 Activity/Human Resource/ Hiring Consultants Description: Use of consultants in order to implement

Implementation Process/Phase 2 Activity/Departmental/Decision Making Description: Decisions that had to be made regarding when and how to implement

Implementation Process/Phase 2 Activity/Departmental/Valuating Assets Description: Activities to valuate assets for the first time

Implementation Process/Phase 2 Activity/Departmental/Policy Review

Description: Reviewing and creating policy surrounding accrual accounting

Implementation Process/Phase 2 Activity/Departmental/Work Groups

Description: Includes multi-disciplinary and cross functional teams

Implementation Process/Phase 2 Activity/Departmental/Consultation

Description: Central and departmental consultation on implementing

Implementation Process/Phase 2 Activity/Departmental/Change Management Description: Change management activities that occurred

Implementation Process/Phase 2 Activity/Financial Systems/Technology Support Description: Technology support activities that were performed at this stage

Implementation Process/Phase 2 Activity/Financial Systems/Chart of Accounts Description: Describes the implementation of a new chart of accounts and trial balance system

Implementation Process/Phase 2 Activity/Financial Systems/Testing the System Description: Testing the accrual accounting system

Implementation Process/Phase 3 Activity

Description: Contains coding relating to all activity that occurred after the system was operational. Combination of the initial Phase 3 and 4

Implementation Process/Phase 3 Activity/System Modification Description: Modifications done to the system

Implementation Process/Phase 3 Activity/Implementation Review

Description: Review of the implementation process and the system

Implementation Process/Phase 3 Activity/System Improvement

Description: Improvements performed on the system 
Implementation Process/Phase 3 Activity/Retraining

Description: Retraining of staff after operational

Implementation Process/Phase 3 Activity/Staffing

Description: Changes in staffing levels

\section{Technical Challenges}

Description: Includes codes pertaining to both ES and non-ES' technical challenges

\section{Technical Challenges/Non-ES}

Description: Includes coding relating to all technical challenges that are not related directly to ES

Technical Challenges/Non-ES/Asset Valuation

Description: Problems trying to value capital assets for the first time

Technical Challenges/Non-ES/Faulty or Incomplete Analysis

Description: Any problems with their initial analysis being faulty or incomplete

Technical Challenges/Non-ES/Underestimating Change

Description: Underestimating the amount of change required for implementation

Technical Challenges/Non-ES/Budgeting

Description: Impact of budget and accounting being done on a different basis

\section{Technical Challenges/ES}

Description: Includes all coding pertaining to ES challenges.

Technical Challenges/ES/Modification

Description: To what extent were modifications required and what kinds

Technical Challenges/ES/Integration

Description: Includes functional and vertical integration

Technical Challenges/ES/User Interface

Description: The impact of user interfaces on the use of system

Technical Challenges/ES/Technological Platform

Description: What platform does the system run on and how does that impact the functioning

Technical Challenges/ES/Other

Description: ES related challenges that do not fall into predefined category 


\section{Cultural/People Challenges}

Description: Contains all coding relating to the cultural/people challenges experienced

Cultural/People Challenges/Resistance and Support/Budgeting Processes

Description: Comparison made or not made between budget and actual results

Cultural/People Challenges/Resistance and Support/Top Management Support

Description: Level of top management support

Cultural/People Challenges/Resistance and Support/Resistance to Change

Description: The resistance experienced

Cultural/People Challenges/Resistance and Support/Communication

Description: Communication during the implementation

Cultural/People Challenges/Resistance and Support/Organizational Needs

Description: Whether or not the system meets organizational needs

Cultural/People Challenges/Comprehension/Understandability

Description: How well do people understand accrual accounting numbers

Cultural/People Challenges/Comprehension/Uniqueness of Public Sector

Description: Difference between how things are done in the private sector versus the public sector

Cultural/People Challenges/Comprehension/Lack of Knowledge

Description: Lack of necessary knowledge within the government

\section{Accrual Accounting Benefits}

Description: Contains all coding relating to the benefits expected and received from accrual accounting implementation

Accrual Accounting Benefits/Integrated/Accountability

Description: How does the implementation of accrual accounting relate to accountability in the government?

Accrual Accounting Benefits/Integrated/Enabling

Description: How does ES enable accrual accounting benefits

Accrual Accounting Benefits/Integrated/Scalability

Description: How does the scalability of ES relate to accrual accounting benefits 
Accrual Accounting Benefits/Integrated/Functionality

Description: How does ES provide functionality that relates to accrual accounting

Accrual Accounting Benefits/Integrated/Real-time Information

Description: How does the real-time information that ES provides relate to accrual accounting benefits

Accrual Accounting Benefits/Integrated/Automation

Description: How does the automation that ES provides relate to accrual accounting

Accrual Accounting Benefits/Integrated/Costing

Description: Is this information being used to do cost accounting

Accrual Accounting Benefits/Integrated/Integration of Financial and Non-financial Information

Description: Relating financial and non-financial information

Accrual Accounting Benefits/Compliance and Reporting/Comparability

Description: Comparisons being made with private industry and/or other governments

Accrual Accounting Benefits/Compliance and Reporting/Financial Reporting

Description: Accrual accounting is being used for external financial reporting

Accrual Accounting Benefits/Compliance and Reporting/Compliance

Description: Departmental compliance with regulation and Fed government compliance with International Standards

Accrual Accounting Benefits/Compliance and Reporting/Understandability

Description: Does outside stakeholders understand accrual accounting information

Accrual Accounting Benefits/Managerial/Asset Management

Description: Is it being used to manage assets and what has been the impact?

Accrual Accounting Benefits/Managerial/Decision Making

Description: Whether or not it is used for decision making purposes other than capital management

Accrual Accounting Benefits/Managerial/Behavioural Outcomes

Description: Aside from capital assets does accrual accounting information affect behaviour?

Accrual Accounting Benefits/Managerial/Efficiency

Description: Has the implementation of accrual accounting created any efficiency?

Accrual Accounting Benefits/Managerial/Compare with Budget

Description: Comparison of expected and actual benefits 


\section{Appendix F: Implementation Processes Coding Hierarchy}

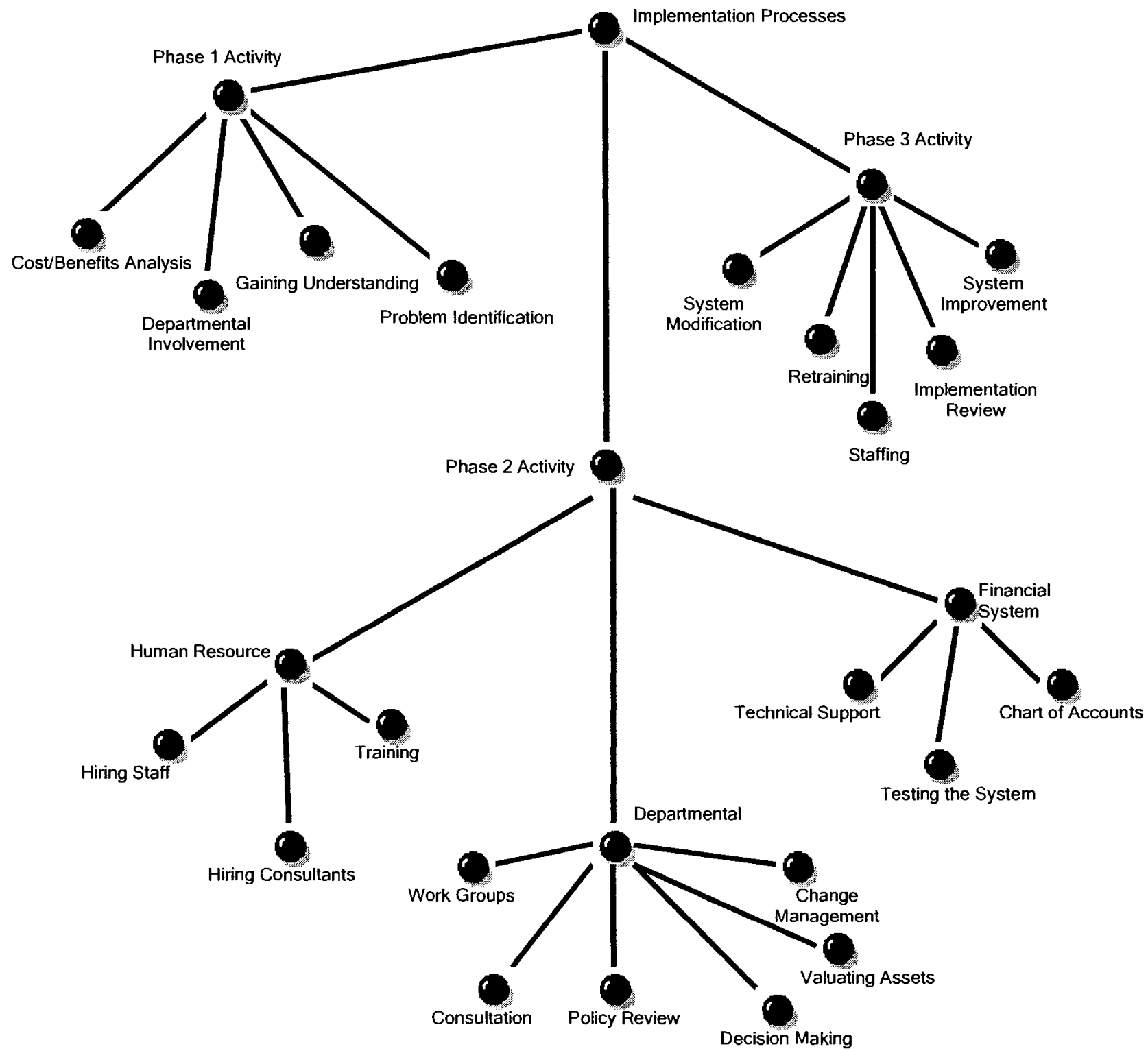




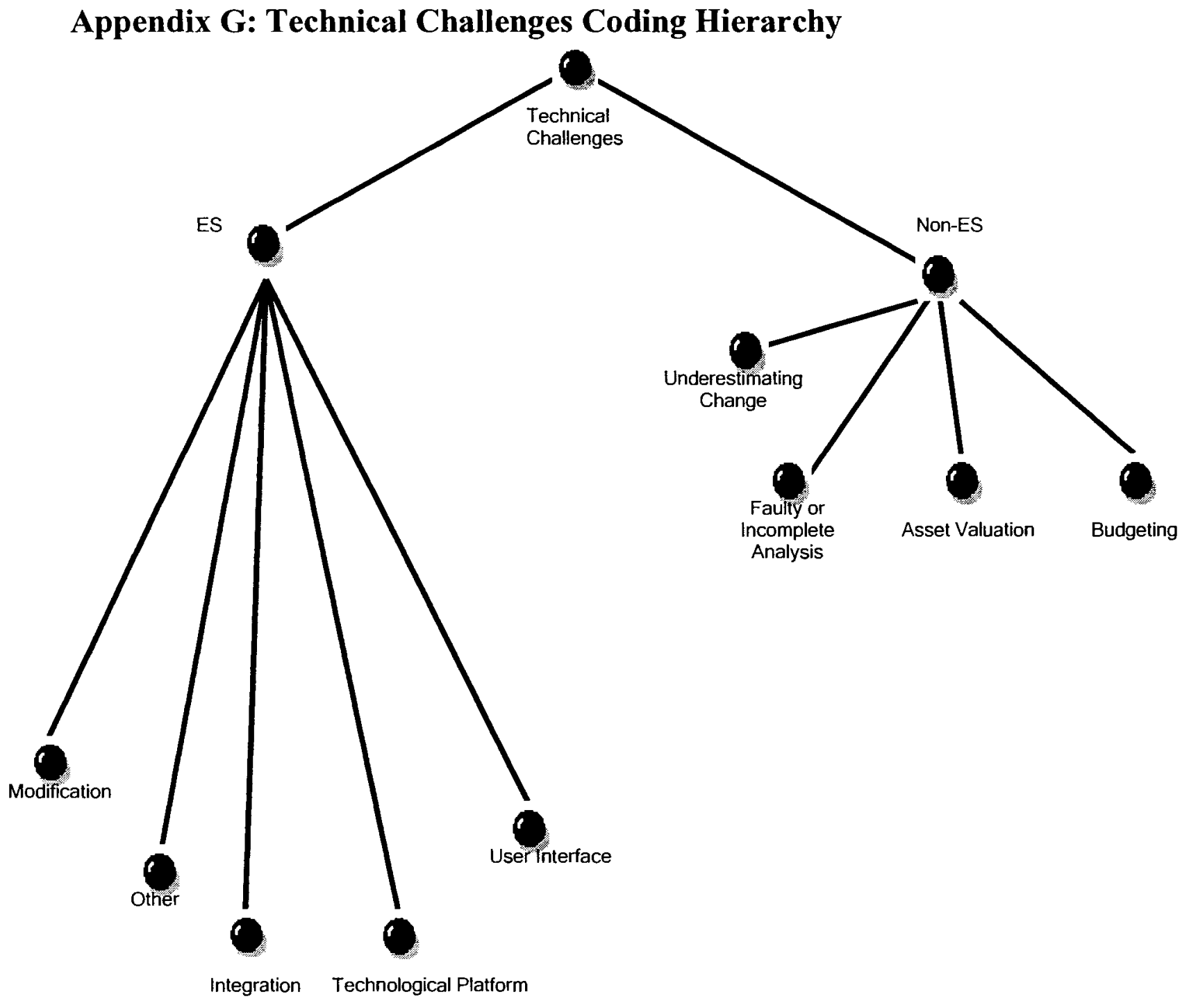




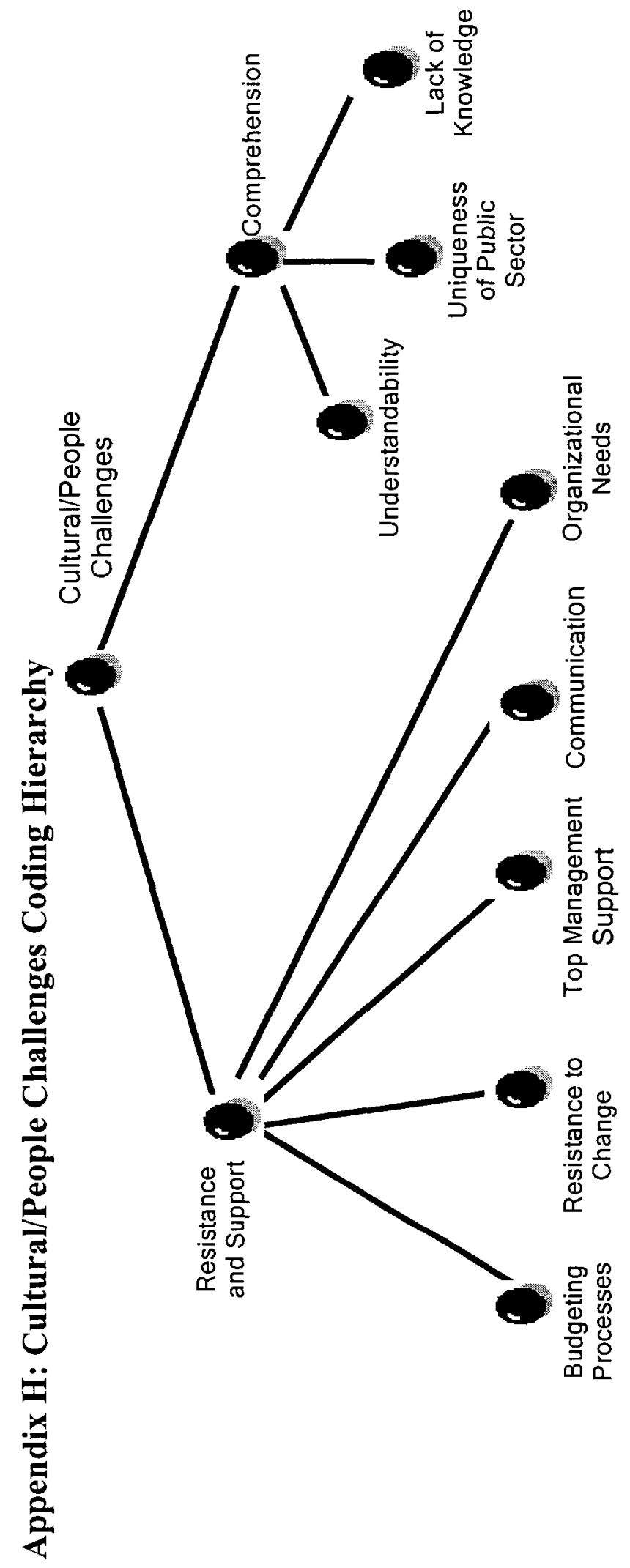




\section{Appendix I: Accrual Accounting Benefits Coding Hierarchy}

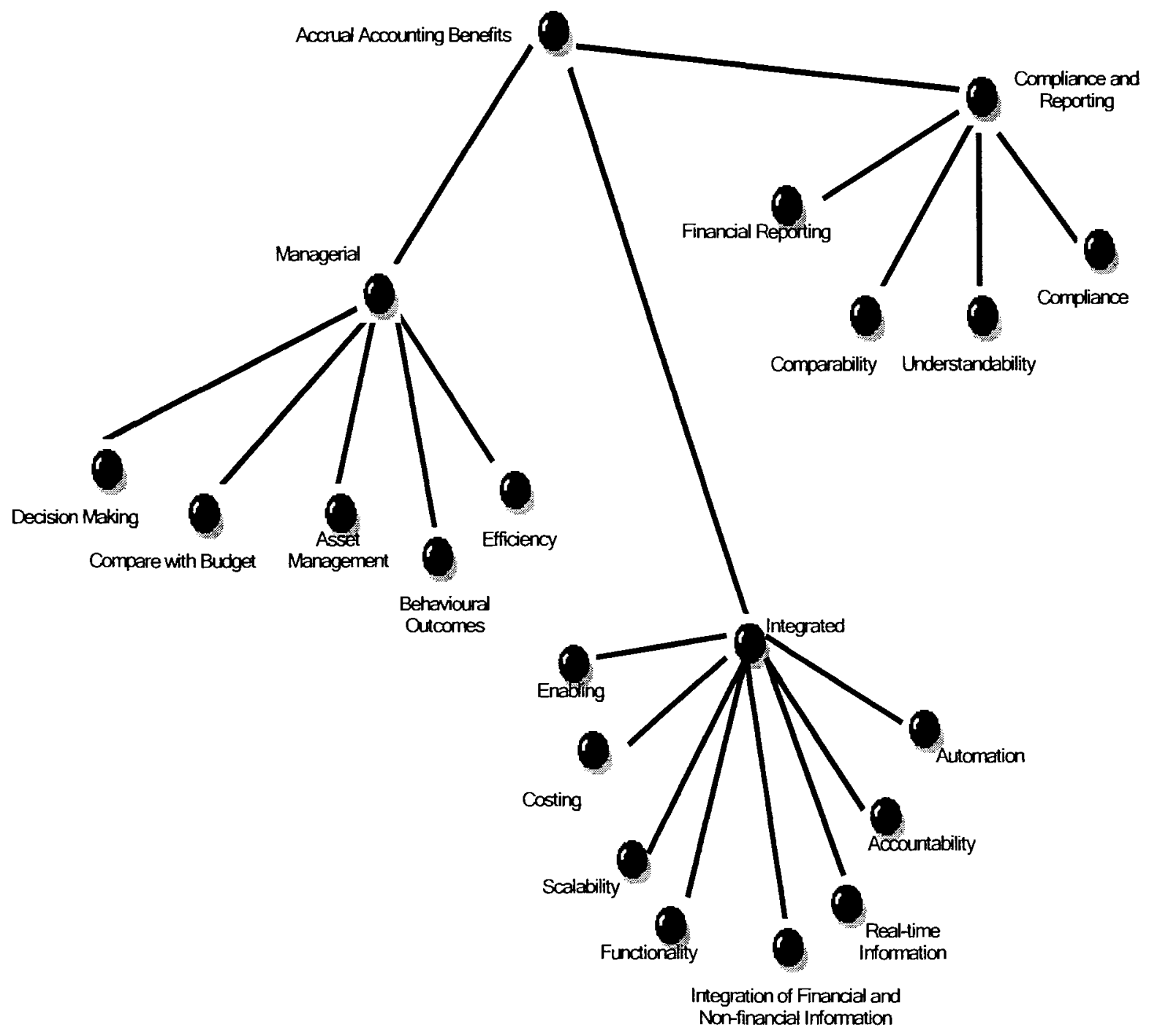

